\title{
APLICAÇÃO DO SISTEMA INTEGRADO DE DIAGNOSE E RECOMENDAC̄ÃO PARA DIFERENTES SOLOS E ÉPOCAS DE AMOSTRAGEM FOLIAR EM SOQUEIRA DE CANA-DE-AÇÚCAR (Saccharum spp).
}

\author{
ERMOR ZAMBELLO JUNIOR \\ Engenheiro Agrônomo \\ IAA - PLANALSUCAR
}

DR. HENRIQUE PAULO HAAG

- ORIENTADOR .

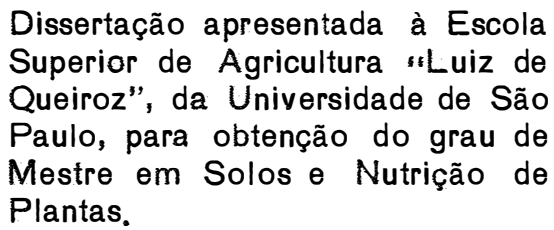

PIRAC ICABA

Estado de São Paulo - Brasil

Dezembro, 1979 
. I .

A minha esposa Leila, Aos meus pais 


\section{\begin{tabular}{lllllllllllllll}
$A$ & $G$ & $R$ & $A$ & $D$ & $E$ & $C$ & 1 & $M$ & $E$ & $N$ & $T$ & $O$ & $S$ \\
\hline
\end{tabular}}

- Ao Professor Dx. Henrique Paulo Haag, pelo apoio, confian ça e orientação dispensados na realização deste trabalho.

- Ao PLANALSUCAR (Programa Nacional de Melhoramento da Cana de-Agúcar) pela oportunidade e ao Superintendente GeraI eng agre Luiz Carlos Corrêa Carvalío e ao Coordsnador Re gional-sul Dr. Newton Macedo pelas facilidades proporcio nadas.

- Aos engls. agros. Dr. Josë Orlando Filho, Dr. Valdomiro Correa de Bittencourt e Dr. Humberto de Campos, pelas su gestões.

- Ao enge agrẹ MS. Edson José de Arruda Leme, Supervisor de Irrigação e Drenagem do PLANALSUCAR pela colaboração no ensaio irrigado.

- Aos Srs. Luiz Gil, Sërgio Zeferino Batista e José Zurita Fernandes e Srtas. Maria Eliza Bianchi e Antonia Apaxeci da Piva, da Coordenadoria Regional-SLi do PLANALSUCAR, Pe las colaborações prestadas.

- A Estagão Central sul do PLANALSUCAR, Usinas Rafard, São José, Bandeirantes, pela cessão das äreas dos ensaios. 


\section{IN D I C E}

Págìna

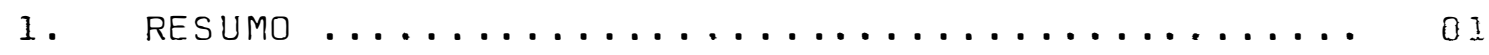

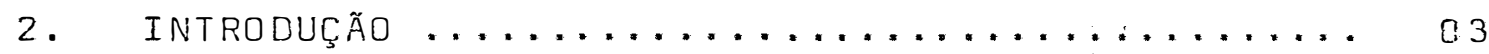

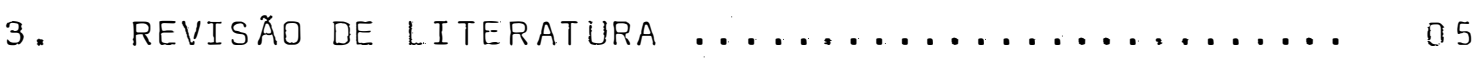

3.1. Efeito da Adubação em Soqueiras ........ 06

3.2. Fatores Interferentes na Diagnose Foiiar

Easeada no Nível Crítico ................ 10

3.3. Fatores Interferentes no Sistema Integrado de Diagnose e Recomendação ........... I 5

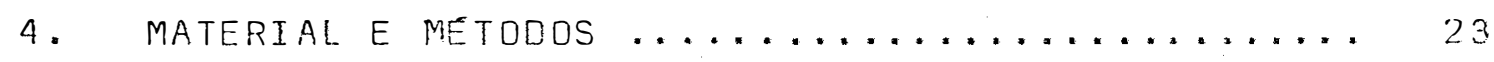

4.1. Variedades ..................... 23

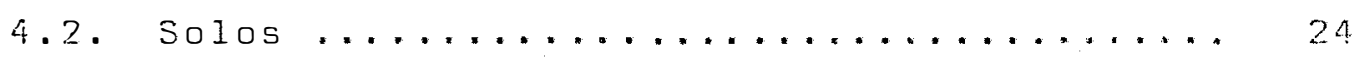

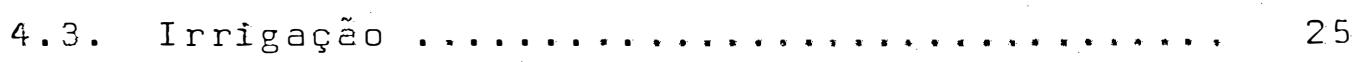

4.4. Instalação dos Ensaios .............. 27

4.5. Coleta de Amostras ................... 23

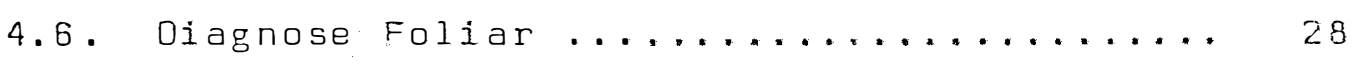

4.7. Sistema Integrado de Diagnose e Recomenda-

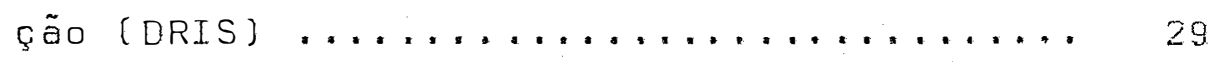

4.8. Produção e Análises Tecnológicas ........ 32

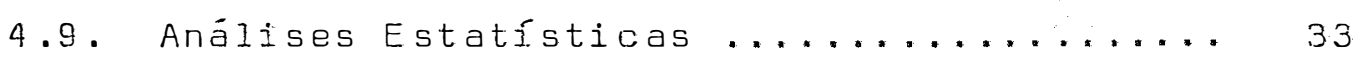

5. Resultados e discussão ................. 34

5.1. Efeito da Adubaçz̃̃o ................ 3 A

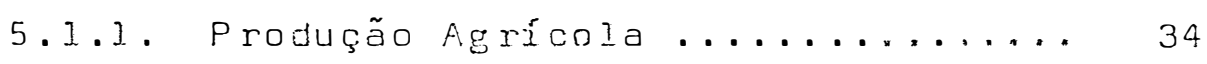

5.1 .2 . Produção de Açúcár ............... 38

5.3.3. Anälise Conjunta dos Ensaios ..... 40

5.2. Diagnose foliar Easeada no Nível Crítico.. 4l

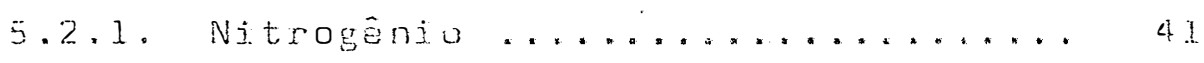


Página

5.2 .2$. fósforo ...................... 45

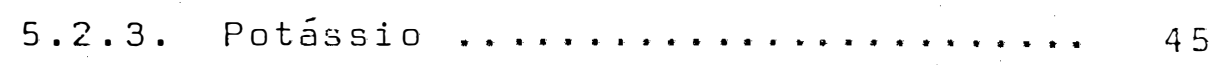

5.3. Sistema Integrado de Diagnose e Recomenda-

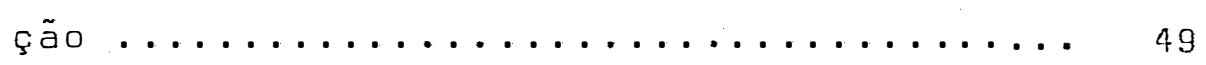

5.3.1. Nitrogênio ............... 49.

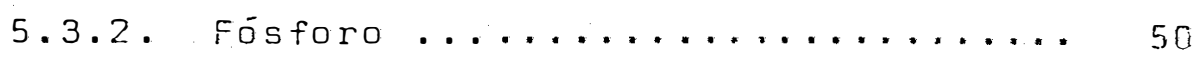

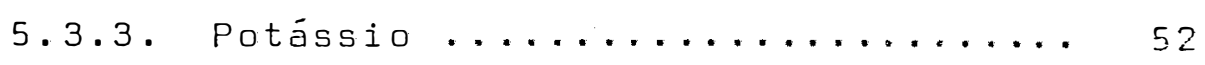

5.3.4. Epoca de Amostragem ........... 52

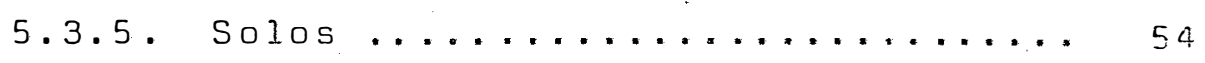

5.4. Observações Gerais $\ldots \ldots \ldots \ldots \ldots \ldots$

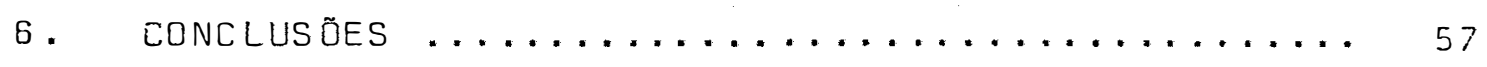

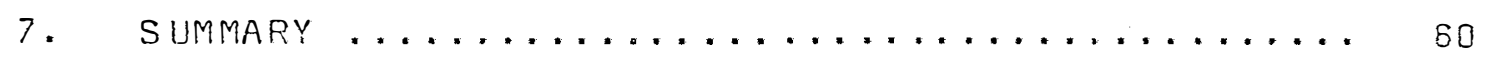

8. apendice ..............................

9. Literatura citada .................... 88 
Com o objetivo de se estudar a aplicação

do Sistema Integrado de Diagnose e Recomendação (DRIS) em canade-açúcar, confrontou-se esta metodologia com a técnica da diagnose foliar baseada no nível crítico. Desse modo, obser vou-se o efeito de diferentes épocas de amostragem foliar de soqueiras cultivadas em 4 Grandes Grupos de Solos e, num de les, dois regimes hídricos : irrigado e não irrigado.

Os ensaios se basearam no esquema fatorial $N \times$

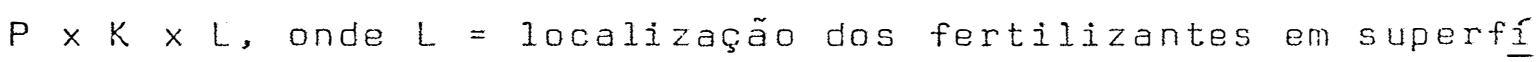
cie e em profundidade, com as dosagens D - $60-120-180 \mathrm{~kg}$ $\mathrm{N} / \mathrm{ha}$, 0 - $45 \mathrm{~kg} \mathrm{P}_{2} \mathrm{O}_{5}$ tha e 0 - 90 - $180 \mathrm{~kg} \mathrm{~K}_{2} \mathrm{D} / \mathrm{ha}$. Os solos utilizados foram Latossol Roxo'( $L R)$, Podzólico vermelho Ame relo - variação Laras (PVIs), Latossol Vermelho Amarelo - fa se arenosa (LVa) e o Latossol Vermeiho Escuro-orto (LE) rião controlado e sob irrigação por aspersão.

A variedade empregada foj a CB4l-76 e coletou- 
se a folha +3 aos $3,4,5$ e 6 meses de idade da cana-soca.

As parcelas eram constituídas por 3 linhas

úteis, 2 linhas de bordadura interna e 2 de bordadura exter na, num total de 7 linhas com $10 \mathrm{~m}$ de comprimento e $1,5 \mathrm{~m}$ de espaçamento, ocupando uma área de $105 \mathrm{~m}^{2}$.

Os dados obtidos mostraram que a localização dos fertilizantes em profundidade não proporcionou efeito po sitivo nas produtividades agrícolas e de açúcar por área,com exceção ao solo PVIs.

De modo geral, o nitrogènio e o potássio aumen taram de forma linear os rendimentos da cana-de-açúcar, sal vo para o potásio no solo LR.

o fósforo elevou a produção agrícola para os solos LE, LR e PVIs e provocou aumento da produção de açúcar por área para os dois primeiros solos.

A irrigação não indicou benetício para a so queira cultivada em solo LE.

Foi possível o estabelecimento dos níveis crí ticos de $N$ e K apenas para algumas épocas de amostragam fo liar, enquanto para o fósforó os mesmos não foram viáveis para nenhuma época de coleta da folha +3. A época de coleta do tecido vegetal e o tipo de solo afetaram os niveis críticos de $N$ e $K$.

Por outro lado, o DRIS mostrou ser metodologia adequada para o diagnóstico de $N, P$ e K em soqueiras de cana de-açúcar e a interpretação dos índices transformados é pra ticamente inalterada com a época de amostragem foliar. Pos suindo também, a propriedade de ter sua aplicação para dife rentes tipos de solos. 
A cultura da cana-de-açúcar vem obtendo desta que dentro da agricultura nacional, onde é meta governamen tal a produção de $10,7 \times 10^{9} l$ de álcool para o ano de 1985. Este, virá substituir parte das importaçóes de petróleo pois será utilizado como carburante e na indústria álcool-química.

Para a obtenção do volume ácima mencionado e mais um montante em açūcar, deverá ser ampliada em muito a fronteira agrícola da cultura, além de melhorado o atial ren dimento agrícola médio do Brasil (50 t cana/ha). Como na re gião centro-sul os solos mais produtivos já estão tradicio nalmente ocupados com cana-de-açúcar ou outras culturas, áreas de menor fertilidade, como as de cerrado, tenderão a ser exploradas.

A adubação participa atualmente com cerce de 20 a $25 \%$ dos custos de produção e tanto para o aumentio da produtividade como na possivel exploração do cerrado, os fer tilizantes teráa um papjel fundamential para o sucesso da cul 
tura. Caso este insumo não seja utilizado de maneira racio nal, poderiam ocorrer elevações no custo de produção, o que afetaria a sua rentabilidade.

Das considerações anteriores infere-se que a cana-de-açúcar, principalmente no caso das soqueiras, as quais são responsáveis por 70 a $80 \%$ da produção total, exi ge especial atenção quando se pretende fornecer os nutrien tes necessários para seu bom desenvolvimento e produtividade. A análise de tecido vegetal surge assim naturalmente como me todologia mais viável para a cana-soca, visto que a análise de solo sofre certas interferéncias da adubação anterior. quando do procedimento das amostragens e também, muitas ve zes, não define a real necessidade nutricional da planta.

No presente trabalho objetiva-se a avaliação de dois métodos de caracterização do estado nutricional "da cana-de-açúcar : a diagnose foliar baseada no nível crítico a - Sistema Integrado de Diagnose e Recomendação, ambos efetua dos com base em análise de tecido vegetal. Assim, estudouse o efeito de diferentes épocas de amostragem foliar em so queiras, cultivadas em 4 Grandes Grupos de solos e, num de les, dois regimes hídricos : irrigado e não irrigado. 
Apesar da alta representatividade das soquei ras na produção global da cana-de-açúcar, poucos trabaihos tèm sido desenvolvidos com enfoque principal a cana-soca e seu estado nutricional. Assim, para se estudar técnicas de recomendação de fertilizantes devemos ter plantas cultivadas em diferentes níveis de fertilidade e sobre as mesmes apli car as metodologias de diagnóstico. Estes níveis deverão es tar em concordáncia com as tendéncias de respostas verificadas pela planta, sendo que a seguir apresenta-se uma revisão sobre a reação da soqueira à adubação $N, P$ e $K$ os fatores interferentes nas técnicas de diagnóse foliar utilizadas pa ra aplicações racionais de adubos. 


\subsection{Efeito da Adubação em Soqueiras}

SAMUELS e LANDRAUI JR. (1952), estudaram o com portamento de 4 variedades, durante a cana-planta e 4 subsequentes soqueiras, sob o efeito de um fatorial incompleto de $N, P$ e $K$, onde observaram uma menor resposta ao $N$ para as $s$ queiras, estabelecendo a recomendação de $150 \mathrm{~kg} \mathrm{~N} / \mathrm{ha}$. Com respeito ao $P$, as doses empregadas não provocaram aumento de produção, recomendando entre 40 a $50 \mathrm{~kg} \mathrm{P}_{2} \mathrm{O}_{5}$ /ha como dosagem suficiente para controlar deficiências não muito extremas. o $K$ mostrou maior reação para cana-scoa, tendo os autores suge rido $150 \mathrm{~kg} \mathrm{~K}$ o/ha.

SAMUELS e. LANDRAU JR. (1954), analisaram mais de 200 experimentos de campo conduzidos pela Estação Agríco la Experimental da Universidede de Porto Rico e observaram que, em média, o potássio era responsável por um aumento de 11,9\% na produção agrícola, sendo as maiores respostas obti das nas soqueiras :

Ciclo

cana-planta
1. soqueira
2 a soqueira
3 . soqueira
4 a soqueira

Aumento devido

\begin{tabular}{c} 
ao potássiø \\
\hline $3,2 \%$ \\
$5,9 \%$ \\
$5,9 \%$ \\
$7,1 \%$ \\
$12,8 \%$
\end{tabular}

MOHAN RAO et alii (1956), na India, estuciando a adubação da cana-soca, variedade co419, constataram um de créscimo de produção da cana-planta para a primeira soca e desta para a subsequente soqueira e concluíram que a produ ção agrícola da primeira soca poderia ser elevada com aplica ção de $150 \mathrm{~kg}$ N/ha.

o P não mostrou efeito para elevação do seu teor no caldo e no aumento de produço agrícola. Todavia, na segunda soqueira, houve uma tendéncia ao aumento de rendimen to com $50 \mathrm{~kg}$ de $\mathrm{P}_{2} \mathrm{O}_{\mathrm{g}}$ /ha. As adubaçóes realizadás 45 dies de 
pois da colneita, ofereceram melhores resultados do que as efetuadas 90 dias após.

\section{JACOB e UEXKÜLL (1961), apresentaram para}

a 1 guns países produtores de cana-de-açúcar, as faixas de dosa gem de nitrogẽnio empregadas :

$\mathrm{kg} / \mathrm{ha}$

Locais

Louisiana

Jamaica

Egito

\begin{tabular}{cc}
\hline Cana-Planta & Soqueiras \\
\hline $45-68$ & $68-90$ \\
$45-100$ & $68-168$ \\
$75-120$ & $100-200$ \\
\hline
\end{tabular}

Observaram ainda, com respeito ao fósforo, que a melhor localização do mesmo é junto às rázzes, no fundo do sulco, sendo que tal técnica não pode ser desenvolvida em ca na-soca a não ser através da colocação do fósforo em certa profundidade e de ambos os lados da linha da planta. Argumen tam que, em regiões com altas precipitações e umidade cons tante na superfície do solo, o sisteme radicular apresenta desenvolvimento superficial e permite um melhor aproveitamen to dos fertilizantes distribuŕdos na superfície. Agora, em regiões com alternáncia de umidade e seca ou sob irrigação, as raízes se desenvolvem em maior profundidade e não oferecem condições de aproveitar o fósforo na supertície.

MALAVOLTA e HAAG (1964), recomendam para o Es tado de são paulo as seguintes dosagens de fertilizantes pa ra as soqueiras, discriminando os diferentes tipos de solos:

\begin{tabular}{|c|c|c|c|c|}
\hline \multirow{2}{*}{\multicolumn{2}{|c|}{ Tipos de Solo }} & \\
\hline & & $N$ & $2^{0} 5$ & $\mathrm{~K}_{2} \mathrm{O}$ \\
\hline Terra & Roxa Legítima & 60 & 50 & 90 \\
\hline \multirow[t]{2}{*}{ Terra } & Roxa Misturada & 90 & 45 & 90 \\
\hline & Outros & 90 & 90 & 90 \\
\hline
\end{tabular}

GELS (1967i, através de vasta revisão sô่ re fertilizaçäo nitrogenada em cana-de-açúcar, observa que a 
a cana-soca requer quantidades maiores de nitrogénio do que a cana-planta :

Na Africa do Sul,

$$
\text { cana-planta }
$$

kgN/ha Resposta ( $t \overline{\text { cana/ha) }}$

50

100

2,9

4,9

150

5,7

No Egito,

\begin{tabular}{|c|c|c|}
\hline \multirow[b]{2}{*}{ Ciclo } & \multicolumn{2}{|c|}{$\mathrm{kg} N / \mathrm{ha}$} \\
\hline & Area $]$ & Aroa 2 \\
\hline $1 . \mathrm{soca}$ & $30-35$ & 50 \\
\hline $2 \cdot \operatorname{soca}$ & $40-45$ & $65-80$ \\
\hline $3^{a} \cdot$ soca & $60-65$ & $90-100$ \\
\hline
\end{tabular}

Outros paises produtores,

kg N/ha

$\begin{array}{cc}\text { Cana-Planta } & \text { Soqueira } \\ 90 & 140 \\ 50 & 100-150 \\ 75-120 & 100-120 \\ 40 & 100 \\ 120 & 200 \\ 110 & 130\end{array}$

Sugere ainda a aplicação de $N$ näo mais tarde que 3 meses je idade e preferencialmente antes dos 2 meses, isto porque aplicações tardias de $N$ reduzem consideravelmen te a percentagem de açúcar da cana a qual apresenta tenden cia a vegetar ao invés de entrar em processo de maturação. 
W000 e w000 (1967), na Africa do sul, estudan do o desenvolvimento e a distribuição do sistema radicular da cana-de-açúcar, verificaram que, sob condições normais de chuva, as raízes ativas predominaram no espaço junto à tou ceira e superficialmente ao solo. As raízes remanescentes da cana-planta, podem continuar em atividade até 4 meses de pois de realizada a colheita.

HUMBERT (1974), salienta que a eficiência do nitrogênio é sempre baixa pois parte é utilizada pelo comple xo microbiológico do solo; parte se converte em nitratos, podendo ser perdida por lixiviação e parte volatiliza-se e per de-se na atmosfera. Assim, plantas com ciclos mais longos (cana-planta 18 meses) apresentam sistema radicular mais de senvolvido e são mais eficientes que as de ciclos curtcs (ca na-soca 12 meses\}, as quais se encontram em condições de maior compactação e menor aeração, diminuíndo aj̇im a efí ciência do seu sistema radicular. O autor apresenta a localização do fósforo como de grande importáncia, pois este elemento possui baixa mobiiidade no solo e altas aplicaçós no sulco de plantio são tão eficientes como dosagens parcela das depois de cada colheita. A partir da segunda soca, eㅍ controu necessidade da aplicação de quantidades adicjonais de fosfato para manter os rendimentos em nível ótimo.

ZAMBELLO JR, et alii (1977), trabalhando com soqueiras de 3 variedades de cana-de-açúcar em solo Terra Ro xa Estruturada, no Estado de São Paulo, observaram respostas económicas até $167 \mathrm{~kg} \mathrm{~N} / \mathrm{ha}$.

ORLANDO FO e ZAMBELLO JR. (1977), em solo La tossol Vermelho Escuro-orto, estudaram a adubação nitrogena da em 4 variedades de cana-de-açúcar, no estágio de primeira soqueira, onde apenas para a variedade CBAl-76 encontraram diferença significativa para as doses utilizadas, sendo 40 kg N/ha suficiente para obtençõo de boa produção.

ORLANDO FC et alii (1977), estudaram, em cana soca, a variedade CB4. 16 em sola Terra Roxa Estruturada, co lheita de início de safra, e em solo Latossol vermelho Amare Io-fase arenosa, colheita de fim de safra. Dbservaram para 
- solo TE, efeito da adubação nitrogenada até a dose de 150 kg N/ha. A localização do fertilizante também foi apresenta da (em superfície e em profundidade) e os autores concluem: que para o início de safra seria recomendada a aplícação em profundidade; já para as canas colhidas no começo do período chuvoso, a localização perde seu efeito.

ESPIRONELO (1979), apresenta as recomendaçõesdo Instituto Agronómico de Campinas para soqueiras, como sen do: $40-90 \mathrm{~kg} \mathrm{~N} / \mathrm{ha}, 25-50 \mathrm{~kg} \mathrm{P}_{2} \mathrm{O}_{5} / \mathrm{ha}$ e $40-80 \mathrm{~kg} \mathrm{~K}_{2} \mathrm{O} / \mathrm{ha}$.

As soqueiras mostram assim, exigências maiores que a cana-planta em fertilizantes nitrogenados, baixa rea ção ao fósforo e respostas da mesma ordem de grandeza que a cana-planta para o potássio. A melhor época de aplicação dos fertilizantes parece ser imediatamente após a colheita da cana-planta e a localização dos adubos ainda não se encon tra em situação definida, sendo provavelmente correlacionada com as condições climáticas.

3.2. Fatores Interferentes na Diagnose foliar Basea da no Nivel Critico

SAMUELS (1969), apresente vasta revisão sobre diagnose foliar em cana-de-açúcar e seus fatores interferen tes, mostrando as limitações e vantagens nas aplicações da referida técnica.

Na Rodésia, GOSNELL e LONG 11971i, divulgaramconsiderações sobre a hora de coleta das amostras, remoção da nervura principal, idade da cultura, estação do ano e va riedade, os quais afetam a diagnose foliar a ponto dos auto res proporem correções e padronizações para os diferentes ca sos.

IAMBELLO JR. C ORLANDO FO (1977), Utilizando 2 variedades de cana-de-açúcar, primeirasoqueira, ensolo res ra Roxa Estruturada do Estado de Säo faulo, apresentaram o mo nível crítico económico fisjológioo, o teor de l, $90 \%$ N P ra a variedade CB46-47 e de 2,05\% N para a CBA1-7e. 
Na região centro-sul do Brasil, ORLANDO Fọ et alii (1978), para soqueiras, encontraram marcante efeito va rietal nas concentrações dos macronutrientes na folha +3 .

Nota-se a existēncia de um número elevado de interferentes na diagnose foliar baseada no nível crítico e uma revisão suscinta do problema é apresentada para tipos de solos, épocas de amostragens e interações entre nutrientes.

SOLOS,

Em Porto Rico, SAMUELS et alii (1955), desen volvendo ensaios fatoriais incompletos de $N \times P \times K$, durante 8 anos e com 13 variedades de cana-de-açúcar, coricluíram que do ponto de vista prático, poderiam ser empregados níveis pa drões de $N=1,68 \%, P=0,18 \%$ e $K=1,71 \%$, independentes do solo e da variedade.

MALAVOLTA et alii (1963), trabalhando nas con dições do Estado de São Paulo, indicaram que a variação dos níveis críticos foi muito pequena para os diversos tipos de solos estudados.

Por outro lado, VITLOS e LAURIE (1963), em Tri nidad, sugeriram diferentes níveis críticos para a cana-soca, de acordo com o tipo de solo considerado.

GALLO et alie (1968), no Brasil, observaram, pe ra 2 variedades de cana-de-acúcar, que os Grandes Grupos de Solos não apresentaram influência consistente, com exceção ao nutriente ferro, o qual foi sempre maior para o Latossol Roxo.

SAMUELS (1969), indica que apesar da interfe réncia do solo no crescimento da cana-de-açúcar, a mesma é capaz de integrar as variáveis peresente no mesmo, representar o estado nutricional, dispensando as correções nos nI veis críticos.

ORLANDO Fọ et alii (1978), ne região centro Sul do Brasil, através de levantamento do estado nutricional de soqueiras de cane-de-açúcar, cultivadas em a Grandes Gru pcs de solos. verificaram que o solo interfere significante 
mente nos teores foliares de $N, P, K, C a, M g$ e $S$.

ORLANDO Fọ (1978), trabalhando em 3 solos (La tossol Roxo, Latossol Vermelho Escuro-orto e Podzólico Verme Iho Amarelo- var. Laras), notou o efeito dos mesmos sobre o teor foliar de $N, P$ e $K$, coletados aos 4, 6, 8, 10 e 12 me ses de idade da cana-soca.

IDADE DA PLANTA,

Devido a interferência de fatores fisiológicos e ambientais, alguns autores têm proposto correções aos ní veis críticos, por exemplo através da umidade da bainha, no sentido de minimizarem estas variações. Seguindo esta linha de pesquisa, Clements e Kubota, em 1942 laitados por SA MUELS, 1969l, apresentaram trabalino clássico sobre o assunto, sendo seguido por outros, como SAMUELS et alii (1953), em Porto Rico, e MILLER (1962), na Colómbia, os quais sugeriram correçöes de acordo com a referida umidade.

POIDEVIN (1964), na Guiana Inglesa, estabele ceu diferentes níveis críticos foliares para $N$, P e $K$ em so queiras, conforme a época de amostragem 112,18 e 24 sema nas), notando-se diminuição dos teores de $N$ e P com o avan çar da idade enquanto o $K$ permanecia mais ou menos constante.

GOMEZ-ALVAREZ (1971), conduzindo ensaios na Ve nezuela, observou que á concentração dos nutrientes nas fo Ihas é afetada pola idade da cultura, hora do dia, variações climáticas (especialmente nebulosidade) e concluiu que a me lhor hora de coleta das amostras foliares é das 6 às 8 hores da manhã.

McLEAN (1973), apresentou os níveis críticos, para a idade da coleta de amostra entre 12-i5 semanes, como sendo $1,50 \% N$ e $2,00 \% N$, respectivamente para as variededes$0.141 / 45$ e B.41227. Quando a amostragem ocorrer as 20 sema nas de idade, os padröes passariam a $1,50 \% \mathrm{~N}$ e $1,70 \% \mathrm{~N}$, res pectivamente para es mesmas variedades.

ORLANDO F! C ZAMBELLO IR. (1977), OLSERVaram para 4 variedades de sogueiras, cultjvadas em solo Latossol 
Vermelho Escuro-orto no Estado de São Paulo, que os teores de $N$ na folha + 3 decresciam com o aumento da idade da planta, apresentaram também equações de regressão para o ajuste dos teores de nitrogénio de acordo com a idade de coleta das amostras.

ORLANDO FO (1978), estudando a variedade CB4176 em 3 Grandes Grupos de Solos do Estado de São Paulo, adap tou a equação de $3^{\circ}$ grau para representar as flutuações do nitrogénio na cana-soca do $49^{\circ}$ a $12^{\circ}$ més para a folha +3 .

Com respeito a $P$, apresentou equações do 28 grau, onde o teor foliar de $P$ decrescia com o aumento da idade. Para o $x$, foi possível se ajustar uma equação de regressão ( $3^{\circ}$ grau) apenas para o solo Latossol Vermelho Escuro-orto.

\section{INTERAÇÕES,}

Por diferentes mecanismos os nutrientes intera gem entre si e a composição mineral da planta revela estas evidéncias. Relativamente poucos estudos têm sido realiza dos neste campo. Assim, EVANS (1959), assevera que a absorção excessiva de cálcio frequentemente interfere na absorção de outros macronutrientes e reduz a mobilidade de certos mi cronutrientes.

FARQUHAR(1965), na Austrälia, defirie o "índice de fósforo" como a quantidade do nutriente no tecido analisa do em relação a outro (referência) em quantidade fixa e obti da no mesmo tecido (por exemplo, o elemento N por loo partes de matéría seca na folhal. Observa que a relação $P / N$ se cor relaciona melhor com as reações de fosfato do que simplesmen te a percentagem de $P$.

SAMUELS (1969), apresentou um quadro de intera ções entre os nutrientes para a cultura da cana-de-açúcar. 
Elemento

\begin{tabular}{|c|c|c|c|c|c|c|}
\hline Aplicado & N & $P$ & $K$ & $\mathrm{Ca}$ & Mg & Outros \\
\hline $\mathrm{N}$ & & - &,-+ & + & + & $\mathrm{Zn}^{+}, \mathrm{MO}+, \mathrm{Al-}$ \\
\hline$P$ & - & & + & & - & \\
\hline$K$ & - &,-+ & & - & - & \\
\hline $\mathrm{Ca}$ & + & + & - & &,-+ & $\mathrm{Mn}^{-}, \mathrm{Al}-, \mathrm{Fe}-, \mathrm{Mo}+, \mathrm{S}+$ \\
\hline $\mathrm{Mg}$ & + & & - & - & & \\
\hline$M n$ & & & - & & & $\mathrm{Fe}^{-}, \mathrm{Si}-$ \\
\hline $\mathrm{Fe}$ & & & - & & & $\mathrm{Mn-}$ \\
\hline
\end{tabular}

+ indica correlação positiva

- indica correlação negativa

GOMEZ-ALVAREZ (1974), na Venezuela, com refe réncia à feriilização nitrogenada, observa o efeito antagóni. co deste elemento com o cálcio, magnésio, potássio e especial mente com a fósforo.

ORLANDO FO e ZAMBELLO JR. (1977), registraram para 4 variedades, que apenas a dosagem de $180 \mathrm{~kg} \mathrm{k}_{2}$ /ha, foi responsável não só pelo aumento de produção agrícola como também pela elevação substancial dos teores de nitrogênio na foltia +3 .

As limitações desta técnica obrigam a realiza ção de um grande número de ensaios com o fim de se obter os padrões em diferentes épocas de amostragens para uma determi. nada variedade cultivada em um tipo de s.lo e sob específica condição climática. Para se ter noção do problema pode-se considerar o número elevado de variedades cultivadas no Bra sil e o aparecimento de novas variedades através dos váriosprogramas de melhoramento existentes, da expansão da cultura para outros solos, da prolongada safra proporcionando canas com a mesma idade cronológica em diferentes estägios fisioló gicos e as interaçés entre us nutrientos as quais rão são consideradas pela diagrose foliar baseada no nivel crítico. 
3.3. Fatores Interferentes no Sistema Integrado de Diagnose e Recomendação (DRIS*)

Esta técnica foi desenvolvida por Beaufils, primeiramente com o nome de Diagnose Fisiológica e através do estudo de aspectos nutricionais de seringueiras

lHavea brasiliensisl, cultivadas no Vietnã e no Camboja. BEAUFILS (1956), já propõe as relações $N / P, N / K$ e K/P bem como o dia grama para interpretação do balanço nutricional de $N, P$ e $K$ em seringueiras baseado em um conjunto de reaçóes de equilíbrio dos constituintes das foihas, assim estabeiecidos:

- Toda variação do teor de um elemento mineral, num dado momento, correlaciona-se positiva ou negativamente com um ou vários outros elementos, seja qual for sua importân cia ponderal relativa.

- A relação de dois eiementos antagónicos $k$ e Ca pode ser considerada como reflexo, dentro de certos limi tes, de conjunto de equilíbrios químicos ao nível das fo Ihas, pois variações de $N, S$, P, Fe e Cu são relacionadas àquelas do potássio e variações de Mg e Mn são relacionadas às do cálcio.

- Os elementos citados do 1 : Grupo (K) são 1 i gados ao sistema aquoso das folhas; os elementos do $2^{8}$ Grupo ( $\mathrm{C}$ a) estão presentes na matéria seca.

- As variações ua relação K/Ca estão em corre lação inversa altamente negativas com as variações da rela ção $\mathrm{Mn} / \mathrm{Cu}$. Essa constatação constitui um dos critérios so bre os quais se baseiam o diagnóstico.

- Os elementos do "grupo potássio" que são re lativamente mais importantes durante o estágia de cresimento, têm em seguida tendéncja a migrar è medida que os elementosdo "grupo cálcio" se acumulam até a hibernação das seringuei ras. O caso do magnésio, que é constituinte da clorofila, requer atençäo especial, pois ele ocorre igualmente nas fe.

* Dris = Diagnosis and Recommendatione Integrated System. 
Ihas sob uma forma ionizada e susceptível de migrar. A hipó tese é que essa parte ionizada é deslocada progressivamentepelo ion $\mathrm{Ca}^{+2}$, à medida que a assimilação desse último pro duz particularmente o oxalato de cálcio mais insolúvel que a de magnésio.

- Os elementos $N$, $P$ e $K$ das folhas podem ser relacionados entre si por uma fórmula geral aplicada a todas as seringueiras, sob a condição de que o solo, independentemente de sua origem, possa responder às suas necessidades.

- A relação geral que se tem é :

$N \approx a K \simeq a^{2} P$

O coeficiente de assimilação "a" admite certa possibilidade de variação entre os limites que de maneira ge ral vão de 3,4 a 4,3 , para as seringueiras.

Esse valor do coeficiente "a" varia dentro de certos limites amplos, só no caso de carências mínerais ou de desiquilíbrios fisiológicos provocados por uma exploração intensa, fenómeno que pode ser passageiro ou permanente, se gundo os recursos minerais do solo.

BEAUFILS (1971), na África do Sul, observa a possibilidade da utilização da díagnose fisiológica para cul tura do milho, tendo na cportunidade trabalhado com 21.536 observações onde o pesquisador utilizou-se de dados publicados em diferentes revistas científicas, inclusive com resultados obtidos no Ërasil, dividindo as observações em 2 cate gorias:

- plantas não anormais, isto é, plantas que não foram afetadas por condições anormais;

- plantas anormais, isto é, plantas que foram afetadas por condiçöes anormais.

Por convenção, as plantas não anormais pode riam ser chamadas de plantas normais e seriam as que possuem produtividade acima de $3.200 \mathrm{~kg} / \mathrm{ha}$.

Neste trabalino, c eutor introduz os índíces primários de $N$, $P$ e K ; esteg indices representam numericamen 
te o balanço nutricional, substituindo as setas do diagrama interpretativo, valores negativos significam deficiéncia do elemento em relaçăo aos demais, valores positivos indicam um excesso e quanto mais próximos do zero estiverem estes ín dices mais próxima estará a planta do equilíbrio nutricional. outra vantagem dos índices primários é quando se utilizam de mais de 3 elementos (por exemplo $N, P, K$ e $2 n$ ) onde a repre sentação gráfica do balanço nutricional iria requerer uma forma espacial, dificultando a visualização do problema.

Observa ainda que a relação existente entre a produtividade e a composição química do tecido analisado é uma manipulação da Lei do Mínimo (Lei de Liebig) e que a par ticular vantagem da diagnose fisiológica é que esta técnica não é afetada pelos fatores de variabilidade que mascaram a interpretaçáo dos teores dos nutrientes, podendo ser aplice da em qualquer tempo e sob diferentes condições. BEAlfFILS (1971), alerta que a diagnose fisiológica não é uma solução autamática para o problema e que são exigidas características subjetivas, tais como, conhecimento-experiéncia-perspicácia, de quem vai interpretar e recomendar as correções.

BEAUFILS (1973), formulou uma revisão sobre sua técnica e anuncia o Sistema Integrado de Diagnose e Reco mendação (DRIS) em substituição à Diagnose Fisiológica. o autor considera que à produtividade e a qualidade do produ to de uma cultura particular constituem a resposta da planta a vérios estímulos do amoiente e não só diretamente do estí mulo provocado. A representação esquemática para o fato se ria :

\section{Propriedades do Solo}

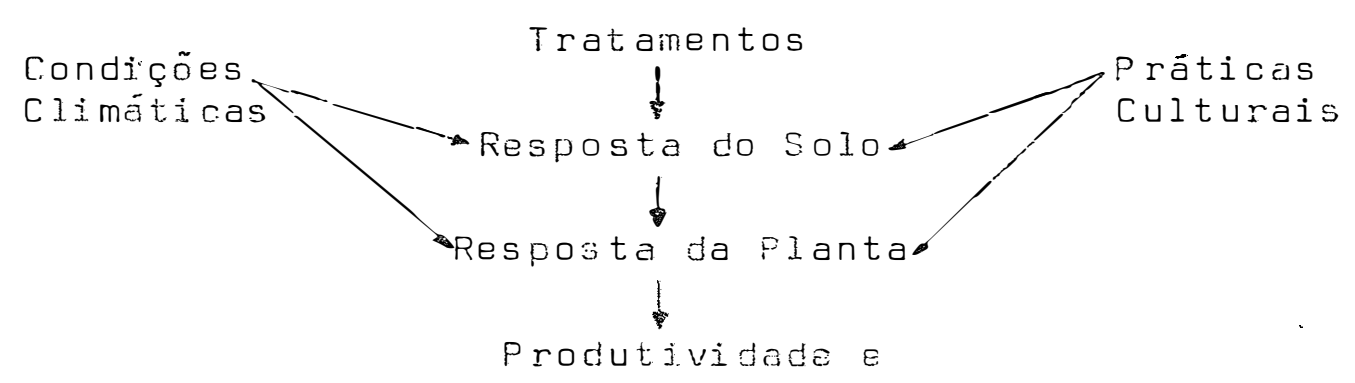

Qualidade 
BEAUFILS (1973), observa que a seleção da população considerada normal é de grande importáncia para o suces so do DRIS e orienta esta escolha:

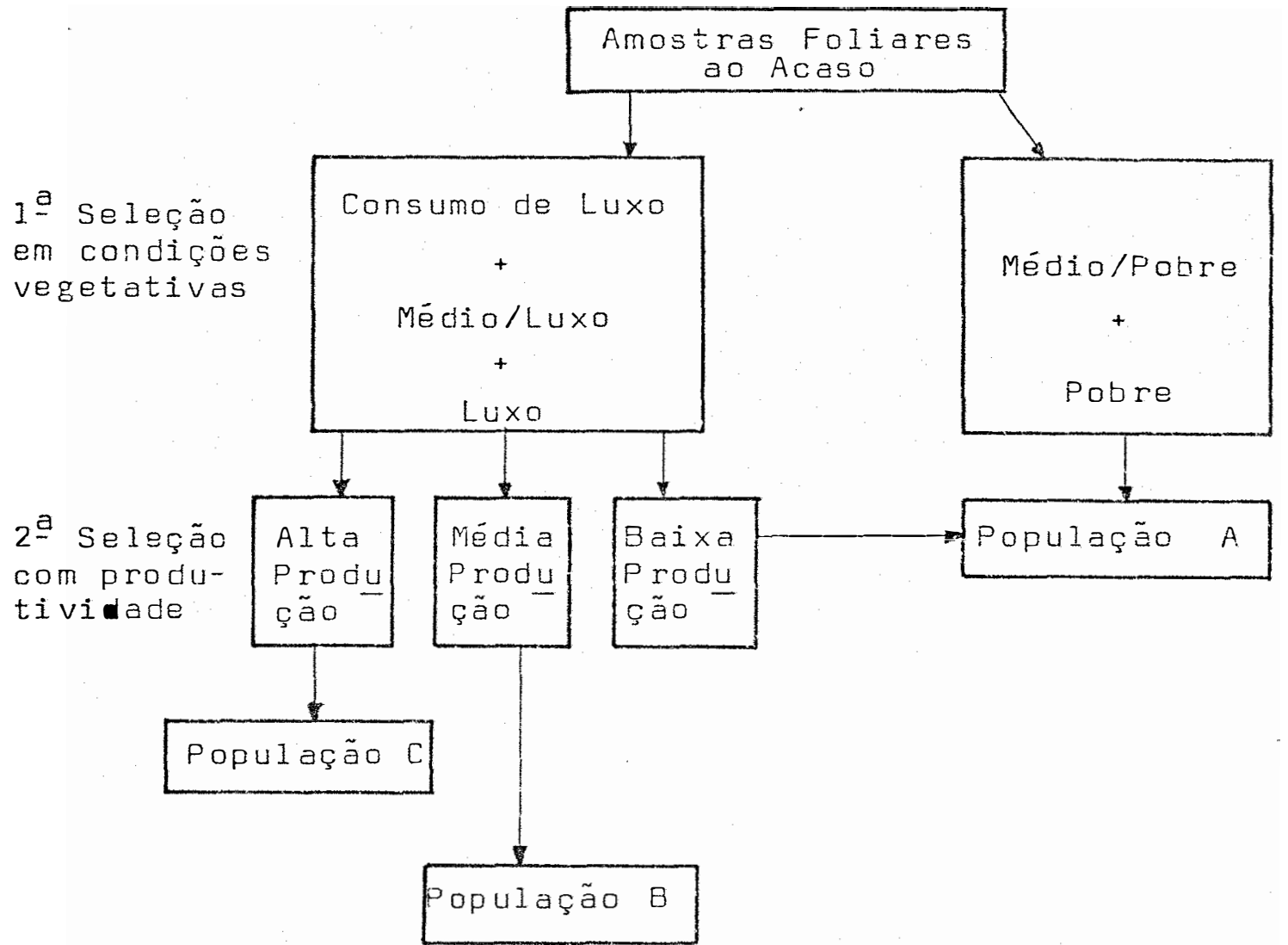

A população $B$ deve ser a escolhida, e segue-se - teste da normalidade desta distribuição podendo-se lançar mão do teste do qui-quadrado. Para o caso do milho,

IBEAL FILS, 1971), a população foi sejecionade mediante o rendimen to médio do USA que, na época, ere de $3.200 \mathrm{~kg} / \mathrm{ha}$.

BEAUFILS (1973), apresenta os índices transfor mados, os quais possuem a propriedade de não alterarem o diagnóstico oferecido pelos índices primários e podem ser usados irrestritamente em qualquer análise estatística. 
MEYER (1975), trabalhando com cana-de-açücar na Africa do Sul, observou efeito significativo da posição da folha na planta, da idade e da época de coleta das amos tras $\left(4^{\circ}, 8^{\circ}, 10^{\circ}\right.$ e $12^{8}$ més) e o efeito varietal sobre o DRIS. Por outro lado, encontrou um melhor diagnóstico da de ficiência de $P$ quando analisou, através das relações $N / P, K /$ $P$ e dos índices de Beaufils, do que simplesmente pelo teor de $P$ na matéría seca.

SUMNER e BEAUFILS (1975), em ensaios desenvolvidos na Africa do Sul com cana-de-açücar, observaram que o DRIS poderia ser aplicado independente da idade da cuitura, da flutuaçâo sazonal e do regime interno de umidade, jä que. a ordem de necessidade em nutrientes do $1^{\circ}$ ao $10^{\circ}$ més de ida de permaneceu inalterada e foi a seguinte $P>K>N$. Quanto ao efeito sazonal, encontraram mensalmente, de agosto a abril, o fósforo como elemento mais deficiente. Estudaram também a cultura da cana-de-açúcar sob diferentes regimes de irrigação e o diegnóstico foi o mesmo para os diversos esta dos internos de umidade.

Ainda neste trabalio, SUMNER e BEAUFILS (1975), encontraram certa independência do DRIS com relação à varie dade como pode ser observado :

\begin{tabular}{|c|c|c|c|c|c|c|}
\hline \multirow[b]{2}{*}{ Variedade } & \multicolumn{3}{|c|}{ teor foliar } & \multicolumn{3}{|c|}{ Ind.transf. } \\
\hline & $\because N$ & $\% P$ & $\% K$ & $N$ & $P$ & $k$ \\
\hline Co 1001 & 1,92 & 0,172 & 1,56 & 12 & -100 & 100 \\
\hline NCo 376 & 1,82 & 0,170 & 1,46 & 6 & -88 & 88 \\
\hline$N 52-219$ & 1,78 & 0,140 & 1,58 & 36 & -156 & 156 \\
\hline m $31-45$ & 1,77 & 0,165 & 1,70 & -30 & -132 & 132 \\
\hline Co 462 & 1,74 & 0.162 & 1,49 & 2 & -104 & 104 \\
\hline Pindar & 1,66 & 0,170 & 1,58 & -45 & -107 & 107 \\
\hline CB40-77 & $I, 54$ & 0,155 & 1,80 & -93 & -167 & 167 \\
\hline$N 55-805$ & 1,73 & 0,172 & 2.43 & -3 & -81 & 81 \\
\hline
\end{tabular}

onde, para todas as variedades, o P foj o elemento mais defi ciente. 
Quando SUMNER e BEAUFILS (1975), compararam uma possível correção, tanto pelo DRIS como pela diagnose do ní vel crítico para 2 ensaios fatoriais $3^{3}$ em soqueiras, encon traram para o DRIS, 38 observações positivas e 20 para o diagnóstico com nível crítico, sendo responsáveis por uma so matória de 458,51 t cana/ha, em oposição a 341,56 t cana/ha pelo método do nível crítico.

BEAUFILS e SUMNER (1976), utilizaram O DRIS Pa ra a variedade NCo 375 em vasos, através dos teores de $N$, $P$, $K$, Ca e Mg na planta e de P, K, Ca $=$ Mg no solo, sendo obser vada a validade da aplicação da referida técnica tanto para solo como para planta.

Para o caso do solo:

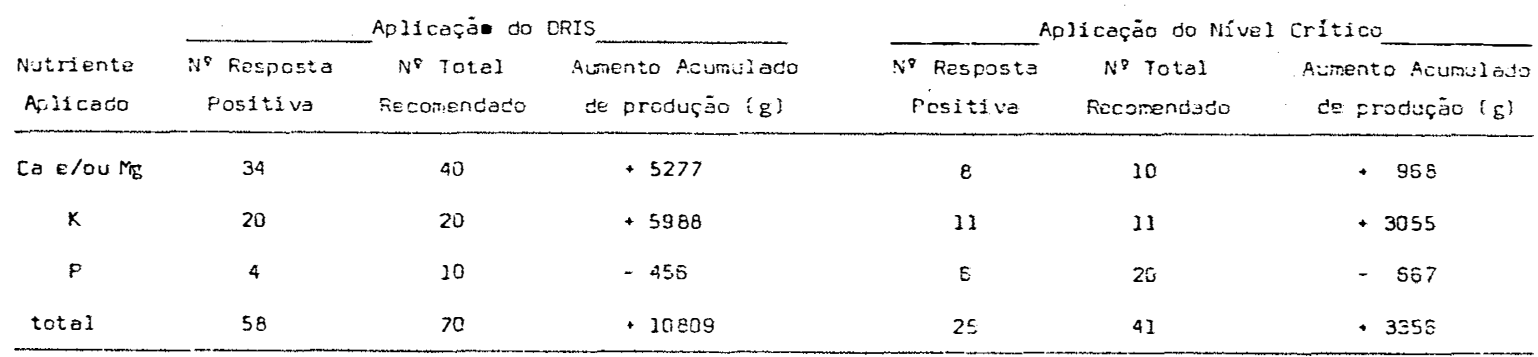

Os autores concluíram que o conceito de balan ço dos nutrientes ocorre também no solo aumentando assim o campo de atuação do DRIS.

Para o caso da planta, Aplicação do DRIS

\begin{tabular}{cccc}
$\begin{array}{c}\text { Nutriente } \\
\text { Aplicado }\end{array}$ & $\begin{array}{c}\text { No } \\
\text { positivas }\end{array}$ & $\begin{array}{c}N^{8} \text { total } \\
\text { Recomendado }\end{array}$ & $\begin{array}{c}\text { Aumento Acumulado } \\
\text { de produção }\end{array}$ \\
\hline$N$ & 6 & 8 & +1387 \\
$P$ & 0 & 0 & - \\
$K$ & 36 & 38 & +9786 \\
$\mathrm{Ca}$ & 0 & 0 & - \\
Mg & 31 & 32 & +6608 \\
Totai & 73 & 78 & +17781
\end{tabular}

BEAIFI LS e SUMNER (1977), estuderam o efeitoda época de amostragem da $3^{\exists}$ folha da variedade nCo 376 em 
um fatorial $3^{4}$ de $N, P, K$ e calagem. As épocas de amostra gem foram aos $3,6,12$ e 18 meses de idade e para todas as épocas o magnésio foi o elemento mais deficiente (com exce ção para as parcelas 0001 e 1002). Os autores concordaram que a ordem de deficiência de nutrientes é mais importante que o valor real do índice.

SUMNER (1977a), aplicou o DRIS para a cultura do trigo e observou a validade de sua interpretação, indepen dente da variedade utilizada e da idade da planta ne época da amostragem foliar. Ainda, SUMNER (1977b), estudando o DRIS para a cultura do milho apresentou conclusões onde esta técnica poderia ser aplicada em qualquer estágio de desenvol vimento e sob quaisquer condições. Mais tarde, SUMNER (1978), observou o ORIS na cultura da soja e sua independéncia da va riedade, idade da planta na época de amostragem e posição da foltha na mesma.

No Brasil, ZAMBELLO JR. e ORLANDO FO (1978), aplicarail pela primeira vez a metodologia do DRIS para a cuI tura da cana-de-açúcar. Estudaram sua validade para soque ras cultivadas em solo Terra Roxa Estruturada no Estado de São Paulo, onde encontraram o nitrogénio como elemento mais deficiente e o equilíbrio nutricionel ocorreu em torno da dose de $150 \mathrm{~kg} / \mathrm{N} / \mathrm{a}$ para as 3 variedades estudadas. Cs auto res também verificaram o efeito varietal e alertaram sobre a perda de sensibilidade do método quando estudaram conjunta mente a CB41-75, a CB46-47 e a CB47-355.

ZAMBELLO JR. e ORLANDO FO (1979a), concluíram que o DRIS poderia ser aplicado independente do estudo de umidade em que se encontrava a cana-planta, variedade CBAl 76, pois esta técnica adaptou-se tanto pâra a cultura sob regime de irrigação como quando sob as condições normais de presipitars ão.

IANBELLO JR. e ORLANDO FC $(19796)$, estudaram o DRIS através da folha +3 e do $8 \%$ a $10 \%$ internódio e para am bos os tecidos coletados a metodologie proposta por Beaufils pode ser apliciada com sivesso.

Esta metadoiogia apresentia-se bastante promis- 
sora, embora tenha-se observado que a sensibilidade da técni ca reside em parte no elevado número de dados e na vaste ex periéncia e perspicácia do indivíduo que irá executar as in terpretações, principalmente na seleção da população não anor mal, pois é esta que proporcionará o diagrama interpretativo do balanço nutricional e os índices primários. 


\section{MATERIAL E METODOS}

\subsection{Variedade}

A variedade utilizada foi a CB4I-76 provenien te de talhöes comerciais, sob o controie de raquitismo, re presentando, na safra de $74 / 75$, cerca de $45 \%$ da área de cor te do Estado de são pauio (PLANALSUCAR - 1975), sendo descri. ta por BASSINELLO (1976), como de desfolha fácil, sanidade relativamente boa, não floresce, não oca, relativamente exi gente à água e fertilidade, boa produtividade agrícola, dià metro médio para grosso, tombamento acentuado, não apresenta enraizamento aéreo e brotação lateral, pouco joçal, brotação de socas regular, sem rachaduras e chochamento, percentagem de fibra média, perícdo útil de industrialização curto e me turą̧ão média. 


\section{$4: 2$ Solos}

Foram selecionados 4 Grandes Grupos de Solos a saber: Latossol Vermelho Escuro - orto - LE (SEITEC-1973), localizado na Estação Central-sul do PLANALSUCAR en Araras, Latossol Vermelho Amarelo - fase arenosa - LVa (FRANÇA e FREIRE - 19761, na Usina São José em Macatuba, Podzólico Ver melho Amarelo - variação Laras - PVIs (BRASIL - Comissão de Solos - Bol. 12, 19601 na Usina Rafard em Rafard e LatossolRoxo - LR IBRASIL- Divisã de Pesquisa Pedológica - Bol. 16, 19711, na Usina Bandeirantes em Bandeirantes. As localiza ções segundo as latitudes e longitudes encontram-se na tabeia 1 .

TABELA 1 - Localização aproximada dos ensaios segundo as la titudes e longitudes.

Solo Latitude sul Longitude Deste Altitude $(\mathrm{m})$

\begin{tabular}{|c|c|c|c|c|c|}
\hline LE & $22^{\circ}$ & $18^{\prime}$ & $47^{\circ}$ & $23^{\prime}$ & 617 \\
\hline LVa & $22^{\circ}$ & $25^{\prime}$ & $48^{\circ}$ & $50^{\prime}$ & 600 \\
\hline PVIs & $23^{\circ}$ & $01 '$ & 478 & $3 I^{\prime}$ & 500 \\
\hline LR & $23^{\circ}$ & $03^{\prime}$ & $50^{\circ}$ & $23^{\prime}$ & 400 \\
\hline
\end{tabular}

Nos locais dos ensaios foram tomadas amostras compostas da camada arável do solo para a obtenção des carac terístjcas químicas, sendo as mesmas determinadas pelo cen tro de Análises do PLANALSUCAR, segundo as técnicas descri tas por CATANI e JACINTHO (1974), apresentando os resuitados na tabeía 2 . 
TABELA: 2 Característices quŚmicas dos solos a interpratę̧ö.

\begin{tabular}{|c|c|c|c|c|c|}
\hline Cosacteristicas Cufmicas & & $\begin{array}{l}\text { Latossol Vermelino } \\
\text { Escuro-0rto }\end{array}$ & $\begin{array}{l}\text { Lotossol Vermalho } \\
\text { Amarelo-Fasa Arentoso }\end{array}$ & $\begin{array}{l}\text { Podsól1co Vermeino } \\
\text { Amarele-Var. Lorss }\end{array}$ & $\begin{array}{l}\text { Latossol } \\
\text { Roxo }\end{array}$ \\
\hline PH* & & 5,20 (ac1dez mëd10) & 4.30 (aciciez elevada) & 4.80 locidez elevaca) & 6.401 ecstez elovesu \\
\hline Carsone* $(:)$ & & $3,27(a i \leq 0)$ & 0.59 (mét1o) & 0,98 imës!o) & 1,55 (a:to) \\
\hline Fústcrot* (ppan p) & & 30 (1gual) & (abalxo\} & 20 (aba: $\times 0$ ) & $(\leq z+a i)$ \\
\hline$P=t \bar{s} s \leq 0$ * $(p \operatorname{pon} x)$ & $"$ & $\leq 3 \quad(m e ̈ 10)$ & (mघ่อ10) & $(a 1: 0)$ & $(0: 1 \pm 0)$ \\
\hline 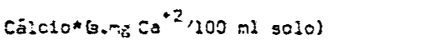 & & $2.40(m e \dot{10} 10)$ & (sa1xo) & $(m e ̈(10)$ & $13.20 \quad(8: \div 0)$ \\
\hline 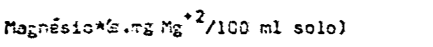 & & 1,30 (alto) & $(m 3010)$ & (aito) & $2,40^{\circ}$ (olto) \\
\hline AILASก10*(2. $n_{5} A 1^{* 3} / 100 \mathrm{nl}$ sclo) & & c.10 (bel $\times 0)$ & 0.70 (alto) & $0.20 \quad(001 \times 0)$ & $0.00(001 \times 0)$ \\
\hline 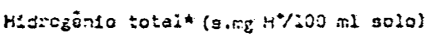 & & $6.20(e \pm \pm 0)$ & 5,00 (méd1o) & (nëd1o) & (mësio) \\
\hline
\end{tabular}

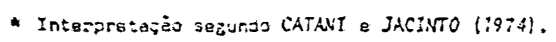

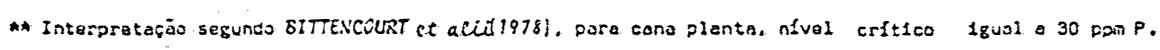

\subsection{Irrigação}

No ensaio irrigado - LE (I)*, as aplicações de água foram efetuadas através de sistema de irrigação por as persão e o controle realizado de acordo com o método gravimé trico (SLAYTER - 1967). Foram obtidas amostragens de solos sendo determinados os parámetros hídricos constantes na tabe la 3 .

TABELA 3 - Características hídricas do solo le estudado.

\begin{tabular}{rcccc} 
Profundidade & $\begin{array}{c}\text { Capacidade de } \\
\text { Campo }\end{array}$ & $\begin{array}{c}\text { Ponto de Murcha } \\
\text { Permanente }\end{array}$ & $\begin{array}{c}\text { Agua } \\
\text { Disponivel }\end{array}$ \\
${$\cline { 2 - 2 }$} }$ & 30,9 & 21,21 & 9,66 \\
$20-40 \mathrm{~cm}$ & 30,6 & 23,34 & 8,24 \\
média & 30,75 & 21,79 & 8,95 \\
\hline
\end{tabular}

* Será utilizada a codificaça (I) para o caso do solo Le irrigado por aspersão. 
Realizaram-se as irrigações quando 60\% da égua disponível do solo foi evapotranspirada ou a uma umidade limite de $25,5 \%$, sendo considerado uma profundidade de $40 \mathrm{~cm}$ com uma eficiência de aplicação de água entre 70 - 80\%.

A partir de abril/77 as irrigações foram. sus pensas para que as condiçães de amadurecimento natural da planta não fossem prejudicadas.

As precipitações pluviométricas são apresentâ das na tabela 4, sendo que para o solo le (I) houve acrésci mo total de $66 \mathrm{~mm}$ de água durante o ciclo, resultantes de apenas 3 irrigações que se fizeram necessárias pelo método gravimétrico.

TABElA 4 - Precipitação pluviométrica nos 5 solos, no pe ríodo de julho de 1976 a setembro de 1977.

\begin{tabular}{|c|c|c|c|c|c|}
\hline \multirow{2}{*}{ Meses } & \multicolumn{5}{|c|}{ Precipitação em mm de água } \\
\hline & $\operatorname{LE}(I)$ & LE & LVa & PVIS & LR \\
\hline JULHO/75 & 106,2 & 105,2 & 76,0 & 154,8 & 69,4 \\
\hline AGOSTO & 75,2 & 72,2 & $9 i, 0$ & 120,1 & 164,8 \\
\hline SETEMBRO & 103,0 & 103,0 & 182,5 & 215,1 & 177,6 \\
\hline OUTUBRO & 122,9 & 122,9 & 128,0 & 150,4 & 229,4 \\
\hline NOVEMBRO & $118,6 \div 20 *$ & 118,5 & 91,0 & 99,0 & 128,5 \\
\hline DEZEMBRO & 223,8 & 223,8 & 310,0 & 198,0 & 188,6 \\
\hline JANEIRO/77 & 427,4 & 427,4 & 444,0 & 325,1 & 211,7 \\
\hline FEVEREIRO & $22,0+32^{*}$ & 22,0 & 32,0 & 63,0 & 98,0 \\
\hline MARÇO & $134,3+15 *$ & 134,3 & 269,0 & 205,7 & 109,3 \\
\hline ABRIL & 72,1 & 72,1 & $.98,0$ & 83,8 & 63,2 \\
\hline MAIO & 10,8 & 10,8 & 10,0 & 8,2 & 30,7 \\
\hline JUNHO & 39,3 & 39,3 & 86,0 & 38,3 & 71,6 \\
\hline JULHO & 7,8 & 7,8 & 15,0 & 36,6 & 25,2 \\
\hline AGOSTO & 30,0 & 30,0 & 8,1 & 15,5 & 9,9 \\
\hline SETEMBRD & 85,3 & 85,8 & 76,0 & 115,5 & 34,1 \\
\hline
\end{tabular}

* mm de ägua adicjonados através de irrigação por aspersão. 


\section{4:4. Instalação dos Ensaios}

Os solos foram preparados de forma convencio nal (SUUSA - 1976), sendo, durante os meses de janeiro, feve reiro e março/75, instaladas em cada local 48 parcelas, pos suindo cada uma 7 ruas com $10 \mathrm{~m}$ de comprimento e $1,5 \mathrm{~m}$ de es paçamento, as quais receberam, por ocasião do plantio, o equi valente a 60-100-120 kg/ha de $N-P_{2}{ }^{0}-K_{2}{ }^{0}$ na forma de uréia, superfosfato triplo e cloreto de potássio.

Após 18 meses de ciclo de cana-planta, portanto em julho/76, para os solos LE (I) e LE, agosto/76 para o LVa e setembro/76 para os PVls e LR, precedeu-se à colheitada cana-planta, sendo a despalha realizada a fogo, e tanto os colmos como o palhiço residual foram removidos manualmen te das parcelas, a fim de se evitar efeitos sacundérios na mesma.

Instalaram-se os ensaios fatoriais com uma re petição $4 \times 2 \times 3 \times 2$ em $N \times P \times K \times L$, onde L signjficá a localização do adubo. As doses foram 0-60-120-180 kg N/ ha, 0-45 kg $\mathrm{P}_{2}{ }^{\mathrm{C}}{ }_{5}$ /ha e $0-90-180 \mathrm{~kg} \mathrm{~K}{ }_{2}$ o/ha, obtidos através do em prego de quantidades equivalentes de urëia, superfosfato tri plo e cloreto de potássio.

Dentro dos níveis utilizados englobam doses de nutrientes bem superiores às recomendações feitas por ORLAN DO Fo (1975), de 60-30-90 kg N-P ${ }_{2} \mathrm{O}_{5}-\mathrm{K}_{2} \mathrm{O} / \mathrm{ha}$ e maiores que as preconizadas por PINAZZA et alii (1979).

As duas localizações estudadas foram: "em sü perfície", sendo o adubo colocado de ambos os lados da linha de cana e a seguir coberto superficialmente com enxadas; e "em profundidade", com pequenos sulcos abertos a $15-20$ cm de profundidade em ambos os lados da linha de cana e distantesdesta cerca de $40 \mathrm{~cm}$. O adubo depois de localizado no sulco foi coberto, conforme metodologia descrita por ORLANDO Fa et alie (1977).

As parcelas assim constiturdas possuiam 03 li nhas úteis, 2 Iinhas de bordaduras internas e 2 linhas de - 
bordaduras externas, num total de 7 linhas com $10 \mathrm{~m}$ de com primento e $1,5 \mathrm{~m}$ de espaçamento, ocupando uma área de $105 \mathrm{~m}^{\overline{2}}$.

\subsection{Coleta de Amostras}

As amostras foliares foram obtidas a partir da coleta dos $20 \mathrm{~cm}$ centrais, sem a nervura principal das folhas +3 (GALLO et alí-1962), em número de 5 por rua útil e num total de 15 folhas $+3 /$ parcela. As épocas de amostragens fo ram aos $3,4,5$ e 6 meses de idade da cana-soca.

Essas amostras coletadas até às 10:00 horas da manhã, secas em estufa de circulação forçada de ar a 60-70 ${ }^{\circ} \mathrm{C}$ até peso constante, foram submetidas a moinho tipo wiley e analisadas quimicamente para determinação de $N, P, K$, segun do técnicas indicadas por SARRUGE e HAAG (1974).

\subsection{Diagnose Foliar}

Será empregado neste trabalho o termo "diagno se foliar baseada no nível crítico", para decrever a metodo logia que se emprega as seguintes premissas:

- Dentro de certos limites ná uma relação dire ta entre teor do elemento no solo Cou dose de adubo adiciona da) e produção obtida.

- Dentro de limites há uma relação direta en tre teor do elemento no solo (ou dose de adubo adicionada) e sua concentração na folha.

- Dentro de limites há uma relação direta en tre concentração do elemento na folha e produção obtida, des de que, como foi visto, as duas premissas anteriores sejam corretas. 
4.7. Sistema Integrado de Diagnose e Recomendação (DRIS)

Para o cálculo do diagrama interpretativo do balanço nutricional obtido pelo DRIS, foram selecionadas as parcelas que possuiam produtividade entre 80 a $100 \%$ da co Iheita relativa e seus teores de $N, P$ e $K$, tomados cada um em relação aos demais $(N / P, N / K, K / P)$.

Estas populações (não anormais) assim selecionadas foram analisadas pelo teste de Liliiefors lCONOVER 1971), para verificar se seguiam a Distribuição Normal e se paradas, segundo BEAUFILS (1971), em faixas:

$$
\begin{aligned}
& m \pm \frac{2}{3} s \simeq 50 \% \text { da população. } \\
& m \pm \frac{4}{3} s=82 \% \text { da população. }
\end{aligned}
$$

$s$ = desvio padräo.

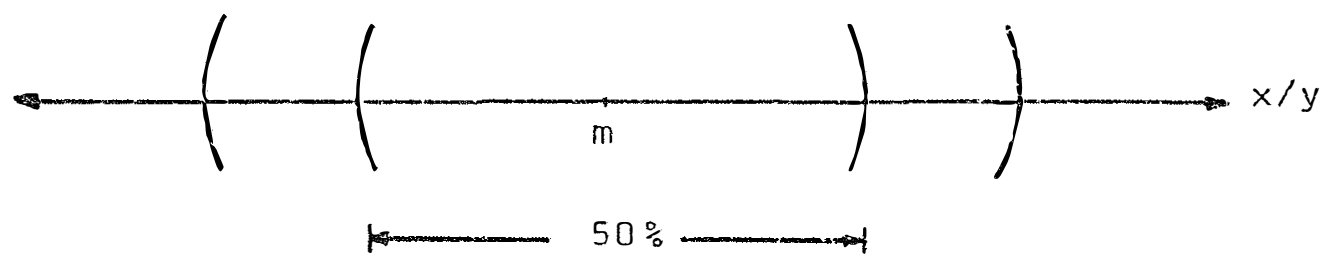

$9 \%$

$82 \%$ $3 \%$

A faixa central dada peio diámetro "4/3 s" com preende uma zona de relativo equilibrio e é representada por uma seta horizontal ( $\longrightarrow)$. As zonas compreendidas entre -

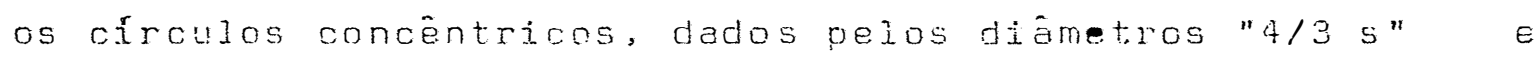
"8/3 s", denotam um desequilíbrio de ilgeiro a moderado, sen do representadas por setas que fazem $45^{\circ} \mathrm{com}$ a horizontal. - 
(-). Por fim, as zonas externas ao maior círculo oferecem um notável desequilíbrio e são representadas por setas verticais $(t, \downarrow)$.

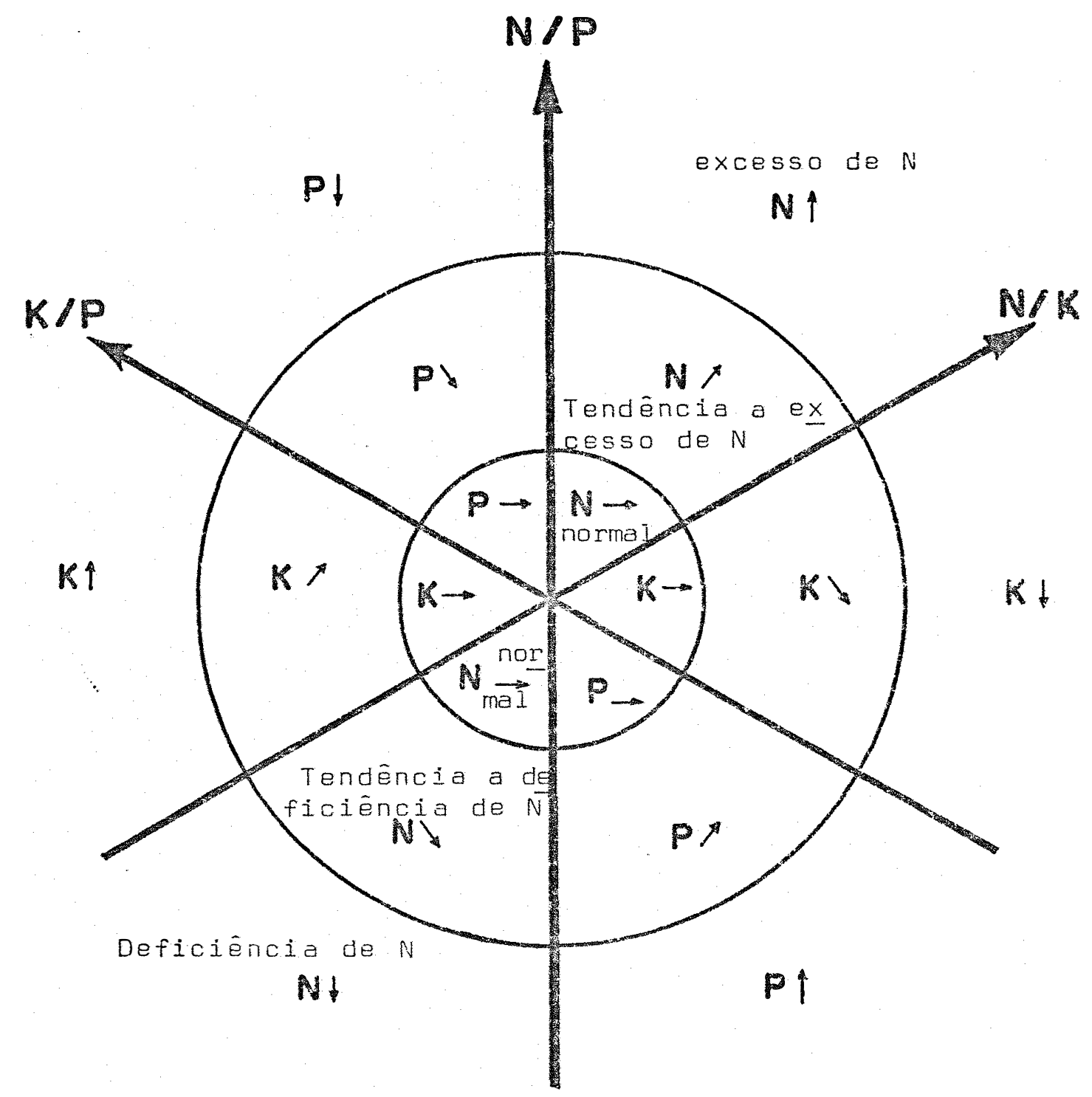

BEAUFILS (1973), menciona a possibilidade de interpretação pelo Sistema Integrado de Diagnose e Recomenda ção por "Índices primários" obtidos segundo a fórmula: 


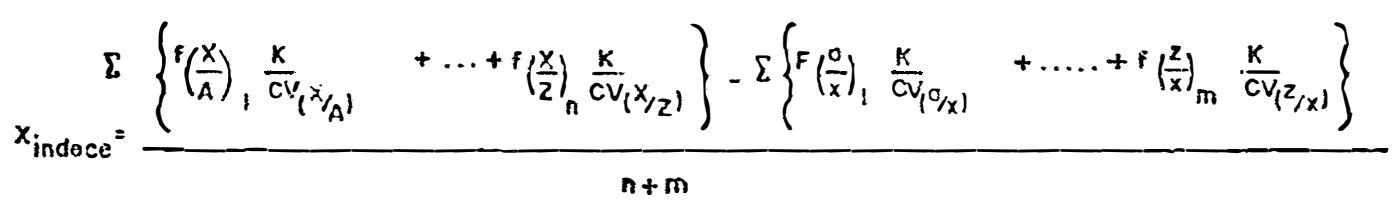

\section{e representados graficamente por :}

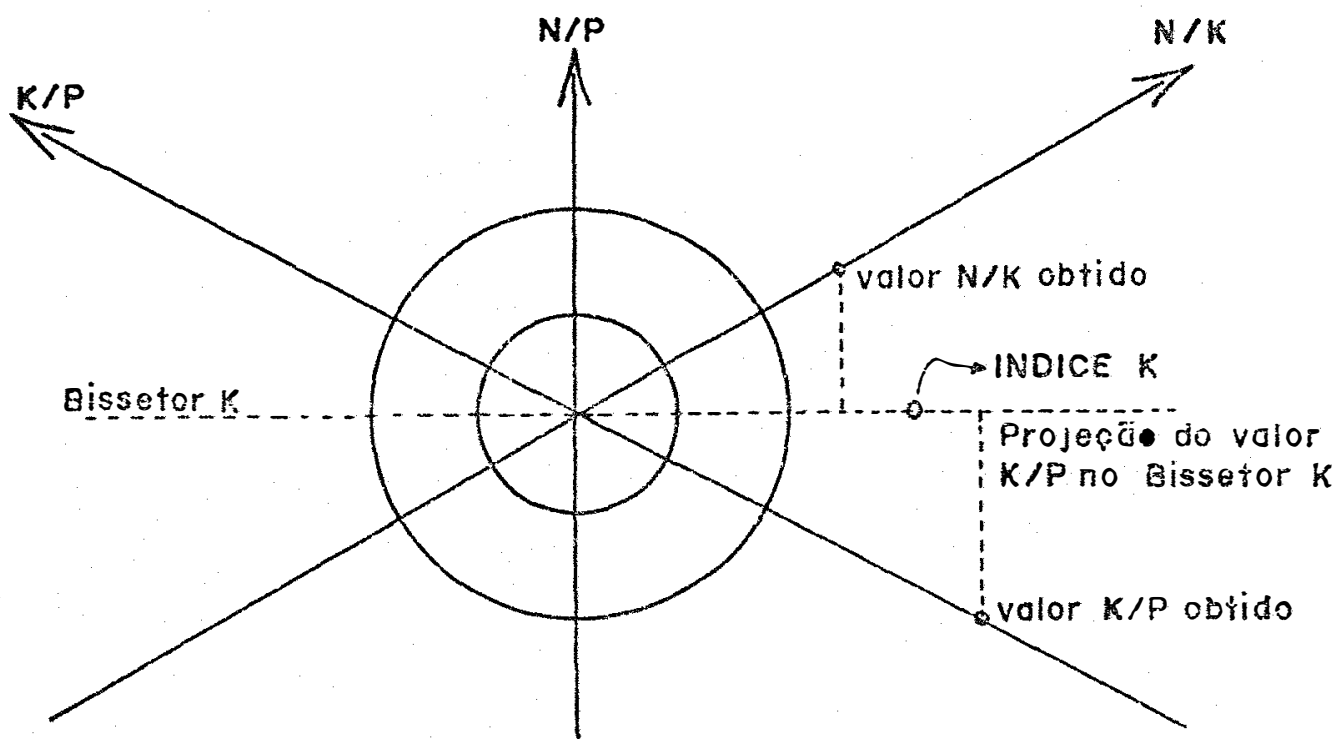

para $N, P, K$ podemos simplificar em :

Indice $N=+\left[\frac{f(N / P)}{2}-\frac{+(N / K)}{f(N)}\right]$

indice $P=-\left[\frac{f(N / P)}{2}+\frac{f(K / P)}{2}\right]$

indice $K=+[f(K / P)-f(N / K)]$ 


$$
\begin{aligned}
& \text { Quando } N / P(a)>N / P(p) \\
& f(N / P)=100\left(\frac{N / P(a)}{N / P(p)}-1\right) \frac{K}{C \cdot V .}
\end{aligned}
$$

C.V. = Coeficiente de variação

$K=$ Coeficiente de sensibilidade, de valor arbitrário (1, 10, 20, etc $)^{*}$.

(a) $=$ Amostra

(p) = Média da população não anormal

$=$ No presente trabalho $K$ foi considerado igual a 10

e para o caso de $N / P(a)<N / P(p)$

$$
f(N / P)=100\left(I-\frac{N / P(p)}{N / P(a)}\right) \frac{K}{C \cdot V} .
$$

raciocínio análogo para $f(N / K)$ e $f(K / P)$.

Os "índices transformados" (BEAUFILS - 1973),

são obtidos através de um balanceamento dos índices primários" ou seja : a) é dado valor zero para o "índice primário" mais negativo e a seguir, b) é dado o valor zero para o "índice primário" mais positivo, sendo o "índice transformado" obtido através da soma de $\underline{a}$ e $\underline{\text {. }}$

Exemplo:

$$
N=-8 \quad P=2 \quad K=6 \text { índ. primário }
$$

$\begin{array}{lll}\text { a) } N=0 & P=10 & K=14 \\ \text { b) } N=-14 & P=-4 & K=0\end{array}$

$N=-14 \quad P=6 \quad K=14$ ind.t.ransf.

4.8. Produção e Anātises Tecnoiōgicas

Após 72 meses dé ciclo as parcelas foram queimadas, sendo as 3 linhas centrais colhidas e pesadas para ob 
tenção da produtividade em toneladas de cana por hectare. Para a determinação da \% de pol da cana (BUCCHANAN - 1966), amostraram-se 7 colmos ao acaso por linha útil num total de 21 colmos por parcela.

Da interação $t$ cena/ha e pol\% cana, obteve- se as produtividades expressas em $t$ pol/ha.

\subsection{Anälises Estatísticas}

O esquema estatístico utilizado foi o fatorial - completo $4 \times 2 \times 3 \times 2(N \times P \times K \times L)$, com apenas uma repetição e tanto para as análises individuais como para a análi se conjunta bem como as regressões seguirem-se as técnicas descritas por PIMENTEL GOMES (1976).

Quanto às regressões, trabalhou-se até o 3? grau para o Nitrogênio e até o $2^{\circ}$ grau para o Potássio, sendo escolhidas as de grau mais elevado com significancia esta tística. 


\section{RESULTADOS E DISCUSSÃO}

\subsection{Efeito da Adubação}

\subsubsection{Produção Agrícola}

Os rendimentos agrícolas obtidos para os 5 ex perimentos encontram-se na tabela 5, onde observam-se maio res produções para os ensaios localizados em solo Latossol Vermelho Escuro-orto e menores para o solo Latossol Vermelho Amarelo-fase arenosa.

A irrigação não mostrou efeito de aumento na produtividade, pois o ensaio LE localizado no mesmo solo, sob condições de não-irrigação apresenteu de maneira geral produ ções superiores ao ensaio irrigado LE \{1\}. O fato ocorrido teria como possível expiicação o ano agrícola, o qual apre sentou inverno chuvoso (tabela 4) e com precipiteçóes, bem distribuídas, sendo que o experimento léti permitiu apenas 3 irrjgaçóes, oncie 2 delas sucederam em $19 i 7$ durante "verani. 
cos" de fevereiro e março.

TABELA 5 : Produçāo da soqueira, variedade CB41-76, em t cana/ha para os diferentes tratamentos estudados.

\begin{tabular}{|c|c|c|c|c|c|}
\hline \multirow[b]{2}{*}{ Tratamentos } & \multicolumn{5}{|c|}{ t cana/ha } \\
\hline & $\operatorname{LE}(T)$ & LE & LVa & PVIS & LR \\
\hline LO & 86 & 90 & 53 & 61 & 67 \\
\hline LI & 84 & 86 & 54 & 68 & 61 \\
\hline NO & 77 & 82 & 48 & 58 & 57 \\
\hline $\mathrm{NI}$ & 82 & 87 & 53 & 67 & 63 \\
\hline N2 & 89 & 90 & 57 & 67 & 69 \\
\hline N3 & 91 & 95 & 59 & 68 & 68 \\
\hline PO & 85 & 86 & 52 & 62 & 59 \\
\hline PI & 85 & 92 & 56 & 57 & 69 \\
\hline $\mathrm{KO}$ & 75 & 79 & 47 & 80 & 68 \\
\hline$K 1$ & 88 & 88 & 53 & 64 & 61 \\
\hline $\mathrm{K} 2$ & 93 & 99 & 62 & 70 & 66 \\
\hline
\end{tabular}

LO = Em superfície

$L I=$ em profundidade

A localização dos fertilizantes em profundidä de não mostrou efeito benéfico, a não ser para o solo pvis, como indica a tabela 5. Apesar do solo LR evidenciar efeitc significativo para a localização do fertilizante, (tabela B), verifica-se que este resultado foi negativo, com a diminui. ção de 6 t canalha.

Os fatos observados contrariam diferentes pes quisadores (HUMBERT, 1974 e ORLANDO Fo et alie, 1977), que encontraram vantagens na aubbação em profundidade. Por o tro lado, pode-se notar pela tabela 4 as altasprecipitaçóes, estranhamente ocorridas no inverno, as quais proporcionaramcondições para que as raízes se desenvolvessem superficial mente e com isto aproveitassem os fertiiizantes ali localiza dos, colocando-se em concordáncia com os trabalhos apresente dos por JACOB e UEXKÜLL (1961), e w000 e wo00 (1967).

o nitrogentio apresentou reação para todos os ensaios (tabelas 5 e 6$)$ a esta resposta foi linear, como in dica a tabela 7 , para o desdobramento da análise estatística. 
A dosagem de $180 \mathrm{~kg} \mathrm{~N} / \mathrm{ha}$ é bem maior do que a preconizada POT MALAVOLTA e HAAG (1964), ORLANDO FO (1975), ORLANDO FG $e$ ZAMBELLO JR. (1977) e ESPIRONELO (1979), e encontra-se em faixa muito superior à utilizada pelas empresas produtoras de cana-de-açúcar da região Centro-sul, como indicam PINAZZA et alii (1979). Este comportamento, de alta reação ao nitro gênio em soqueiras, estaria de acordo com JACOB e UEXKKULL (1961), GEUS (1967), HUMBERT 11974), ZAMBELLO JR. et alii (1977), os quais observaram a maior exigência apresentada pe la cana-soca.

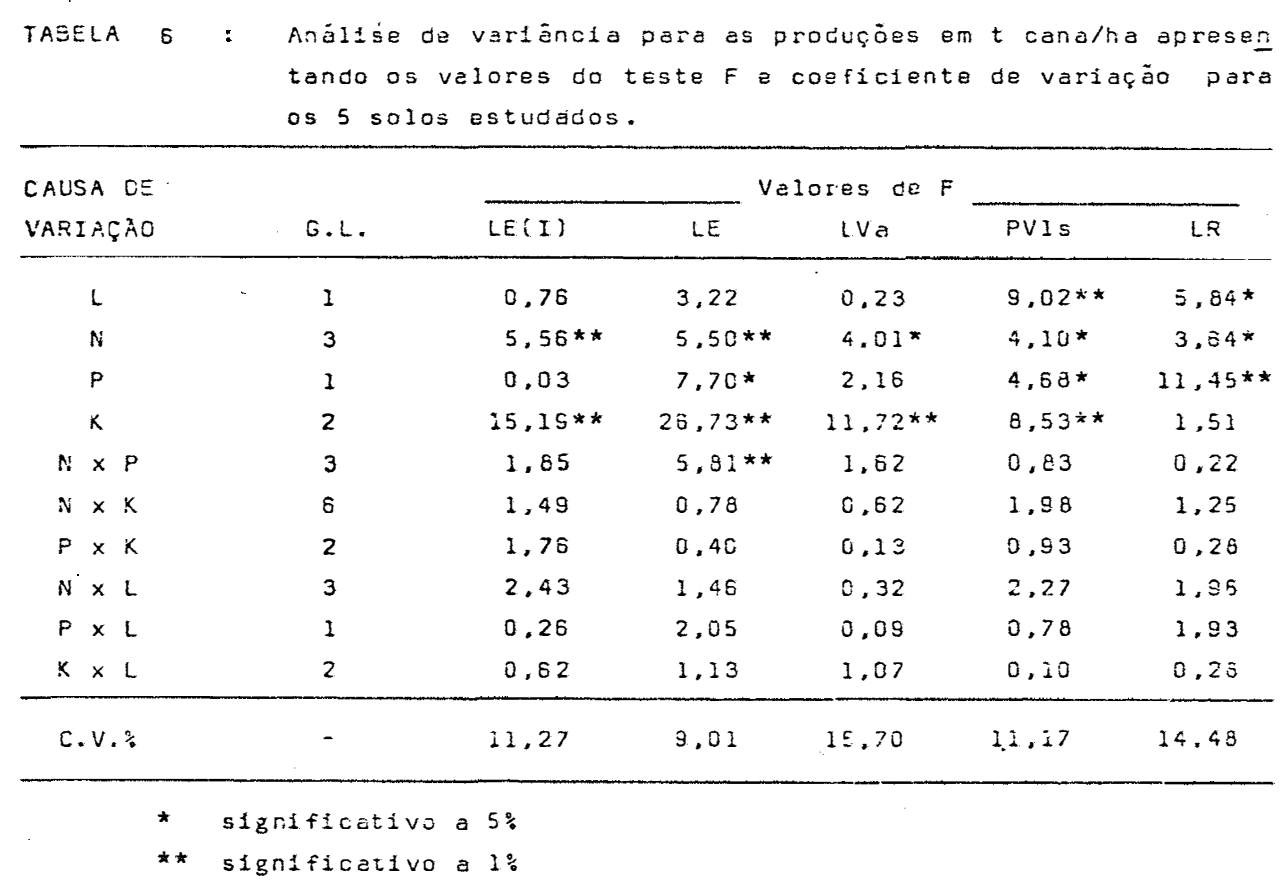

Uma hipótese a ser levantada, em parte discutí da por HUMBERT (1974), seria a de que na região Centro - Sul normalmente encontramos a cana-soca sob efeito da compactação (baixa aeração), provocada pelos caminhões que retiram a colheita do campo e de baixas temperaturas. Estes fatores implicariam e uma decomposição bastante lenta do sistema ra dicular remanescente $(16000$ e W000, 1967), imobilizando o ni trogénioe concorrendo com a planta de cane-de-açúcar. As sim, a adição de $N$ no meio iria beneficiar a plenta, resul tando em aumentos de produção. 
A adubação fosfatada provocou, via de regra,au mentó de produção (tabela 5), a não ser para o ensaio LE (I) sob efeito da irrigação. Os valores do teste F encontram-se na tabela 7 e evidenciam diferenças significativas para os solos LE, PVIs e LR. Os solos, antes de receberem a aduba ção de $100 \mathrm{~kg} \mathrm{P} \mathrm{P}_{5}$ /ha no plantio, encontravam-se em classede fertilidade (tabela 2) inferior ou igual ao nível crítico Proposto por BITTENCOURT et alie (1978), e a reação de $45 \mathrm{~kg}$ $\mathrm{P}_{2} \mathrm{O}_{5}$ /ha para a soqueira, estaria em concordāncia com SAMUELS e LANDRAL JR. (1952), MOHAN RAO et alii (1956) e HUMBERT $(1974)$.

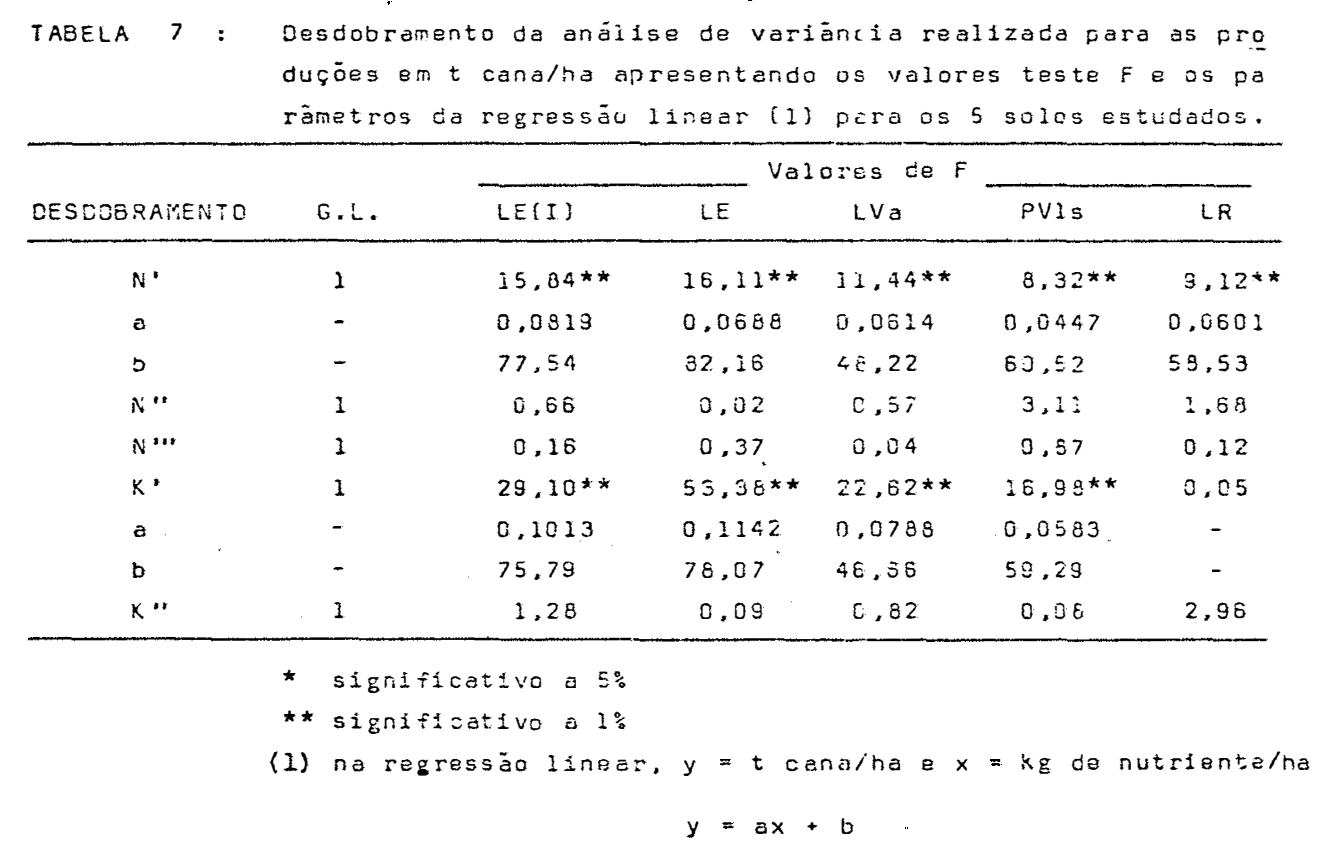

Nada se observou com efeito a interação entre as doses de fósforo e a localização do mesmo (tabela 6) como seria If́ito esperar-se face aos comentärios de HUMBERT $(1974)$.

As maiores reações foram para o potássio ctabe la 5), onde apenas para o solo Latossol Roxo (cujo teor de $k$ no plantio era de $196 \mathrm{ppm}$ ) não foram registradas diferençassignificativas (tabela 6). SAMUELS e LANDRAU JR. (1954), apresentaram um aumento da resposta ao potäsio com o avan çar dos ciclos da cana-de-açúcar. 
O desdobramento da análise estatística é apre sentado na tabela 7 e para os 4 ensaios com reação ao $k$ no tam-se os valores significativos do teste F para a equação linear.

\subsubsection{Produção de Açücar}

Os resultados em percentagem de pol da cána não acusaram diferenças estatisticamente significantes, de maneira que os dados foram trabaihados diretamente para quan tidades de açúcar por área $(t$ pol/ha) e a tabela 8 apresenta os resultados.

TABELA 8 : Frodução do soqueira, variedade CB41-76, em $t$ pol' ha para os diferentes tratementos estudados.

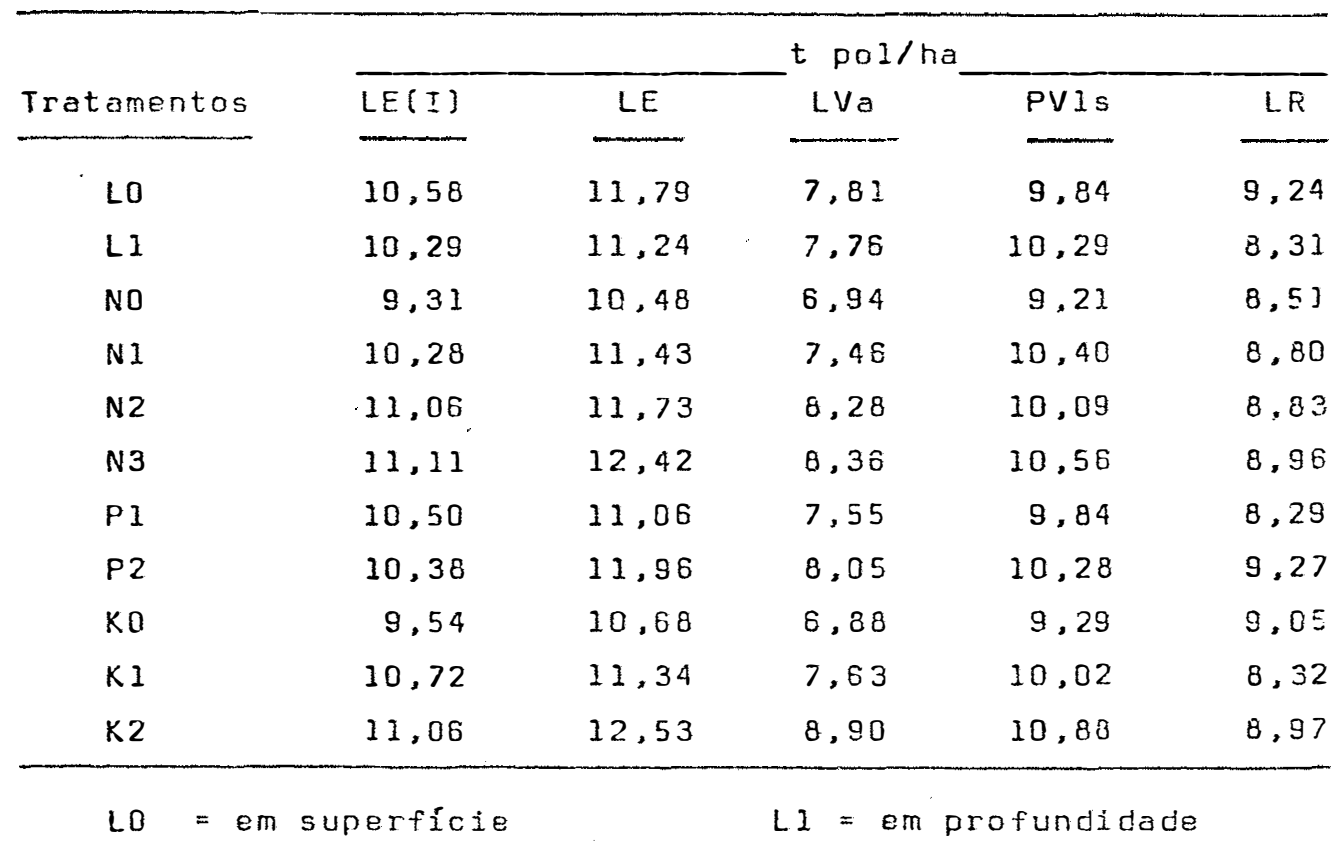

A reação ao nitrogênio foi semelhante ao das produções agrícolas (tabela g) somente para o solo LR que o efeito, significativo a $5 \%$, passou a não significativo devi do à interação t cana/ha $x \%$ pol de cana. Dbserva-se que pe ra este ensaio o nitrogénio provocou uma menor maturaça, ou 
mo sugere GEUS (1967). Para os demais, o efeito continuou sendo linear conforme mostra a tabela 10.

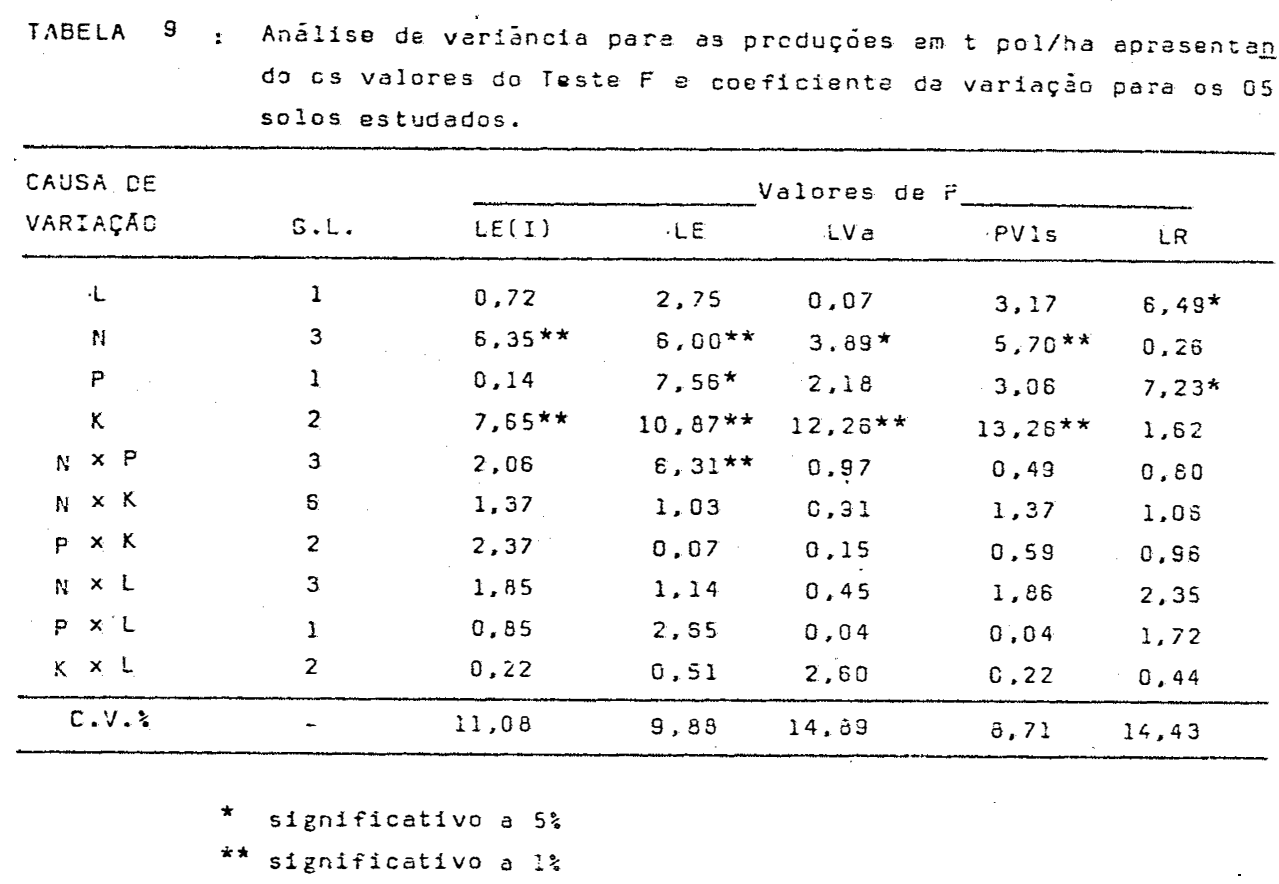

0 fósforo teve sua reação diminữ̛́da para o so 10 PVIs, onde a diferença de $440 \mathrm{~kg}$ de açúcar/ha (tadela 8 ) passou a ser não significativa (tabela 9).

- elemento potássio continuou a apresentar as maiores reações (tabelas 8 e 9 ) e seu efeito foi linear pa ra as doses estudadas de até $180 \mathrm{~kg} \mathrm{~K}_{2}$ o/ha, como demonstra o desdobramento da análise estatística apresentada na iabela 10 .

\begin{tabular}{|c|c|c|c|c|c|c|}
\hline \multirow{2}{*}{ DESDOBRAMENTO } & & & \multirow[b]{2}{*}{ PVIS } & \multirow[b]{2}{*}{$L R$} \\
\hline & & \multicolumn{3}{|c|}{$\begin{array}{l}\text { Desdobramento da análise de veriáncia } \\
\text { duçöes em t pol/ha apresentando os valo } \\
\text { os } 5 \text { solos estudados. } \\
\text { G.L. LE(I) LE Laloros de F }\end{array}$} & & \\
\hline$N^{\prime}$ & 1 & $17.02^{* \star}$ & $17.34 * *$ & $10.73 * *$ & $10,85^{* *}$ & - \\
\hline $\mathrm{Nn}$ & 1 & 1.90 & 0,15 & 0.80 & 2.05 & - \\
\hline $\mathrm{N} \cdot \cdot$ & $\cdot 1$ & 0.12 & 0.49 & 0.12 & 4.25 & - \\
\hline$K^{\prime}$ & 1 & $13.87 * *$ & $2 i, 17 * *$ & $24,00 * *$ & $26.45^{* *}$ & - \\
\hline$x \cdot "$ & 1 & 1.42 & 0.56 & 0.52 & 0.06 & - \\
\hline
\end{tabular}


A observação da tabela 11 evidencia que,

modo geral, a localização em profundidade não apresentou van tagens na produção agrícola e na produção de açúcar, sendoainda uma operação mais demorada, exigindo equipamento de maior poténcia e consumindo mais combustível por hectare.

A reação ao fósforo persistiu na análise do rendimento agricola, o mesmo não acontecendo para t pol/ha.

TABELA 11 : Anälise de variencia conjunta para os 5 solos estudados apresentando os valores do teste $F$ e coeficiente de va riaça para as produçōes obtidas em $t$ cana/ha $e t$ poi ha.

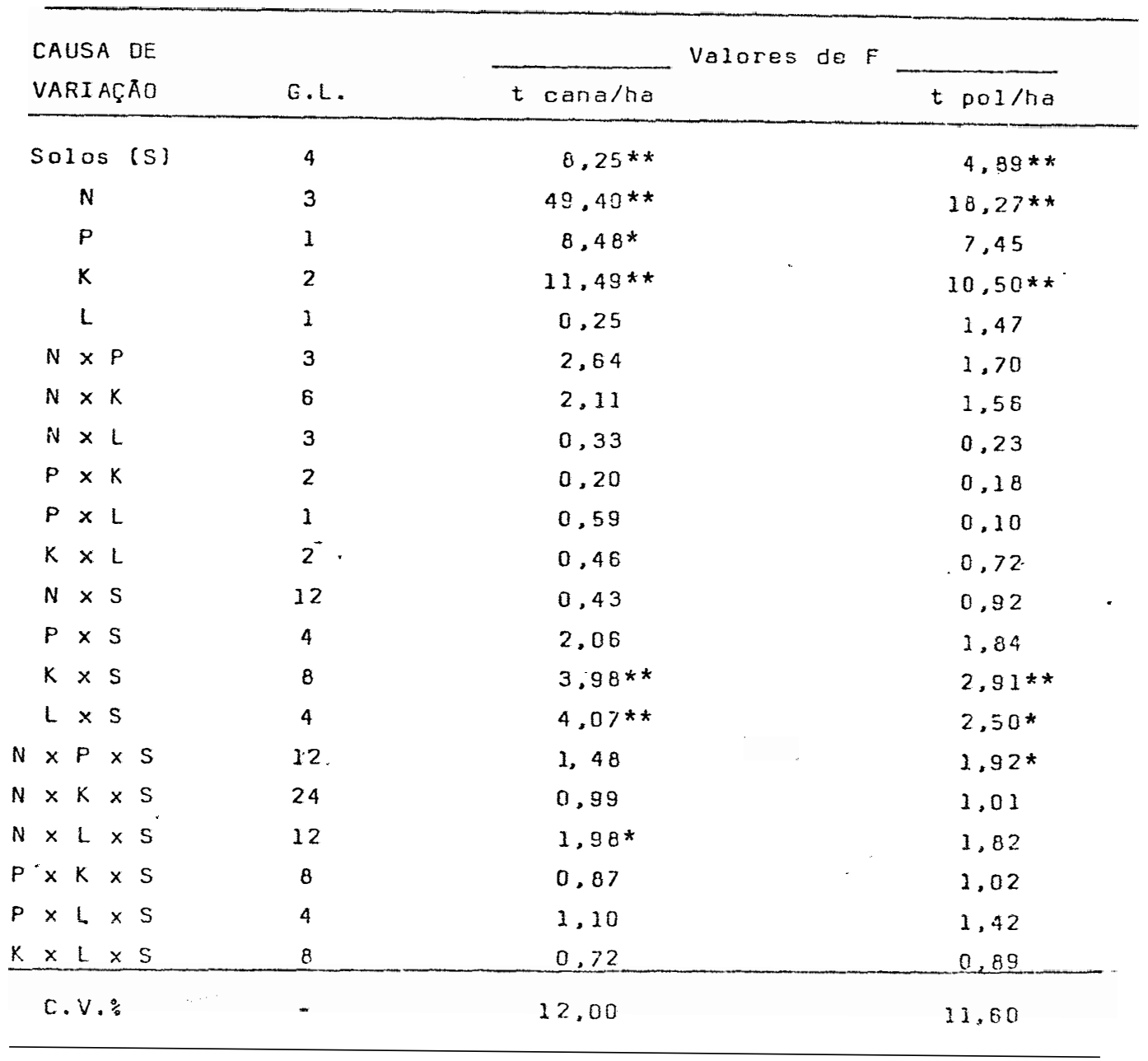


0 nitrogènio e potássio foram os elementos de maior resposta, patenteando que quantidades maiores de fer tilizantes que as recomendadas por MALAVOLTA e HAAG (1964), ORLANDO FO (1975) e ESPIRONELO (1979), podem ser realizadascom sucesso.

\subsection{Diagnose Foliar Baseada no Nivel Crítico}

Os resultados em percentagens de $N$ e $K$ na fó Iha +3 , que permitiram anälise estatistica evidenciaram atra vés das tabelas 12 e 16 que o efeito da localização do ferti lizante foi mínimo, apenas significativo a $5 \%$ no solo LR pạ ra \% $N$, de maneira que a diagnose foliar, baseada no nível crítico, foi executada observando-se apenas os tratamentos e as épocas de amostragem para cada tipo de solo.

\subsubsection{Nitrogênio}

A anālise de variància para a percentagem de $N$ na folha +3 para os diferentes tratamentos do fatorial $N x$ $P \times K \times L$, encontra-se na tabela 12 . Observa-se que as quan tidades de nitrogénio adicionadas através dos fertilizantesprovocaram diferenças significativas no teor foliar do citado elemento para os 5 ensaios estudados.

As doses de potássio aplicadas interferiram no teor do $N$ no ensaio sob efeito da irrigação LE (I), mostrando a tabela 12 este efeito a 5\% de significância. A interação entre os elementos não é novidade na cultura da cana-deaçücar, conforme EUANS (1959), FARQUHAR (1965), SANUELS (1969) a GOMEZ-ALVAREZ (1974), jè a haviam mencionado, sendo que ORLANDO FO e ZAMBELLO JR. (1977), registraram especifica mente a interação $N \times K$.

As Épocas de amostragem $\left(3^{\circ}, 4^{8}, 5^{\circ}\right.$ e $6^{8}$ mês de idade interferiram significativamente nos teores de $\mathrm{N}$ na folha + (tabela l2). Os eneaios localizados em solo le e LR acusaram comportamento do $N$, para os diversos tratamentos 
diferente para cada época de amostragem e provocaram intera ções significativas para $N \times E$.

TABEla 12 : Análise de variància para a percentäem de $N$ na folhe + 3 apresen tando os valores do teste $F$ e coeficiente de variaçào para os 5 solos estudados.

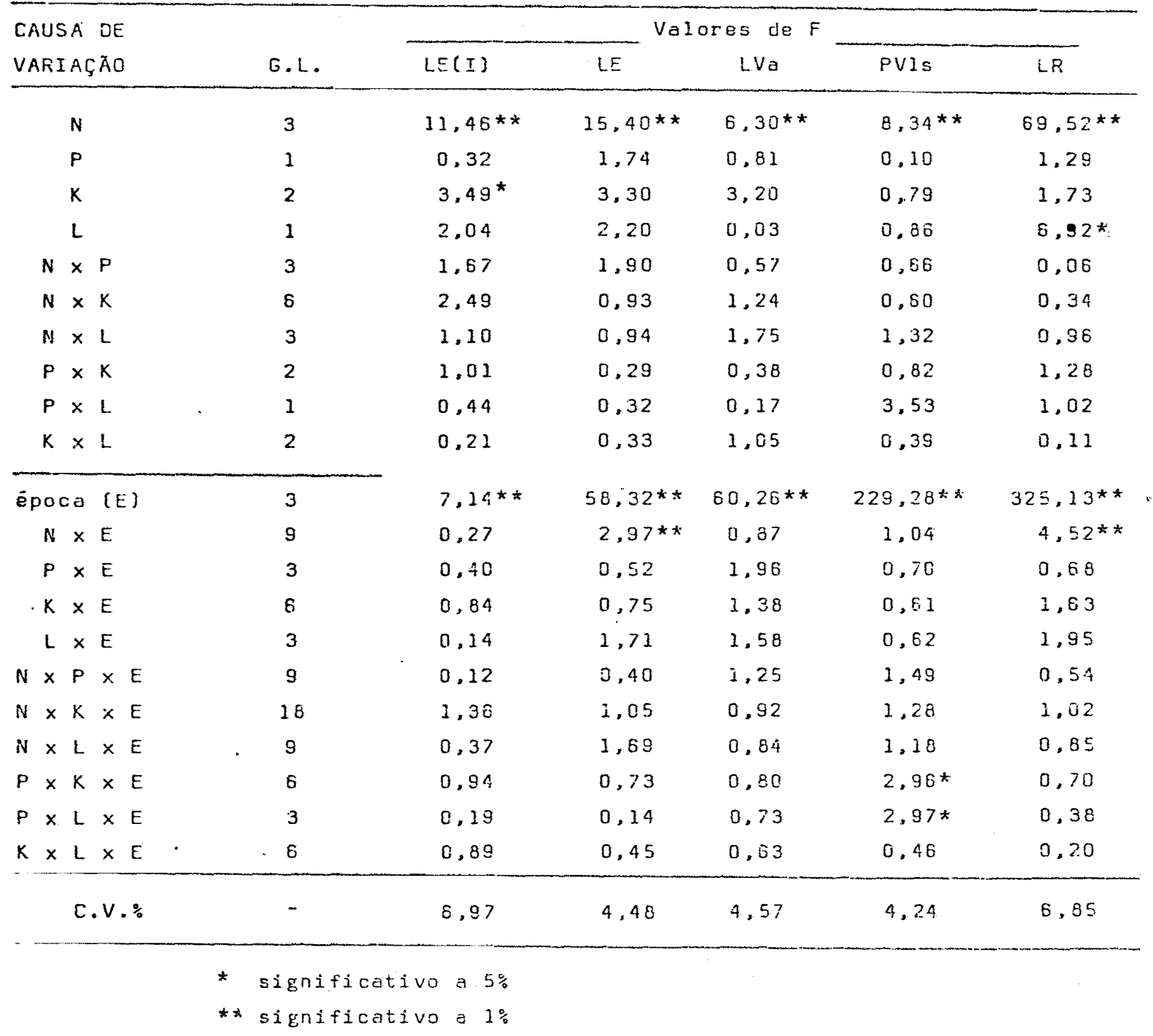

A tabela 13 apresenta os desdobramentos da aná lise estatistica para o nitrogénio e observa-se, para a maio ria dos cascs, que a equaça linear pode ser estabelecida.

Para o solo LE (I), apenes foj possivel o rela cionamento entre os teores de $N$ ne folna e as doses de nitro gênio aplicadas ao solo para o 5 s més de idade (tabela 13 ), 
enquanto para o mesmo solo LE, agora sem irrigação, correlacionou-se tanto para o $5^{8}$ como para o $5^{8}$ més de idade. 0 en saio localizado em solo LVa proporcionou equação linear en tre o $N$ aplicado e $N$ foliar durante a primeira épocia de cole ta da folha +3 . Os ensaios em solo PVIs e LR permitiram o ajuste de correlações para o $4^{\circ}, 5^{\circ}, 6^{8}$ e $3^{8}, 4^{\circ}, 5^{8} \mathrm{més}$ de idade, respectivamente.

TABELA 13 : Desdubramento Ja analiso de variancia realizada fara a percentagein de $N$ na folha +3 opresentando os valores do teste f para cs 5 solos estudados.

\begin{tabular}{|c|c|c|c|c|c|c|}
\hline \multirow{2}{*}{$\begin{array}{l}\text { CAUSA DE } \\
\text { VARIAÇX̃O }\end{array}$} & \multirow{3}{*}{$\frac{\text { G.L. }}{(3)}$} & \multirow{3}{*}{$\frac{\operatorname{LE}(I)}{0.40}$} & \multirow{3}{*}{$\frac{L E}{1.13}$} & \multirow{3}{*}{$\begin{array}{c}\begin{array}{c}\text { Vulores de } \\
\text { LVa }\end{array} \\
4.82^{* *}\end{array}$} & \multirow{3}{*}{$\frac{\mathrm{FV} 1 \mathrm{~s}}{1.25}$} & \multirow{3}{*}{$\frac{L R}{22.35 * *}$} \\
\hline & & & & & & \\
\hline$N \quad$ d EI & & & & & & \\
\hline$N \cdot \quad a E I$ & 1 & - & - & $14,40 * \star$ & - & $50,28 * *$ \\
\hline$N " d E I$ & 1 & - & - & 0.01 & - & $11,4 \pi * *$ \\
\hline$N \cdots$ d El & 1 & - & - & 0.03 & - & 2,32 \\
\hline$N$ d $E Z$ & (3) & 1,02 & 1.71 & 2,06 & $6,74 * *$ & $40,56^{* x}$ \\
\hline$N^{\prime} \quad$ OEZ & 1 & - & - & - & $19.43^{\star \star}$ & $116,30 * *$ \\
\hline$N "$ d $E Z$ & 1 & - & - & - & 0.19 & $4.32^{\star}$ \\
\hline$N \cdots \quad \& E 2$ & 1 & - & - & - & 0.59 & 1,34 \\
\hline$N$ d $E 3$ & (3) & $2,70 *$ & $7,80 * *$ & 0.52 & $3.84 *$ & $2 1 \longdiv { 5 0 * \pi }$ \\
\hline$N$ d $E 3$ & 1 & $7.35 * *$ & $7.28 * *$ & - & $7.75 * *$ & $52.92 * *$ \\
\hline$N " d E 3$ & 1 & 0,11 & $16.07 * \pi$ & - & 3.20 & 2.86 \\
\hline $\mathrm{N \cdots} d=3$ & 1 & 0,64 & 0.07 & - & 0.52 & 0.0003 \\
\hline$N \quad O E 4$ & $(3)$ & 1.57 & $12.63 * *$ & 2.87 & $5,37+*$ & 2.51 \\
\hline$N=\quad d E A$ & 1 & - & $30,56 * \star$ & - & $15.90 * *$ & - \\
\hline$N=\Leftrightarrow E 4$ & 1 & - & $7,25 * *$ & - & 0,21 & - \\
\hline$N \cdots$ d E4 & 1 & - & 0.09 & - & 0,0001 & - \\
\hline
\end{tabular}

\footnotetext{
* significazivo a $5 \%$

** significativo a $1 \%$

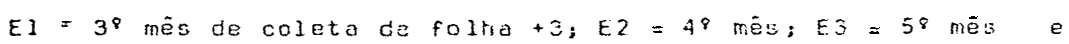

$E 4=G^{8}$ mès.
}

Os parämetros das equações lineares signîicetivos pelo teste $F$ (tabela 13 ), encontram-se na tabela 14. Através destas equações e de quantidade de $N$ que apresente as naiores produções, ou as mejs económioas, serie possivej- estabolecimento de níveis críticos fara o Nitrogenio. 


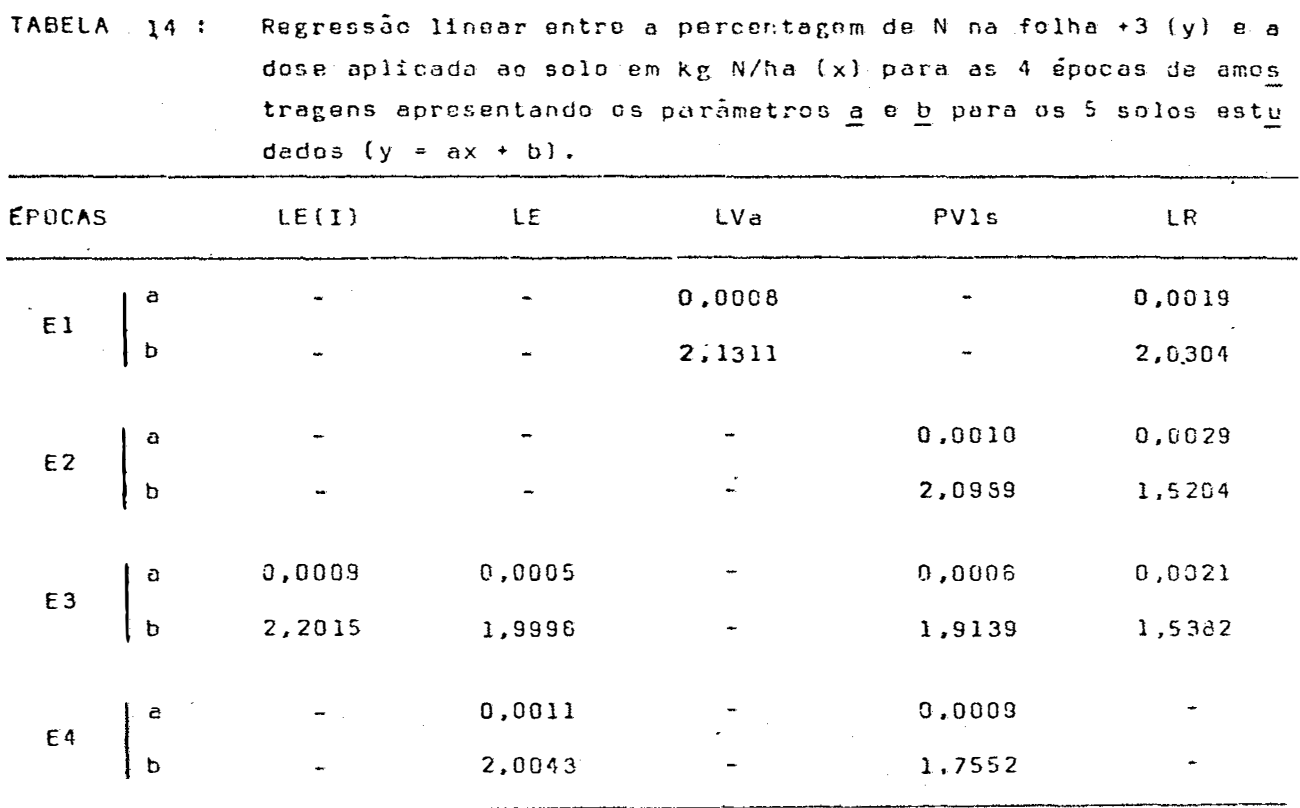

Apesar de utilizadas doses de até $180 \mathrm{~kg} \mathrm{~N} / \mathrm{ha}$, bem superiores às preconizadas por ORLANDO Fo $(1975)$ e ESPIRONELO (1979), não foi possivel o estaveiecimento de uma equaça do $2^{\circ}$ grau ou de Mitscherlich entre as doses de $N$ a produção, ou, em outras palavras, a produção aumentou 1 i. nearmente com as quantidades de $N$. Em razão cistu não se tem uma dose que provoque uma produção máxima ou uma produ çă máxima económica e estabeleceu-se a quantidade de $180 \mathrm{~kg}$ N/ha como a responsável pelo nível crítico (tabela 15\}.

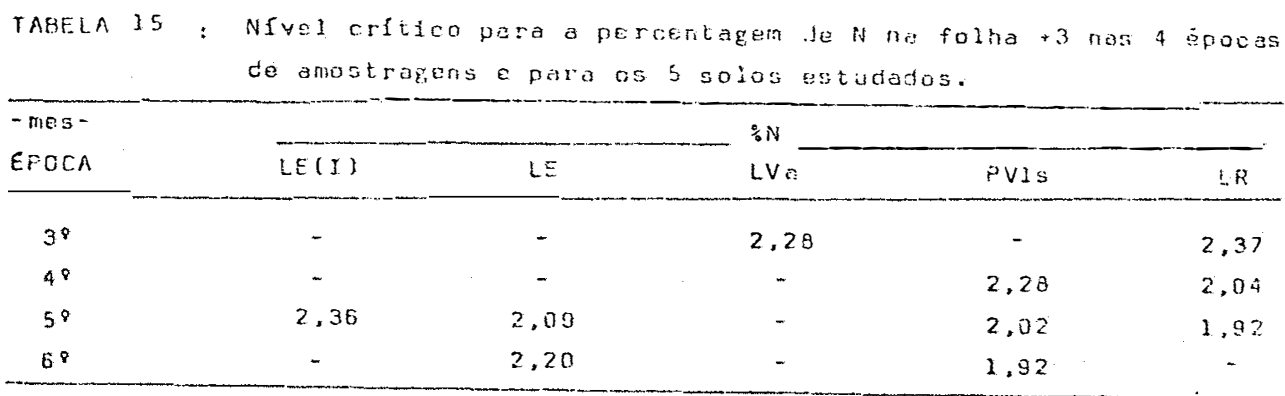


0 efeito da idade da planta nos teores folia res foi discutido por POIDEVIN $(1964)$, GOMEZ-ALVAREZ (1971)e MCLEAN (1973), como de importáncia para o estabelecimentodos níveis críticos.

ORLANDO Fọ e ZANBELLO JR. (1977), encontrarem a percentagem de $N$ na folha decrescendo linearmente do 48 ao $8^{8}$ més de idade, enquanto ORLANDO Fọ (1978), constatou a me Ihor adaptação da equação do $3^{8}$ grau para 0 teor de $N$ do 48 aо $12^{\circ}$ mês.

Nos ensaios em solo PVls e LR verifica-se um decréscimo dos níveis críticos com o avançar da idade, o que näo ocorre para o solo LE.

Apesar de não se ter realizado anälise conjur:ta para solos, observa-se seu efeito nos níveis críticos,com faixa de variaçäo de $1,02 \%$ a $2,37 \%$, concordando com os $\dot{\tau}$ raba Ihos desenvolvidos por VITLOS e LAWRIE (1963), ORLANDO FO et alii (1978) e ORLANDO Fo (1978), sem a possitilidade de epresentação de padrões fixos, independentemente do solo, corifor me indicam SAMUELS et alii (1955), MALAVOLTA c.t alii (1963)e GALLO et ali.i (1968).

\subsubsection{Fösforo}

A despeito da anälise estatística evidenciar o efeito das doses de fosfatos utilizadas sobre as produções, não se registraram variaçöes consistentes nos teores fulia res de $P$, de maneira que se tornou impossível o emprego se quer da análise de variáncia para os referidos teores.

\subsubsection{Potássio}

A tabelá 18 mostra a anālise de variéncia para os teores de $k$ na falha +3 , segundo os diferentes tretamen tos estudados no fatorial. observa-se que as doses de $k$ afe taram significativamente os teores do próprío elemento ná fo 
Iha como era de se esperar; no entanto, as doses de $P$ nos solos LE e PVIs influíram também significativamente nos teores foliares de $K$, apresentando interações entre elementos como observaram diferentes pesquisadores, (EVANS, 1959; FAR QUHAR, 1965; SAMLIELS, 1969; GOMEZ-ALVAREZ, 1974 e ORLANOO Fō e ZAMBELLO JR. 1977 I.

TABELA 16 : Análise de variáncia pöra a percentąen de $k$ na folha t 3 aptosen tando os vaiores do teste $F$ e coeficlente de variação para os 5 solos estudados.

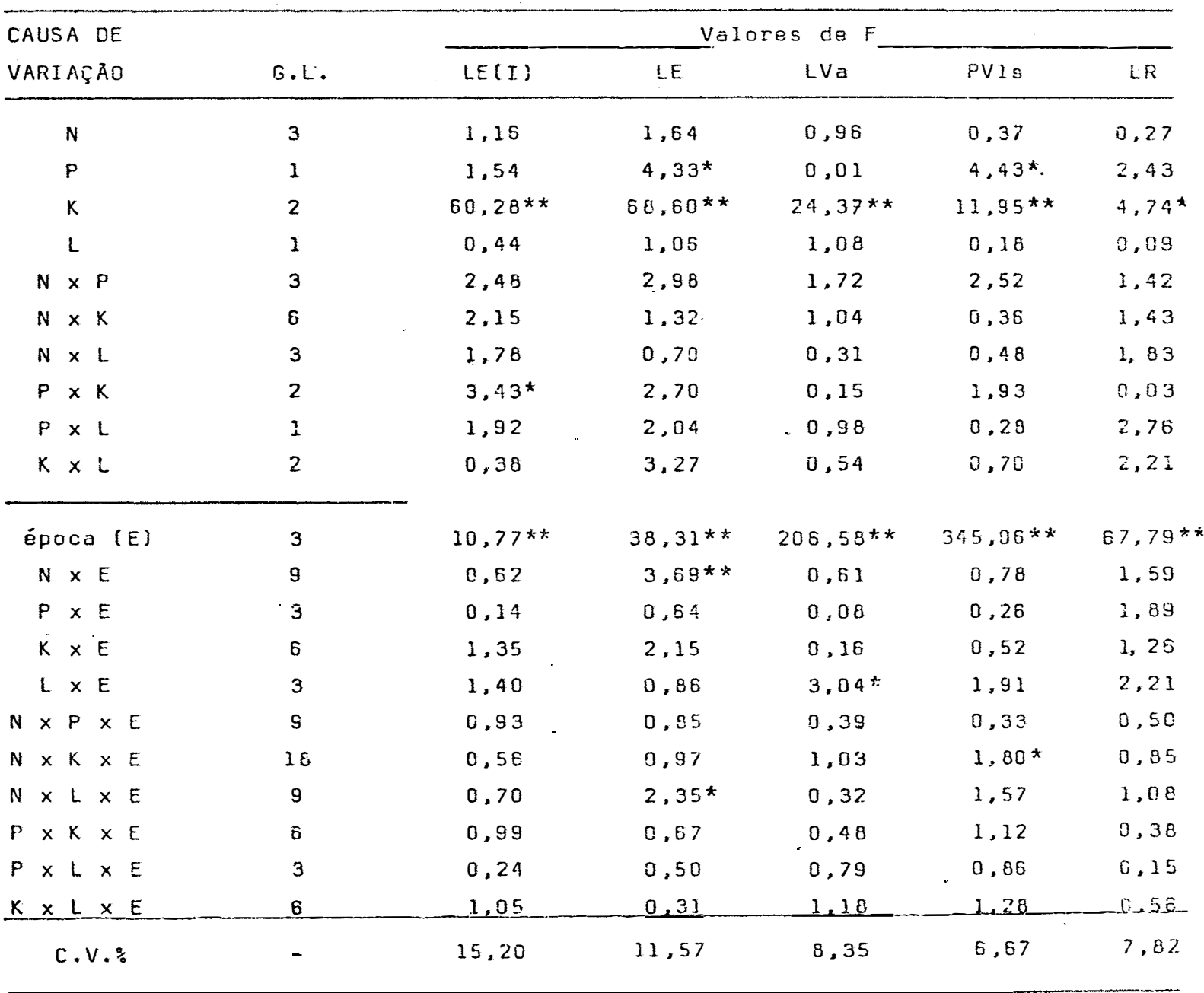

* Significativo a $5 \%$

**Significativo a $1 \%$

o solo LR não ofereceu respostas significativas para aumento de produção segundo as doses de k utilizadas no fertilização, evidenciando que as significáncias observadas nes tabelas 18 e $l i$ para o referido solo indicem uma absoreäa 
de Iuxo do elemento potássio.

TABELA 17 : Descobramento ca anólise de variáncla reallzada para a fercenta gem de $K$ lla folna +3 apresentando os valores do teste $F$ para es 5 solos estudedos.

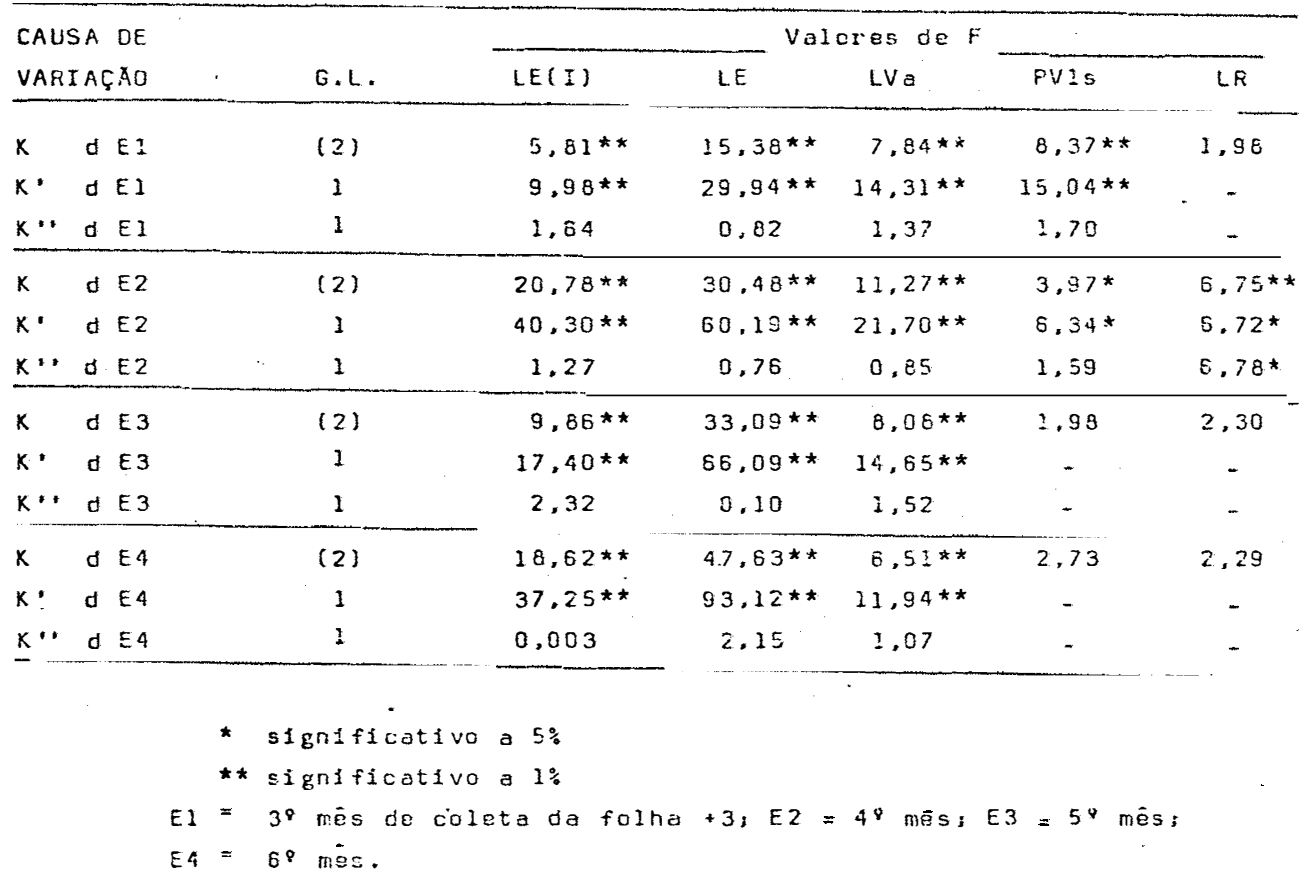

TABEla 18 : Regressajo iinear entre a percentugen de $x$ na folna $z(y)$ a dose aplicada ao solo ein $k g K_{2} 0$ ha $(x)$ para as 4 épocas des amostragens apresuntando os parémetros a $e$ para os 5 solosestudatios $\{y=a x+b\}$.

\begin{tabular}{|c|c|c|c|c|c|c|}
\hline EPOCAS & & $L E(I)$ & LE & $L V_{3}$ & PVls & $L R$ \\
\hline \multirow{2}{*}{ El } & $a$ & 0,0011 & 0.0018 & 0.0009 & 0.0009 & - \\
\hline & b & 1,1307 & 1,1055 & 1,6593 & 2.9848 & - \\
\hline \multirow{2}{*}{ E2 } & $a$ & 0,0022 & 0.0023 & 0,0011 & 0,0006 & 0,0008 \\
\hline & $\mathrm{t}$ & 1,0499 & 0.9263 & 1,0019 & 2,3437 & 1.3052 \\
\hline \multirow{2}{*}{ E3 } & a & 0,0014 & 0.0024 & $0.00 \bigcirc \mathrm{s}$ & - & - \\
\hline & $b$ & 1,0075 & 0.8103 & 1,2625 & - & - \\
\hline \multirow{2}{*}{$E:$} & a & 0,0021 & 0.0028 & 0.0008 & - & - \\
\hline & b & 0,8774 & 0.7453 & $1: 3857$ & - & - \\
\hline
\end{tabular}


Nota-se de modo semelhante ao descrito para o nitrogênio o efeito marcante da época de amostragem interferindo nos teores de potássio, como evidenciaram

POIDEVIN (1974), GOMEZ-ALVAREZ (1971) e ORLANDO FO (1978).

Para o potássio os desdobramentos da análise de variância, dentro de épocas são apresentajos na tabela 17, e observa-se que a equaça linear se adapta para quase todas as épocas de amostragem. No solo PVIs näo foram possí veis os desdobramentos, devido à ausência de diferenças signi ficativas entre os teores de K durante o 5 : e $6^{\circ}$ més da cole ta da folha +3 .

A tabela 18 apresenta os parâmetros da equação linear entre as quantidades de potássio aplicadas ao solo e os teores foliares do elemento. Aqui também é indispensável estabelecer a dose de $130 \mathrm{~kg} \mathrm{~K}_{2}$ o/ha como a responsável pelos níveis críticos, de meneira anéloga a considerada para o ni trogènio.

Os níveis críticos pará o potássio encoitran se na tabela 19 e não conduzem ao emprego de uma regressão de acordo com a época de amostragen devido ès flutuaçães apresentadas. O efeito do solo também pode ser observado com variações bastante amplas de $1,25 \% \mathrm{~K}$ a $2,15 \% \mathrm{~K}$, estando em concordāncia com VITLOS e LAWRIE 13963), ORLANDO Fo et alik $(1978)$ e ORLANDO FO $(1978)$.

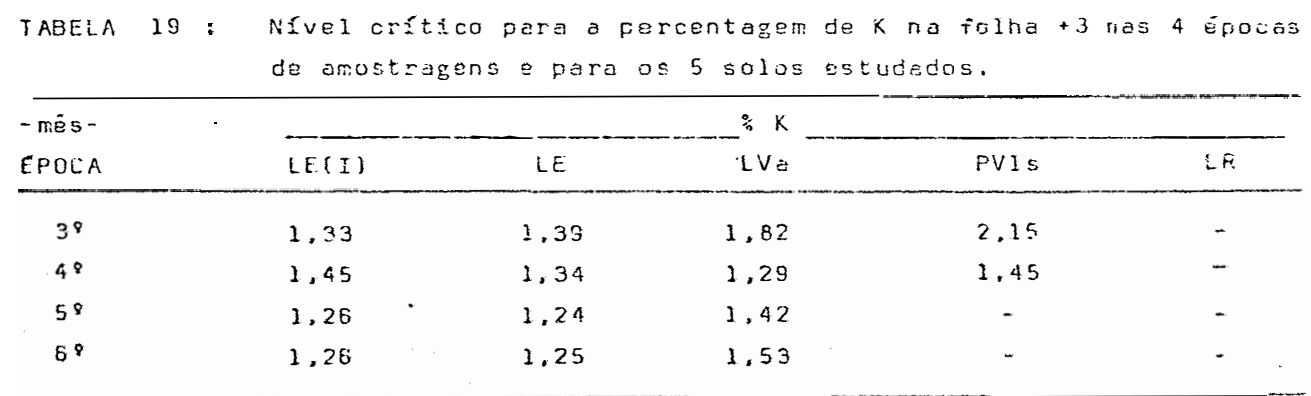


Observa-se a dificuldade da utilização destes níveis críticos já que os mesmos variam de acordo com : a va riedade, conforme demonstraram GOSNELL e LONG (1971), MCLEAN (1973), ZAMBELLO JR. e ORLANDO F! (1977) e ORLANDO Fo e et alie (1978), o tipo de solo e a época de amostragem.

\subsection{Sistema Integrado de Diagnose e Recomendação}

Baseando-se nas produtividades agrícolas obti das para os diferentes tratamentos, foram selecionacos os rendimentos compreendidos entre 80 e $100 \%$ da colheita relati $v a$ e respectivamente a estas parcelas escolnidas, as rela ções de N/P, N/K e K/P. Estas relações formaram para cada época de amostragem e para cada solo as populações não arror mais (BEAUFILS, 1971I.

O teste Lilliefors (CONOVER, 1971), indicou que as populações assim selecionadas poderiam ser estudadasatravés da Distribuição Normal, enquadrando-se na metodolo gia proposta por BEAUFILS (197)

As tabelas de $n^{8} \mathrm{~s} .20$ a 39 , constantes do apên dice, apresentam os resultados manipuiadoj através do DRIS, conforme sugerido por BEAUFILS (1973) e SUMNER e BEAUFILS $(1975)$.

Foram consideradas as localizações dos fertili zantes como repetições cios tratamentos fatoriais NxPXK - $7 x$ $2 \times 3$.

5.3.1. Nitrogênio

Como foi observado nas discussões anteriores, o nitrogênio indicou resposta atë a dosagem de $180 \mathrm{~kg} \mathrm{~N} / \mathrm{he}$ para os 5 ensaios estudadcs e a tabela 40 apresenta um resu mo das tabelas 20, 24, 28, 32 e 36 do apéndice, com respeito ao diagnóstico da dose no anctacto pará o $3^{\circ}$ más de idade nos $s$ experimentos. 
TABELA " 40 - Efeito do tratamento zero de nitrogénio (No) sobre o balanço de NPK, em ordem decrescentede necessidade, para os diferentes solos estL dados.

\begin{tabular}{|c|c|c|c|c|c|c|c|}
\hline \multicolumn{3}{|c|}{ Tratamentos } & \multirow{2}{*}{ (N) $>K>P$} & \multirow{2}{*}{$\frac{L E}{K>N>P}$} & \multirow{2}{*}{$\frac{L V a}{K>N>P}$} & \multirow{2}{*}{$\frac{\text { PVIS }}{P>K>N}$} & \multirow{2}{*}{$\frac{L R}{(\mathbb{N})>K>P}$} \\
\hline NO & PO & KO & & & & & \\
\hline NO & PO & $K I$ & $K>P>N$ & (N) $>P>K$ & (N) $>P>K$ & (N) $>P>K$ & (N) $>P>K$. \\
\hline NO & PO & $k 2$ & (N) $>P>K$ & $P>N>K$ & (N) $>P>K$ & (N) $>P>K$ & (N) $>K>P$ \\
\hline ND & PI & KO & $K>N>P$ & $K>N>P$ & (N) $>K>P$ & N $>K>P$ & (N) $>K>P$ \\
\hline NO & $P I$ & $K I$ & $K>N>P$ & $K>N>P$ & (N) $>P>K$ & (N) $>K>P$ & (N) $>P>K$ \\
\hline NO & $P I$ & $k 2$ & (N) $>P>K$ & (N) $>P>K$ & $P>N>K$ & (ii) $>P>K$ & (N) $>P>K$ \\
\hline
\end{tabular}

Nota-se que de um modo geral, o nitrogênio -. apresenta-se como deficiente (tabela 40) sendo por vez, suts tituído pelo potéssio, principalmente para os solos LE(I) e LE.

Pela tabeia 5, pode-se extrair os aumentos de vido às doses de nitrogēnio para os solos LE(I) e LE (14) 13 t cana/na respectivamentel e devido às dosagens de potássio ( 18 e 20 t canaiha) respectivamente para os mesmos solos. Observa-se que as respostas foram maiores para o potássio, im plicando que a substituição do $N$ pelo $K$, como elemento mais deficiente, é perfeitamente aceitável.

ZAMBELLO JR, e ORLANDO FO (1978), observaram que o DRIS poderie ser aplicado com sucesso fara o diegnóstí co da deficiência de nitrogénio em soqueiras de cana-de- açú car, concordando assim com os resultados aqui apresentados.

\subsubsection{Fösforo}

Para se estudar o efeito do fósforo, extraiuse jas tabelas $20,24,28,32$ e 35 do apêndico os tratamen tos N3POK2 a N3Plk?, os diagnósticos pelo ORIS, com as respec tives produtividades elaborando-se a tabela 4 i. 
Foram selecionadas as doses de fósforo na pre sençá das maiores quantidades de nitrogênio (N3) e potássio (K2), visto que a reação ao fósforo é baixa em soqueira e se ria melhor analisada depois que as maiores respostas de $N$ e K já estivessem ocorrido.

TABELA 41 - Efeito do fósforo com as doses mais elevadasde nitrogênio e potéssio, balanço de NPK pelo DRIS, em ordem decrescente de necessidade e as respectivas produtividades.

\begin{tabular}{|c|c|c|c|c|c|c|c|c|c|}
\hline Solos & Tratamentos & & & RIS & & $t$ & cana/ha & $\Delta t$ & cenaltia \\
\hline \multirow{2}{*}{$\operatorname{LE}(I)$} & N3 PO K2 & $P$ & $>$ & $N$ & $>$ & $k$ & 101 & \multirow{2}{*}{\multicolumn{2}{|c|}{+3}} \\
\hline & $N 3 \mathrm{Pl} K 2$ & N & $>$ & $\mathrm{P}$ & $>$ & K & 104 & & \\
\hline \multirow{2}{*}{ LE } & N3 PO K2 & $P$ & $>$ & $N$ & $>$ & k & 92 & \multirow{2}{*}{\multicolumn{2}{|c|}{+30}} \\
\hline & N3 PI K2 & $P$ & $>$ & $\mathrm{N}$ & $>$ & $k$ & 122 & & \\
\hline \multirow{2}{*}{ LVa } & N3 PO K2 & $P$ & $>$ & $N$ & $>$ & $k$ & 62 & \multirow{2}{*}{\multicolumn{2}{|c|}{+10}} \\
\hline & N3 FI K2 & $P$ & $>$ & $N$ & $>$ & $k$ & 72 & & \\
\hline \multirow{2}{*}{ PVIs } & N3 PO K2 & $P$ & $>$ & $N$ & $>$ & $k$ & 73 & \multirow{2}{*}{\multicolumn{2}{|c|}{+2}} \\
\hline & N3 PI K2 & $N$ & $>$ & $P$ & $>$ & K & 75 & & \\
\hline \multirow{2}{*}{ LR } & N3 PO K2 & $k$ & $>$ & $P$ & $>$ & $\mathrm{N}$ & 68 & \multirow{2}{*}{\multicolumn{2}{|c|}{+12}} \\
\hline & N3 FI K2 & $P$ & $>$ & $K$ & $>$ & $N$ & 80 & & \\
\hline
\end{tabular}

Cbserva-se pela tabela 41 que o fósforo foi. responsável por um aumento médio de ll, 4 t cana/ha, diagnos ticado através do DRIS para todos os ensaios, com excefão ao solo LR, onde o fósforo apresentou-se em segundo Iugar na escala de necessidade $(K>P>N)$.

Mesmo com a dosagem bastante baixa de fósfuroutilizada nos ensaios $\left(45 \mathrm{~kg} \mathrm{P} 2_{5} / \mathrm{ha}\right.$, foi possível um diag nóstico de sua deficiéncía pelo ORIs, estando de acordo com MEYER (1975), o qual observou que os índices de Beaufils ser viam com relativa sensibilidade pora oste fim. 


\section{5:3.3. Potássio}

- potássio apresenta-se como elemento de maior reação nos solos estudados, com exceção ao LR que não mos trou acréscimos de produção com as dosagens de $k$ utilizadas.

A tabela 42 foi organizada extraindo-se as do ses kO das tabelas $20,24,28,32$ e 36 do apêndice, bem como - diagnóstico levantado pelo DRIS.

TABELA 42 - Efeito do tratamento zero de potássio (KO) so bre o balanço de NPK, em ordem decrescente de necessidade, para os diferentes solos estudados.

\begin{tabular}{|c|c|c|c|c|c|c|c|}
\hline \multicolumn{3}{|c|}{ Tratamentos } & \multirow{2}{*}{ 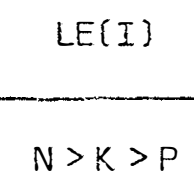 } & \multirow{2}{*}{ LE $>N>P$} & \multirow{2}{*}{ LVa $>N>P$} & \multirow{2}{*}{$\begin{array}{c}\text { PVIs } \\
P>K>N\end{array}$} & \multirow{2}{*}{$\frac{L R}{N>K>P}$} \\
\hline NO & PO & KO & & & & & \\
\hline NO & $\mathrm{Pl}$ & KO & (R) $>N>P$ & (R) $>N>P$ & $N>K>P$ & $N>K>P$ & $N>K>P$ \\
\hline $\mathrm{NI}$ & PO & KO & $N>K>P$ & (B) $>P>N$ & (R) $>N>P$ & (1) $>P>N$ & $P>K>N$ \\
\hline NI & $\mathrm{PI}$ & KO & (B) $>N>P$ & (R) $>N>P$ & (B) $>P>N$ & (1) $>N>P$ & (R) $>P>N$ \\
\hline N2 & $\mathrm{PO}$ & KO & (K) $>P>N$ & (B) $>P>N$ & $(\mathbb{K})>N>P$ & $N>K>P$ & (B) $>P>N$ \\
\hline $\mathrm{N} 2$ & $\mathrm{Pl}$ & KO & (1) $>N>P$ & 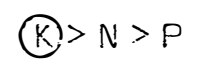 & (K) $>N>P$ & $(B)>P>N$ & $(X) P>N$ \\
\hline iN3 & PO & KO & $P>N>K$ & (1) $>P>N$ & $P>K>N$ & (R) $>N>P$ & $(N)>P>N$ \\
\hline N3 & PI & $\mathrm{KO}$ & (i) $>P>N$ & (R) $>i v>P$ & (B) $>N>P$ & $P>N>K$ & $(R)>P>N$ \\
\hline
\end{tabular}

Notia-se que o DRIS indicou para a dose $\mathrm{KO}$, de um modo geral, o potássio como elemento mais deficiente (ta bela 42) estando de acordo com as respostas na produtjuidade para todos os solos, com exceção feita novamente para o LR.

\subsubsection{Epoca de Amostragem}

As tabelas de $n^{8} \mathrm{~s} .43$ a 47 do apêndice, respec tivamente para os solos LE(I). LE, LVa, PVIs E LR, acusam a ordem decrescente de necessidade de nutrientes obtida através do diapnóstico dos índices trensformados do oris para as di ferentes épocas de amostragem estudadas. 
Verifica-se, de maneira geral, que para um mes mo tratamento o elemento mais deficiente permanece o mesmo para as 4 épocas de amestragem da folha +3 , inferindo-se que a metodologia do Sistema Integrado de Diagnose e Recomenda ção pode ser aplicada em qualquer dos estágios de desenvolvi mento estudado.

Estas od̀servações estão de acordo com os traja Ihos desenvolvidos por SliMNER e BEAUFILS (1975), BEAUFILS SUMNER (1977), SUMNER (1977a,b), e contrariam os resultados demonstrados por MEYER (1975), que constatou interferência da época de amostragem na referida técnica.

TABELA 48 - Somatória das diferenças, em t cana/ha, que se obteria caso fosse corrigido o elemento mais deficiente diagnosticado através do DRIS, para as 4 épocas de amostragem nos solos estu dados.

\begin{tabular}{|c|c|c|c|c|c|}
\hline Epocas & $L E\{I\}$ & LE & LVa & PVIs & LR \\
\hline $3^{8}$ mês & +145 (OUT) & +190 (OUT) & +127 (NOV) & $+90(D E Z)$ & $+137($ DEZ) \\
\hline $4^{\circ}$ mês & $+193(\mathrm{NOV})$ & +201 (NOV) & $+140(D E Z)$ & +120 ( J AN) & $+119($ JARN $)$ \\
\hline $5^{\circ}$ mẽs & $+1.98(D E Z)$ & $+209(D E Z)$ & $+153($ JAN $)$ & $+103(\mathrm{FEV})$ & $+118(F E V)$ \\
\hline $6^{\circ}$ mès & +181 ( J AN $)$ & $+24.4(J$ AN $)$ & $+126($ FEV $)$ & +114 (MAR) & +93 ( MAR $)$ \\
\hline
\end{tabular}

Na elaboração da tabela 48 , extraiu-se das ta belas de $n^{8} \mathrm{~s} .20$ a 39 do apêndice, as sometórias das diferen ças entre as produções registradas no ensaio e aquelas que se obteria caso fosse corrigido, em apenas uma dose superior, - elemento mais deficiente. Nota-se um certo efeito sazonai implj.cando em época ciimática de maior sensibilidade. Assim, dezembro e janeiro demostraram as maiores somatórias de pro dução para os ensaios.

Estes meses, na regiäo centro-sul, coincidem com altas precipitaçós (tabeja 4), elevadas temperaturas inf́cio de grande desenvolvimento vegetativo por perte de cul. tura da caina-de-ä̧üar. 
Estas considerações evidenciam que, embora o DRIS possa ser aplicado em qualquer época de amostragem, de zembro e janeiro projetam-se coma meses preferenciais para a coleta da folna +3 .

\section{$5 \cdot 3 \cdot 5$. Solos}

A técnica do DRIS pode ser utilizada pára os 4 tipos de solos estudedos e em todos proporcionou aumentos po sitivos na produtividade esperada, como demonstra a tabela 49, com os dados médios das 4 épocas de amostragens.

TABELA 49 - Somatória das diferenças, em t cana/ha que se obteria caso fosse corrigido o elemento mais deficiente diagnosticado pelo DRIS, para os 5 locais estudados.

\begin{tabular}{|c|c|c|c|c|c|}
\hline & $\operatorname{LE}(I)$ & LE & L.Va & PVIS & $L R$ \\
\hline$\Sigma$ & +179 & $+2 I I$ & +137 & +107 & +117 \\
\hline
\end{tabular}

Gbserva-se ainda na tabela 49, que o DRIS pode ser empregado tanto pare solo LE(I) como para o solo LE ssm o efeito da irrigação, o que confirma os resuitados apresentados por SUMNER e BEAUFILS 199751 \& ZAMBELLO JR. e ORLANOOFo (1979a), os quais notaram que esta metodologia reduz o efeito do estado interno de umidade da planta, possivelmente através das relações $N / P, N / K$ e K/P, pois:

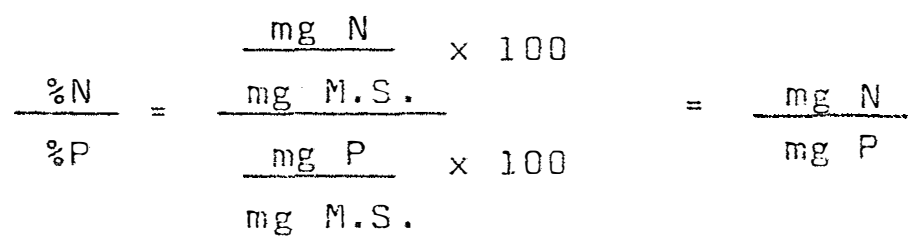

M.S. = matéria seca

eliminando a matéria seca e por conseguinte a umidade inter na da planta. 
O solo LR demonstrou certas

i rregularidades com respeito ao diagnóstico do potássio, sendo este fato ex plicado através da escolha, talvez não a mais adequada da p으 pulação não anormal. Esta população foi selecionada com ba se nas parcelas que registraram produções entre 80 a $100 \%$ da colheita relativa, näo sendo considerada uma possível absorção de luxo do potássio, como ficou evidenciada sua existência no ítem 5.2.3. Segundo BEAUFILS (1973), a população com absorção de luxo deveria ser excluída para o estabelecimento do diagrama interpretativo dos talanģos nutricionais.

\subsection{Observações Gerais}

O Sistema Integrado de Diagnose e Recomendação apresenta-se como metodologia de fácil vtilização na prátice, já que sua aplicação pode ser imediata, dispensando ensaios com diferentes doses de nutrientes para o estabelecimento dos níveis críticos.

Assim, uma determinada ärea pode ser controla da pelo DRIS, aplicando-se parte da adubação normal em área total e a instalação de microparcela com a dose completa pre tendida. o diagrama interpretativo do balanço nutricionai seria obtido a partir das microparceias e as adubações comple mentares seriam realizadas segundo os diagnósticos provenien tes deste diagrama.

Observa-se que um esquema assim estabelecido seria independente de uma série de fatores, tais cono os cli máticos, onde se porventura ocorresse uma seca ou uma geada na área, as microparcelas também seriam atingidas, implican do em um diagnóstico especírico para aquelas condigéés impos tas.

Deve-se tomer especial cuidado com o elemento potássio, evitando-se a instalaģäo das microparceias com do ses que possanproporcionar absorgão de luxo do citado elemen to. o éxito do sistema Integrado de Diagnose e Recomendarão depende, como observa BEAUfILS (1971), em muito do conheci - 
mento, experiência e perspicácia de quem irá iriterpretar e recomendar as adubações. 
6.

Dentro das condições em que se desenvolveram os ensaios e do que foj discutido, pode-se concluir que:

6.1. Resposta ao Fatorial $N \times P \times K \times L$

- A localização dos fertilizantes em profundi dade não proporciona benefício para a produção agrícola ou produção de açúcar por área, com exeeção para o solo fodzóli co Vermelho Amareio - variagão Laras.

- A soqueira, da variedade CB4I-75, reage li nearmente, em termos de produtividade, com as dosagens de até $180 \mathrm{~kg}$ Ni/ha, para todos os solos estudados.

- o fósforo provoca aumenta da produça agrícola para os $5010 s$ Latossol Vermelho Escuro-orto, Latossoi Roxo e Podzólico Vermeino Amarelo - variaçäl laras e eleva a produça de açúc por área para os dois primeiros solos. 
- Encontra-se resposta linear para os rendimen tos agrícolas e de açúcar por área da soqueira até a dosagem de $180 \mathrm{~kg} \mathrm{~K}$ o/ha, com exceção ao solo Latossol Roxo.

- A irrigação não apresenta benefício para a soqueira da variedade CB4l-76 cultivada em solo Latossol Ver melto Escuro-orto.

\subsection{Diagnose Foliar Baseada no Nivel Critico}

- São os seguintes os níveis críticos para o nitrogênio (percentagem com base na matéria seca), de acordo com a época de coleta das amostras foliares :

\begin{tabular}{|c|c|c|c|c|c|}
\hline \multirow[b]{2}{*}{ Epoca } & \multicolumn{5}{|c|}{ Solos } \\
\hline & $L E(I)$ & LE & LVa & PVIS & $L R$ \\
\hline $3^{8} \mathrm{mes}$ & - & - & 2,28 & - & 2,37 \\
\hline $4^{\circ} \mathrm{mês}$ & - & - & - & 2,28 & 2,04 \\
\hline $5^{8} \mathrm{més}$ & 2,36 & 2,09 & - & 2,02 & 1,92 \\
\hline $6^{\circ} \mathrm{més}$ & - & 2,20 & - & 1,92 & - \\
\hline
\end{tabular}

- Não é possível o estabelecimento do níveicrítico para o elemento fósforo.

- São os seguintes os níveis críticos para o potássio (percentagem com base na matéria seca), de acordo com a época de coleta da amostragem foliar :

\begin{tabular}{|c|c|c|c|c|c|}
\hline \multirow[b]{2}{*}{ Epoca } & \multicolumn{5}{|c|}{ Solos } \\
\hline & LEE (I) & LE & LVa & PVIs & LR \\
\hline $3^{\circ} \mathrm{més}$ & 1,33 & 1,39 & 1,82 & 2.15 & - \\
\hline $4^{8} \mathrm{mes}$ & 1,45 & 1,34 & 1,29 & 1,45 & - \\
\hline $5^{8}$ mês & 1,26 & 1,24 & 1,42 & - & - \\
\hline $6^{8} \mathrm{mes}$ & 3,26 & 1,25 & 1.53 & - & - \\
\hline
\end{tabular}


- Há efeito da época de coleta das amostras fo liares e do solo nos níveis críticos de $N$ e $K$.

- Constatam-se as interações K $\times N$ e P $\times$ K dos fertilizantes potássicos e fosfatados interferindo nos teo res foliares de nitrogênio e potássio, respectivamente.

6.3. Sistema Integrado de Diagnose e Recomendą̧a DRIS

- O DRIS permite a interpretação de deficién cias e de balanços nutricionais de $N, P$ e K para as soquei ras de cana-de-açúcar.

- o diagnóstico do DRIS ë praticamente inaite rado com a época de amostragem foliar e tem sua aplicaçãc pe ra os diversos solos estudados. 
7 .

APPLICATION OF THE DIAGNOSIS AND RECOMMENDATION INTEGRATED SYSTEM (DRIS) FOR DIFFERENT SOILS AND TIME OF FOLIAR SAMPLING ON SUGAR-CANE (SACCharum SPP.) RATOON CROPS.

In order to study the Diagnosis arid Recom mendation Integrated system (DRIS), this technique was compared with that of foliar diagnosis based on threshold values. The effect of different foljar sampling times of ratoon crops grown in the 4 Great Soil Groups was observed.

The trials were based on the $N \times P \times K \times L$ factorial design, where $L=$ surface and sub-surfaceplacement. of fertilizers. Application rates were : 0 - 60 - $120-180$ kg N/ha; $0-45 \mathrm{~kg} \mathrm{P}_{2} \mathrm{O}_{5}$ /ha; and, $0-90-180 \mathrm{~kg} \mathrm{k}_{2} \mathrm{olh}$. $\mathrm{h}$. The soils under study were : Latosalic B "Terra Roxa" (LR); RedYellow podzolic - Leras variation (PVls); Red-Yejlow Latosol 
sandy phase (LVa), and Ortho Dark Red Latosol (LE). In the latter soil (LE), the cane was grown with and without irrigation.

Variety CB41-76 was used, and leaf +3 was col lected at $3,4,5$ and 6 months of age of the ratoon crop.

The plots comprised 7 rows $10 \mathrm{~m}$ long, where only the 3 central rows were harvested and the others considered as borders. The inter-row spacing was $1.5 \mathrm{~m}$.

The data obtained showed that the sub-surface placement of fertilizers did not bring about any positive effect on cane or sugar yield, with the exception of plants grown in PVls soil.

In general, sugar-cane yields were increased, in linear form, with the application of nitrogen and potassium, with the exception of potassium in LR soil.

Phosphorus increased cane yield for LE, LR and PVIs soils, and brought about an increase in sugarproduction per area for LE and LR soils.

Irrigation did not benefit ratoon crops planted in LE soils.

Determination of critical levels in foilar diagnosis for $N$ and $K$ was only possible for some of the times of +3 leaf sampling, whereas for phosphorus it was feasible for any of the times of foliar sampling. Time of plant tissue sampling and soil type affected the critical levels of $N$ and $K$.

On the other hand, the DRIS approach proved to be an adequate methodology for $N$, $P$ and $K$ diagnosis in sugar cane ratoon crops, and the interpretation of the transformed indices does not substantiaily change with foliar sampiing time. Also, application of the ORIS on different types of soil is feasible. 
8. APENDICE 
TABELA 20 - Tratamentos (fatorial $N \times P \times K-4 \times 2 \times 3$ ) aplicados ao solo LE(I) irrigado, percentagens de $N, P$ e $K n a$ folha +3 coletada aos 3 meses de idade, indices transformados do DRIS e a diferen ça entre as produções $(\triangle T C H)$, obtidas e esperadas através das correções pelo DRIS.

\begin{tabular}{|c|c|c|c|c|c|c|c|c|c|c|c|}
\hline \multirow{2}{*}{\multicolumn{3}{|c|}{ Tratamentos }} & \multirow{3}{*}{$\frac{\mathrm{TCH}^{*}}{75}$} & \multirow{3}{*}{$\frac{\% N}{2,22}$} & \multirow{3}{*}{$\frac{\% P}{0,23}$} & \multirow{3}{*}{$\frac{\% k}{1,25}$} & \multicolumn{3}{|c|}{ Ind.Transf. } & \multirow[b]{2}{*}{ TCH** } & \multirow[b]{2}{*}{$\triangle T C H$} \\
\hline & & & & & & & $N$ & $P$ & K & & \\
\hline NO & $\mathrm{PO}$ & $\mathrm{KO}$ & & & & & -19 & 19 & -9 & 52 & -13 \\
\hline NO & PO & KI & 83 & 2,20 & 0,22 & 1,16 & 15 & 9 & -15 & 84 & $+i$ \\
\hline NO & PO & $\mathrm{K} 2$ & 84 & 2,21 & 0,22 & 1,23 & -3 & 3 & 3 & 98 & +14 \\
\hline NO & Pl & KO & 73 & 2,16 & 0,21 & 0,96 & 36 & 42 & -42 & 66 & -7 \\
\hline NO & $P I$ & KI & 66 & 2,18 & 0,21 & 1,18 & 3 & 3 & -3 & 78 & +12 \\
\hline NO & PI & $\mathrm{K} 2$ & 78 & 2,17 & 0,22 & 1,41 & -31 & -9 & 31 & 94 & +16 \\
\hline NI & PO & $\mathrm{KC}$ & 52 & 2,19 & 0,22 & 1,23 & -7 & 7 & 3 & 73 & +11 \\
\hline$N I$ & $\mathrm{PO}$ & $K I$ & 80 & 2,29 & 0,22 & 1,50 & -27 & -35 & 35 & 90 & +10 \\
\hline$N I$ & PO & $\mathrm{k} 2$ & 98 & 2,24 & 0,23 & 1,25 & -28 & 28 & -6 & 104 & +6 \\
\hline $\mathrm{NI}$ & $P I$ & $\mathrm{KO}$ & 74 & 2,19 & 0,22 & 1,05 & 18 & 31 & $-3 I$ & 90 & +16 \\
\hline$N I$ & PI & $\mathrm{KI}$ & $90^{\circ}$ & 2,22 & 0,22 & 1,25 & -11 & 11 & 3 & 91 & +1 \\
\hline $\mathrm{NI}$ & PI & k'2 & 94 & 2,27 & 0,23 & 1,36 & -19 & 6 & 19 & 81 & -13 \\
\hline $\mathrm{N} 2$ & $P O$ & KO & 73 & 2,28 & 0,22 & $I, I 4$ & 21 & 15 & -21 & 100 & $+2 \pi$ \\
\hline N2 & PO & $K I$ & 100 & 2,29 & 0,22 & 1,21 & 10 & 3 & -10 & 104 & +4 \\
\hline N2 & PO & $k 2$ & 104 & 2,30 & 0,22 & 1,21 & 10 & 0 & -10 & 81 & -23 \\
\hline $\mathrm{N} 2$ & $P I$ & KO & 88 & 2,20 & 0,22 & 0,90 & 60 & 62 & $-E I$ & 91 & +3 \\
\hline N2 & $P I$ & KI & 91 & 2,28 & 0,23 & 1,34 & -15 & 3 & 15 & 102 & +11 \\
\hline $\mathrm{N} 2$ & $\mathrm{PI}$ & $\mathrm{K} 2$ & 81 & 2,24 & 0,21 & 1.37 & 3 & -29 & 29 & 104 & +23 \\
\hline N3 & $P O$ & $\mathrm{KO}$ & 78 & 2,25 & 0,22 & 1,27 & 6 & -8 & 8 & 75 & -3 \\
\hline N3 & PO & $K I$ & 85 & 2,20 & 0,21 & 1,30 & -3 & -17 & 17 & 102 & +17 \\
\hline N3 & $\mathrm{PO}$ & $k 2$ & 101 & 2,27 & 0,22 & 1,30 & 6 & -12 & 12 & 104 & +3 \\
\hline N3 & $\mathrm{Pl}$ & $\mathrm{KO}$ & 75 & 2,29 & 0,22 & 1,08 & 37 & 3 & -37 & 302 & +27 \\
\hline N3 & $P I$ & $k l$ & 102 & 2,27 & 0,22 & 1,25 & 2 & 0 & -2 & 104 & +2 \\
\hline N3 & $P I$ & $k 2$ & 104 & 2,24 & 0,22 & 1,30 & -9 & 3 & 9 & - & - \\
\hline
\end{tabular}

* Produçäo (t cana/ha) obtida no ensaio fatorial.

** Produção (t cana/ha) que se obteria, ceso fosse corrigido o elemen to meis deficiente (através dos indjoes transformados) com a dose imediatemente superior. 


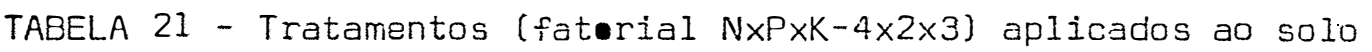

$L E(I)$

irrigado, percentagens de $N, P$ e $K$ na folha +3 coletada aos

4 meses de idade, indices transformados do DRIS e a diferen ça entre as produções $(\triangle T C H)$, obtidas e esperadas através das correções pelo DRIS.

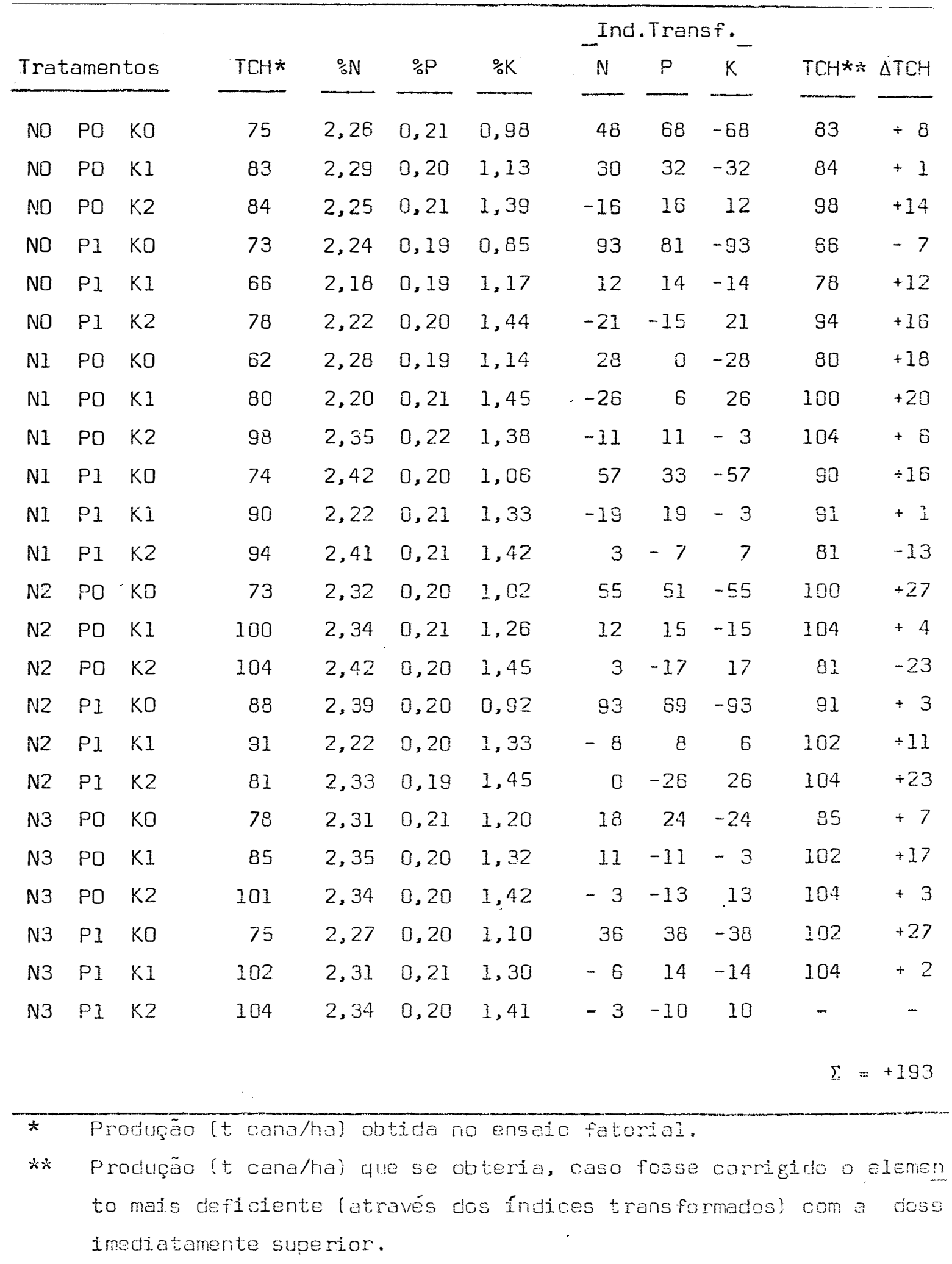


TABELA 22 - Tratamentos (fatorial $N \times P \times K-4 \times 2 \times 3$ ) aplicados ao solo $\operatorname{LE}(I)$ irrigado, percentagens de $N, P$ e $K$ na folha + 3 coletada aos 5 meses de idade, Indices transformados do DRIS e a diferen ça entre as produçc̃es ( $\triangle T C H$ ), obtidas e esperadas através das correções pelo DRIS.

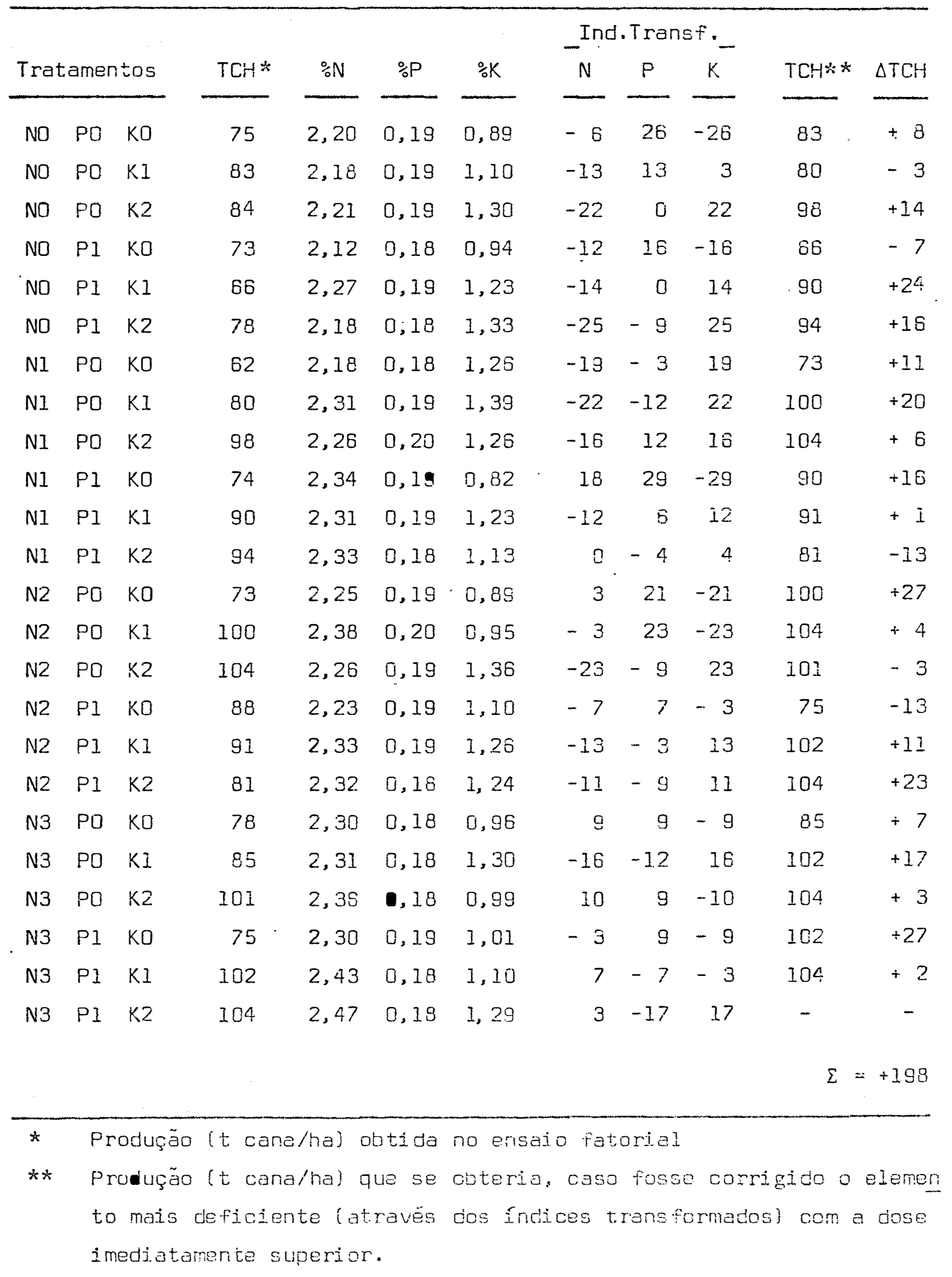




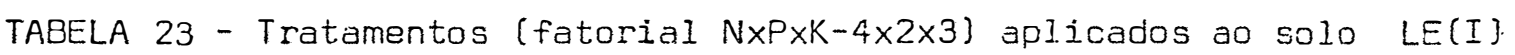
irrigado, percentagens de $N, P$ e $K$ na folha + 3 coletada acs 6 meses de idade, indices transformados do DRIS e a diferen ça entre as produções $(\triangle T C H)$, obtidas e esperadas através das correções pelo ORIS.

\begin{tabular}{|c|c|c|c|c|c|c|c|c|c|c|c|}
\hline \multirow{2}{*}{\multicolumn{3}{|c|}{ Tratamentos }} & \multirow{3}{*}{$\frac{\text { TCH* }}{75}$} & \multirow{3}{*}{$\frac{\% N}{2,44}$} & \multirow{3}{*}{$\frac{\% P}{0,16}$} & \multirow{3}{*}{$\frac{\% k}{0,88}$} & \multicolumn{3}{|c|}{ Ind.transf. } & \multirow{3}{*}{$\frac{\mathrm{TCH} * *}{83}$} & \multirow{3}{*}{$\frac{\triangle T C H}{+8}$} \\
\hline & & & & & & & \multirow{2}{*}{$\frac{N}{46}$} & \multirow{2}{*}{$\frac{P}{30}$} & \multirow{2}{*}{$\frac{k}{-46}$} & & \\
\hline NO & PO & KO & & & & & & & & & \\
\hline NO & PO & $K I$ & 83 & 2,28 & 0,17 & 1,05 & 9 & 11 & -11 & 84 & +1 \\
\hline NO & PO & $\mathrm{K} 2$ & 84 & 2,30 & 0,16 & 1,19 & 12 & -16 & 16 & 78 & -6 \\
\hline NO & P1 & KO & 73 & 2,10 & 0.17 & 1,11 & -12 & 12 & -6 & 74 & +1 \\
\hline NO & Pl & $K I$ & 66 & 2,28 & 0,17 & 1,16 & -3 & 3 & -3 & 78 & +12 \\
\hline NO & PI & $\mathrm{K} 2$ & 78 & 2,45 & 0,17 & 1,21 & 11 & -11 & 9 & 34 & +16 \\
\hline NI & PO & KO & 62 & 2,27 & 0,18 & 1,00 & 3. & 37 & -37 & 80 & +18 \\
\hline NI & PO & $K I$ & 80 & 2,51 & 0,17 & 1,04 & 28 & 0 & -20 & 98 & +18 \\
\hline NI & PO & $\mathrm{K} 2$ & 98 & 2,40 & 0,18 & 1,14 & 6 & 20 & -10 & 104 & +8 \\
\hline$N I$ & $\mathrm{Pl}$ & KO & 74 & 2,15 & 0,17 & 0,85 & 21 & 57 & -.57 & 90 & +16 \\
\hline $\mathrm{NI}$ & Pl & $K I$ & 90 & 2,75 & 0,16 & 1,08 & 31 & -31 & -27 & 34 & +4 \\
\hline $\mathrm{NI}$ & $P I$ & $k 2$ & 94 & 2,29 & 0,18 & 1,20 & -6 & 5 & 3 & 81 & -13 \\
\hline N2 & PO & $\mathrm{KO}$ & 73 & 2,48 & 0,18 & 0,75 & 69 & 91 & -91 & 100 & +27 \\
\hline N2 & PO & $K I$ & 100 & 2,45 & 0,18 & 1,09 & 15 & 15 & -15 & 104 & +4. \\
\hline N2 & PO & $k 2$ & 104 & 2,28 & 0,18 & $I, 30$ & -.16 & 0 & 16 & 101 & -3 \\
\hline N2 & $\mathrm{FI}$ & KO & 83 & 2,24 & 0,18 & 0.67 & 57 & 126 & -126 & 91 & +3 \\
\hline N2 & $P I$ & $K I$ & 91 & 2,65 & 0,15 & 1,00 & 29 & -3 & -29 & 81 & -10 \\
\hline N2 & PI & $\mathrm{k} 2$ & 81 & 2,31 & 0,18 & 1.43 & -29 & -27 & 29 & 104 & +23 \\
\hline N3 & PO & $\mathrm{KO}$ & 78 & 2,50 & 0,16 & 0,90 & 54 & 27 & -.54 & 85 & +7 \\
\hline N3 & PO & $K I$ & 85 & 2,27 & 0,17 & 1,38 & -27 & -27 & 27 & 102 & +17 \\
\hline N3 & PO & $K 2$ & 101 & 2,54 & 0,17 & 1,27 & 9 & -14 & 14 & 104 & +3 \\
\hline N3 & $P I$ & KO & 75 & 2,25 & 0,18 & 0,89 & 42 & 53 & -53 & 102 & +27 \\
\hline N3 & $\mathrm{PI}$ & $K I$ & 102 & 2,28 & 0,18 & 1,23 & -8 & 8 & 6 & 104 & +2 \\
\hline N3 & PI & $k 2$ & 104 & 2,47 & 0,18 & 1,29 & 0 & -10 & 10 & $\Sigma=$ & $\begin{array}{r}- \\
+18 \bar{I}\end{array}$ \\
\hline
\end{tabular}

* Produção (t cana/ha) obtida no ensaio fatorial.

* Produção (t cana/ha) que se cbteria, caso fosse corrigido o elemen to mais deficiente (através dos índices transformadus) com a abse imediatamente superior. 
TABELA 24 - Tratamentos (fatorial $\mathrm{N} \times \mathrm{P} \times \mathrm{K}-4 \times 2 \times 3$ ) aplicados ao solo LE,per centagens de $N$, $P$ e $K$ na folha +3 coletada aos 3 meses de idade, Indices transformados do DRIS e a diferença entre as produções $(\triangle T C H)$, obtidas e esperadas através das correções pelo DRIS.

\begin{tabular}{|c|c|c|c|c|c|c|c|c|c|c|c|}
\hline \multicolumn{3}{|c|}{ Tratamentos } & \multirow{2}{*}{$\frac{\text { TCH* }}{72}$} & \multirow{2}{*}{$\frac{\% N}{2,20}$} & \multirow{2}{*}{$\frac{\% P}{0,21}$} & \multirow{2}{*}{$\frac{\% K}{0,84}$} & \multirow{2}{*}{$\frac{N}{45}$} & \multirow{2}{*}{$\frac{P}{77}$} & \multirow{2}{*}{$\frac{k}{-77}$} & \multirow{2}{*}{$\frac{\text { TCHx* }}{94}$} & \multirow{2}{*}{$\frac{\Delta T C H}{+22}$} \\
\hline NO & PO & KO & & & & & & & & & \\
\hline NO & PO & $K I$ & 94 & 2,27 & 0,22 & 1,34 & -7 & 3 & 7 & 83 & -11 \\
\hline NO & PO & $k 2$ & 86 & 2,23 & 0,21 & 1,39 & -6 & -17 & 17 & 83 & +3 \\
\hline NO & $P I$ & KO & 76 & 2,25 & 0,22 & 1,09 & 15 & 27 & -27 & 76 & 0 \\
\hline NO & PI & $K I$ & 76 & 2,25 & 0,22 & 1,12 & 12 & 24 & -24 & 89 & +13 \\
\hline NO & $\mathrm{PI}$ & K2 & 89 & 2,30 & 0,23 & 1,37 & -6 & s & 6 & 96 & +7 \\
\hline NI & PO & KO & 80 & 2,26 & 0,21 & 1,16 & 13 & 9 & -.13 & 83 & +3 \\
\hline NI & PO & $K I$ & 83 & 2,33 & 0,21 & 1,46 & 12 & -34 & 34 & 84 & +1 \\
\hline NI & PO & $\mathrm{K} 2$ & 102 & 2,33 & 0,22 & 1,39 & 3 & -13 & 13 & 96 & -6 \\
\hline NI & $P I$ & Ko & 77 & 2,28 & 0,22 & 1,18 & 3 & 19 & -19 & 84 & +7 \\
\hline $\mathrm{NI}$ & $P I$ & $K I$ & 84 & 2,33 & 0,22 & 1,18 & 15 & 9 & -15 & 96 & +12 \\
\hline $\mathrm{NI}$ & $P I$ & $\mathrm{k} 2$ & 96 & 2,28 & 0,22 & 1,28 & -3 & 5 & -5 & 108 & +12 \\
\hline N2 & PO & KO & 64 & 2,23 & 0,21 & 1,14 & 16 & 6 & -16 & 78 & +14 \\
\hline N2 & PO & $K I$ & 78 & 2,28 & 0,21 & 1,32 & 12 & -16 & 16 & 93 & +21 \\
\hline N2 & PO & $k 2$ & 98 & 2,23 & 0,22 & 1,43 & -19 & -3 & 19 & 92 & -6 \\
\hline$N 2$ & $P I$ & KO & 88 & 2,23 & 0.22 & 1,10 & 9 & 27 & -27 & 99 & +11 \\
\hline N2 & $P I$ & KI & 99 & 2,33 & 0,22 & 1,37 & 6 & -12 & 12 & 86 & -13 \\
\hline N2 & $\mathrm{Pl}$ & $K 2$ & 108 & 2,31 & 0,22 & 1,37 & 3 & -11 & 11 & 122 & +14 \\
\hline N3 & PO & KO & 86 & 2,30 & 0,22 & 1,21 & 11 & $\exists$ & -11 & 86 & 0 \\
\hline N3 & PO & $K I$ & 85 & 2,32 & 0,22 & 1,30 & 6 & -6 & 0 & 102 & +16 \\
\hline N3 & PO & $k 2$ & 92 & 2,37 & 0,22 & 1,43 & 3 & -15 & 15 & 122 & +30 \\
\hline N3 & $P I$ & $\mathrm{KO}$ & 82 & 2,24 & 0,22 & 1,04 & 24 & 42 & -42 & 102 & +20 \\
\hline N3 & PI & $K I$ & 102 & 2,29 & 0,22 & 1,14 & 18 & 20 & -20 & 122 & +20 \\
\hline N3 & PI & $K 2$ & 122 & 2,37 & 0,23 & 1,39 & 6 & -8 & 8 & - & - \\
\hline
\end{tabular}

* Produção (t canahal obtida no ensaio fatorial.

** Produção (t canaha) que se obteria, caso fosse corrigijo o elemen to mais deficiente (atrevés dos índices transformados) com a dose imediatamente superior. 


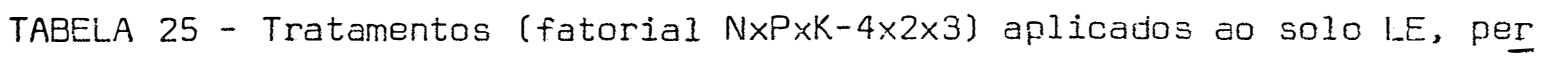
centagens de $N, P$ e $K$ na folha +3 coletada aos 4 meses de idade, indices transformados do DRIS e a diferença entre as produções $(\triangle T C H)$, obtidas e esperadas através das correções pelo DRIS.

\begin{tabular}{|c|c|c|c|c|c|c|c|c|c|c|c|}
\hline \multirow{2}{*}{\multicolumn{3}{|c|}{ Tratamentos }} & \multirow{3}{*}{$\frac{\mathrm{TCH}^{*}}{72}$} & \multirow{3}{*}{$\frac{\% N}{1,98}$} & \multirow{3}{*}{$\frac{\% P}{0,19}$} & \multirow{3}{*}{$\frac{\% k}{0,64}$} & \multicolumn{3}{|c|}{ Índ.transf. } & \multirow{3}{*}{$\frac{\text { TCH** }}{94}$} & \multirow{3}{*}{$\begin{array}{c}\triangle T C H \\
+22\end{array}$} \\
\hline & & & & & & & \multirow{2}{*}{$\frac{N}{89}$} & \multirow{2}{*}{$\frac{P}{39}$} & \multirow{2}{*}{$\frac{k}{-83}$} & & \\
\hline NO & PO & KO & & & & & & & & & \\
\hline NO & PO & $\mathrm{KI}$ & 94 & 2,02 & 0,20 & 1,07 & 5 & 22 & -22 & 86 & -8 \\
\hline NO & PO & K2 & 86 & 2,08 & 0,21 & 1,39 & -20 & 6 & 20 & 102 & +16 \\
\hline NO & $P I$ & KO & 76 & 2,02 & 0,20 & 0,88 & 42 & 54 & -54 & 76 & 0 \\
\hline NO & PI & $K I$ & 76 & 2,06 & 0,20 & 1,10 & 9 & 17 & -17 & 89 & +13 \\
\hline NO & $\mathrm{Pl}$ & $k 2$ & 89 & 2,12 & 0,21 & 1,40 & -18 & a & 18 & 96 & +7 \\
\hline NI & PO & KO & 80 & 2,08 & 0,20 & 0,94 & 39 & 41 & -41 & 83 & +3 \\
\hline NI & PO & $\mathrm{KI}$ & 83 & 2,22 & 0,20 & \pm .27 & 10 & -10 & 0 & 77 & -6 \\
\hline NI & $\mathrm{PO}$ & K2 & 102 & 2,17 & 0,19 & 1.24 & 12 & -.12 & 3 & 98 & -6 \\
\hline$N I$ & PI & $K D$ & 77 & 2,06 & 0,19 & 0,92 & 47 & 39 & -47 & 84 & +7 \\
\hline$N I$ & $P I$ & $K I$ & 84 & 2,19 & 0,21 & 1,29 & -3 & 3 & -3 & 96 & +12 \\
\hline NI & P1 & $K 2$ & 96 & 2,06 & 0,20 & $i, 24$ & -10 & 30 & 0 & 99 & $\div 3$ \\
\hline N2 & PO & KO & 64 & 2,09 & 0,20 & 0,97 & 36 & 36 & -.36 & 78 & +14 \\
\hline N2 & PO & $K I$ & 78 & 1,99 & 0,18 & 1,10 & 9 & 3 & -9 & 98 & +20 \\
\hline $\mathrm{N} 2$ & PO & $\mathrm{K} 2$ & 98 & 2,12 & 0,20 & 1,42 & -15 & -9 & 19 & 32 & -5 \\
\hline$N 2$ & $P I$ & KO & 88 & 2,07 & 0,20 & 1,04 & 18 & 32 & -32 & 99 & +11 \\
\hline $\mathrm{N} 2$. & Pl & $K I$ & 99 & 2,07 & 0,19 & 1,16 & 10 & -6 & -10 & 108 & +9 \\
\hline N2 & PI & $k 2$ & 108 & 2,04 & 0,18 & 1,18 & 9 & -9 & 3 & 122 & +14 \\
\hline N3 & $\mathrm{PD}$ & $\mathrm{KO}$ & 86 & 2,05 & 0,20 & 1,07 & 6 & 26 & -26 & 86 & 0 \\
\hline N3 & PO & $K I$ & 85 & 2,12 & 0,20 & 1,21 & 0 & 6 & -6 & 92 & +6 \\
\hline N3 & PO & $\mathrm{k} 2$ & 92 & 2,20 & 0,20 & 1,36 & 0 & -14 & 14 & 122 & +30 \\
\hline N3 & $P I$ & $\mathrm{KO}$ & 82 & 2,06 & 0,20 & 0,88 & 48 & 54 & -54 & 102 & +20 \\
\hline N3 & PI & $k 1$ & 102 & 1,79 & 0,28 & 1,07 & -23 & 23 & -9 & 122 & +20 \\
\hline N3 & PI & $k 2$ & 122 & 2,22 & 0,20 & 1,32 & .0 & -10 & 9 & - & - \\
\hline
\end{tabular}

$\Sigma=+201$

\footnotetext{
* Produção (t cana/hal obtida ro encaio fatoríal.

** Produção (t cana/ha) que se obteria, caso fosse corrigido o eiemento nais deficiente (através dos indices transfornodos), com a dose imediatamente superior.
} 


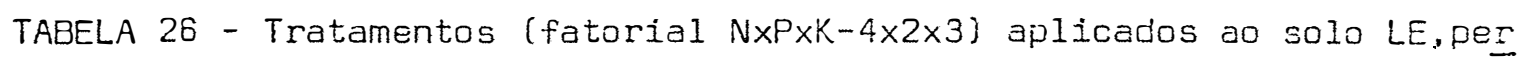
centagens de $N$, P e $K$ na folha + 3 coletada aos 5 meses de idade, indices transformados do DRIS e a diferença entre as produções ( $\triangle T C H)$, obtidas e esperadas através das correções pelo DRIS.

\begin{tabular}{|c|c|c|c|c|c|c|c|c|c|c|c|}
\hline & & & & & & & Ino & tra & f. & & \\
\hline Тга & tame & ntos & $\mathrm{TCH}^{*}$ & $\% N$ & $\% P$ & $\% K$ & $N$ & $P$ & K & $\mathrm{TCH} *$ & $\triangle T C H$ \\
\hline NO & PO & $\mathrm{KO}$ & 72 & 1,93 & 0,19 & 0,64 & 33 & 77 & -77 & 94 & +22 \\
\hline NO & PO & $K I$ & 94 & 1,99 & 0,19 & 1,04 & -20 & 20 & -18 & 83 & -11 \\
\hline NO & $\mathrm{PO}$ & $k 2$ & 86 & 1,98 & 0,19 & 1,27 & -22 & 22 & 18 & 102 & +16 \\
\hline NO & PI & KO & 76 & 1,85 & 0,18 & 0,83 & 3 & 35 & -35 & 76 & \\
\hline NO & $\mathrm{Pl}$ & $K I$ & 76 & 1,91 & 0,19 & 0,97 & -26 & 26 & -24 & 84 & $+\theta$ \\
\hline NO & P1 & $k 2$ & 89 & 2,02 & 0,19 & 1,24 & -14 & 14 & 12 & 96 & +7 \\
\hline$N 1$ & PO & KO & 30 & 2,09 & 0,19 & 0,95 & 30 & 40 & -40 & 83 & +3 \\
\hline$N I$ & PO & $K I$ & 83 & 2,09 & 0,20 & 1,30 & -20 & 20 & 12 & 78 & -5 \\
\hline$N I$ & PO & $k 2$ & 102 & 2,09 & 0,20 & 1,26 & -11 & 11 & 9 & 98 & -4 \\
\hline $\mathrm{Nl}$ & $P I$ & $K O$ & 77 & 2,09 & 0,19 & 0,94 & 18 & 24 & -24 & 84 & +7 \\
\hline NI & $P I$ & $K I$ & 84 & 2,11 & 0,20 & 1,12 & -3 & 9 & -9 & 96 & +12 \\
\hline $\mathrm{NI}$ & $P I$ & $k 2$ & 96 & 2,09 & 0,19 & 1,27 & -9 & -3 & 9 & 108 & +12 \\
\hline N2 & PO & KO & 64 & 2,11 & 0,20 & 0,97 & -6 & 30 & -30 & $7 B$ & +14 \\
\hline N2 & PO & $K I$ & 78 & 2,08 & 0,19 & 1,15 & -5 & 5 & -3 & 86 & +8 \\
\hline $\mathrm{N} 2$ & PO & $\mathrm{K} 2$ & 98 & 2,14 & 0,19 & 1,38 & -6 & -15 & 15 & 108 & +10 \\
\hline N2 & $P I$ & KO & 88 & 2,15 & $c, 20$ & 0,89 & 15 & 37 & -37 & 98 & +31 \\
\hline N2 & $P I$ & $K I$ & 99 & 2,04 & 0,20 & 1,00 & -18 & 26 & -25 & 108 & +9 \\
\hline N2 & $P 1$ & $k 2$ & 108 & $2, \mathrm{i} 8$ & 0,19 & 1,38 & 3 & -17 & 17 & 1.22 & +14 \\
\hline N3 & PO & KO & 86 & 1,98 & 0.19 & 0,74 & 27 & 53 & -53 & 86 & 0 \\
\hline N3 & PO & $K I$ & 86 & 2,09 & 0,19 & 1,07 & 3 & 11 & -11 & 92 & +8 \\
\hline N3 & PO & K2 & 92 & 2,24 & 0,20 & 1,19 & 10 & -10 & -6 & 122 & +30 \\
\hline N3 & $P 1$ & $\mathrm{KO}$ & 82 & 2,04 & 0,29 & 0,64 & 60 & 68 & -58 & 102 & +20 \\
\hline N3 & $P I$ & $k I$ & 102 & 2,15 & 0,19 & 1,13 & 7 & -3 & -7 & 122 & +20 \\
\hline N3 & $\mathrm{Pl}$ & $k 2$ & 122 & 1,79 & 0,17 & 0,87 & 3 & 21 & -2 & - & - \\
\hline
\end{tabular}

$\Sigma=+209$

* Frodução (t canaíra) obtida no ensaio fatorial.

** Produção (t cana/ha) aue se obteria, caso fosse corrigido o elemento mais deficiente (atraves dos índices transformacios) com a dose imediatamente superior. 


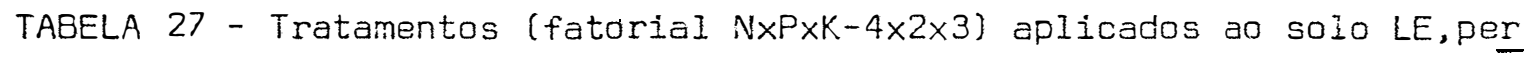
centagens de $N$, $P$ e $K$ ne folha +3 coletada aos $E$ meses de idade, índices transformados do DRIS e a diferença entre as produções ( $\triangle T C H)$, obtidas e esperadas através das correções pelo DRIS.

\begin{tabular}{|c|c|c|c|c|c|c|c|c|c|c|c|}
\hline \multirow{2}{*}{\multicolumn{3}{|c|}{ Tratamentos }} & \multirow{3}{*}{$\frac{T C H *}{72}$} & \multirow{3}{*}{$\frac{\% N}{2,01}$} & \multirow{3}{*}{$\frac{\because P}{0,18}$} & \multirow{3}{*}{$\frac{\% K}{0,64}$} & \multicolumn{3}{|c|}{ Ind.transf. } & \multirow[b]{2}{*}{$\mathrm{TCH} * \%$} & \multirow{3}{*}{$\begin{array}{l}\triangle T C H \\
+22\end{array}$} \\
\hline & & & & & & & \multirow{2}{*}{$\frac{N}{12}$} & \multirow{2}{*}{$\frac{P}{48}$} & \multirow{2}{*}{$\frac{k}{-48}$} & & \\
\hline NO & PO & KO & & & & & & & & 94 & \\
\hline NO & PO & KI & 94 & 1,98 & 0,18 & 1,10 & -15 & 16 & 6 & 83 & -11 \\
\hline NO & PO & $K 2$ & 86 & 1,91 & 0,17 & 1,29 & -22 & 0 & 22 & 102 & +16 \\
\hline NO & PI & KO & 76 & 1,91 & 0,18 & 0,98 & -19 & 19 & -3 & 77 & +1 \\
\hline NO & PI & $K I$ & 76 & 1,99 & 0,18 & 1,08 & -16 & 15 & 6 & 84 & +8 \\
\hline NO & $\mathrm{Pl}$ & $k 2$ & 89 & 2,01 & 0,18 & 1,23 & -17 & 9 & 17 & 96 & +7 \\
\hline NI & PO & KO & 80 & 2,09 & 0,19 & 0,74 & $\dot{6}$ & 34 & -34 & 83 & +3 \\
\hline $\mathrm{NI}$ & PO & $K_{1}$ & 83 & 2,16 & 0,18 & 1,05 & 3 & -3 & -3 & 102 & +19 \\
\hline NI & PO & $\mathrm{K} 2$ & 102 & 2,08 & 0,18 & 1,14 & -6 & 3 & 6 & 98 & -4 \\
\hline$N I$ & Pl & KO & 77 & 2,14 & 0,19 & 0,80 & 3 & $3 i$ & -31 & 64 & +7 \\
\hline NI & $P I$ & $\mathrm{KI}$ & 84 & 2,09 & 0,19 & $I, 10$ & -10 & 10 & כ & 99 & +15 \\
\hline NI & $P I$ & $K 2$ & 96 & 2,14 & 0,19 & 1,08 & -6 & $E$ & 0 & 108 & +12 \\
\hline N2 & PO & KO & 64 & 2,21 & 0,18 & $0,7 I$ & 33 & 21 & -33 & 78 & +14 \\
\hline N2 & PO & $K I$ & 78 & 2,19 & 0,19 & 1,17 & -3 & -3 & 3 & 99 & +21 \\
\hline N2 & PO & $k 2$ & 98 & 2,18 & 0,19 & 1,33 & -15 & -3 & 15 & 92 & -6 \\
\hline$N 2$ & $P I$ & KO & 88 & 2,13 & 0,19 & 0,70 & 9 & 43 & -43 & 99 & +11 \\
\hline N2 & PI & $K I$ & 99 & 2,14 & 0,18 & 0,77 & 28 & 12 & -23 & 108 & +9 \\
\hline N2 & $\mathrm{PI}$ & $k 2$ & 108 & 2,18 & 0.19 & 1,18 & -6 & 6 & 8 & 122 & +14 \\
\hline N3 & PO & KO & 86 & 2,18 & 0,19 & 0,73 & 24 & 34 & -34 & 86 & 0 \\
\hline N3 & PO & $K I$ & 86 & 2,21 & 0,19 & 1,12 & -2 & 0 & 2 & 102 & +16 \\
\hline N3 & PO & $K 2$ & 82 & 2,19 & 0,18 & 1,41 & -3 & -23 & 23 & 122 & +30 \\
\hline N3 & $P I$ & KO & .82 & 2,18 & 0,18 & 0,53 & .80 & 62 & -62 & 102 & +20 \\
\hline N3 & $P I$ & $K I$ & 102 & 2,12 & 0,19 & 0,98 & -6 & 10 & -10 & 122 & +20 \\
\hline N3 & $P 1$ & $k 2$ & $12 ?$ & 2,16 & 0,17 & $I, 20$ & 22 & -22 & 18 & - & - \\
\hline & & & & & & & & & & & +244 \\
\hline * & & oduçä & it car & $a / r i a)$ & obtida & no e & io fa & tori & & & \\
\hline$* *$ & $\begin{array}{l}\text { Pr } \\
\text { to } \\
\text { im }\end{array}$ & oduçãa c & (t can & a/ha) & $\begin{array}{l}\text { que se } \\
\text { través }\end{array}$ & $\begin{array}{l}\text { doter } \\
\text { dos } 1\end{array}$ & , cos & o fos & Ee co & $\begin{array}{l}\text { rigido } \\
\text { tos) com }\end{array}$ & $\begin{array}{l}\text { elemen } \\
\text { dose }\end{array}$ \\
\hline
\end{tabular}




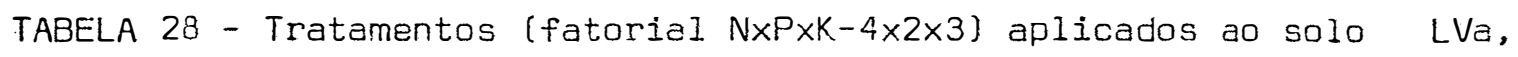
percentagens de $N$, P e K na folha +3 coletada aos 3 meses de idade, índices transformados do DRIS e a diferença entre as produções $(\triangle T C H)$, obtidas e esperadas através das corre ções pelo DRIS.

\begin{tabular}{|c|c|c|c|c|c|c|c|c|c|c|c|}
\hline & & & & & & & Ind & tran & $f$. & & \\
\hline Tra & tame & itos & TCH* & $\% N$ & $\% P$ & $\% \mathrm{k}$ & $N$ & $P$ & $k$ & TCH** & $\triangle T C H$ \\
\hline NO & PO & $K O$ & 40 & 2,17 & 0,22 & 1,55 & 21 & 27 & -27 & 50 & +10 \\
\hline NO & PO & $K I$ & 50 & 2,10 & 0,22 & 1,71 & -12 & 0 & 12 & 51 & +1 \\
\hline NO & PO & $\mathrm{K} 2$ & 61 & 2,19 & 0,23 & 1,84 & -22 & -9 & 22 & 54 & -7 \\
\hline NO & $P I$ & KO & $4 I$ & 2,06 & 0,22 & 1,71 & -23 & 23 & 18 & 59 & +18 \\
\hline NO & $\mathrm{Pl}$ & $K I$ & 43 & 2,09 & 0,22 & 1,73 & -18 & 0 & 18 & 46 & +3 \\
\hline NO & Pl & $K 2$ & 52 & 2,19 & 0,22 & 1,78 & -9 & -13 & 13 & 63 & +11 \\
\hline NI & PO & KO & 44 & 2,18 & 0,23 & 1,62 & -6 & 30 & -30 & 51 & +7 \\
\hline $\mathrm{NI}$ & PO & $K I$ & 51 & 2,10 & 0,22 & 1,73 & -17 & -3 & 17 & 44 & -7 \\
\hline $\mathrm{NI}$ & PO & $k 2$ & 54 & 2,21 & 0,23 & 1,73 & -4 & 4 & 0 & 64 & +10 \\
\hline NI & PI & KO & 59 & 2,21 & 0,22 & 1,55 & 32 & 6 & -32 & 46 & -13 \\
\hline NI & $P I$ & $K I$ & 46 & 2,16 & 0,23 & 1,90 & -36 & -9 & 36 & 65 & +19 \\
\hline$N I$ & $P I$ & $K 2$ & 63 & 2,24 & 0,24 & 1,80 & -16 & 16 & 6 & 68 & +5 \\
\hline N2 & PO & $K O$ & 49 & 2,22 & 0,23 & 1,68 & -6 & 17 & -17 & 44 & -5 \\
\hline N2 & PO & $\mathrm{KI}$ & 44 & 2,20 & 0,22 & 1,75 & -3 & -8 & 8 & 65 & +21 \\
\hline N2 & PO & $k 2$ & 64 & 2,33 & 0,24 & 1,84 & -5 & -3 & 5 & 62 & -2 \\
\hline N2 & $\mathrm{Pl}$ & KO & 53 & 2,15 & 0,22 & 1,55 & 15 & 28 & -28 & 65 & +12 \\
\hline N2 & $P I$ & $K I$ & 65 & 2,14 & 0,22 & 1,77 & -18 & 0 & 18 & 66 & +2 \\
\hline N2 & PI & $k 2$ & 68 & 2,29 & 0,24 & 1,87 & -18 & 18 & 18 & 72 & +4 \\
\hline N3 & PO & KO & 54 & 2,32 & 0,23 & 1,73 & 17 & -17 & -15 & 42 & -12 \\
\hline N3 & PO & $K I$ & 55 & 2,29 & 0,23 & 1,80 & 11 & $-I I$ & 9. & 60 & +11 \\
\hline N3 & PO & $k 2$ & 62 & 2,29 & 0,23 & 1,84 & 3 & -17 & 17 & 72 & +10 \\
\hline N3 & $P I$ & KO & 42 & 2,31 & 0,24 & 1,80 & -9 & 12 & -12 & 86 & +24 \\
\hline N3 & $P I$ & $k I$ & 66 & 2,25 & $C, 23$ & 1,77 & 0 & -6 & 6 & 72 & +6 \\
\hline N3 & $P I$ & $\mathrm{k} 2$ & 72 & 2,20 & 0,22 & 1,75 & -3 & -9 & 9 & - & - \\
\hline & & & & & & & & & & $\Sigma$ & +127 \\
\hline
\end{tabular}

* Produção ( $t$ cana/ha) obtida no enseio fatorial

** Produção (t cana/ha) que se obteria, caso fosse corrigido o eiemen to mais deficiente (através dos índices transformados) com a dose imediatamente superior. 


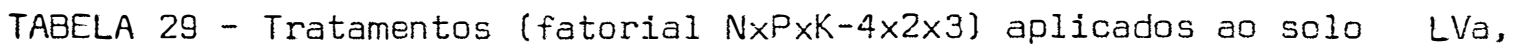
percentagens de $N, P$ e K na folha +3 coletada aos 4 meses de idade, Indices transformados do DRIS e a diferença entre as produções ( $\triangle T C H$ ), obtidas e esperadas através das corre ções pelo DRIS.

\begin{tabular}{|c|c|c|c|c|c|c|c|c|c|c|c|}
\hline & & & & & & & & & \\
\hline & & & \multirow[b]{2}{*}{$\mathrm{TCH}^{*}$} & \multirow[b]{2}{*}{$\% N$} & \multirow[b]{2}{*}{$\% P$} & \multirow[b]{2}{*}{$\% k$} & \multicolumn{3}{|c|}{ Ind.transf. } & \multirow[b]{2}{*}{$\mathrm{TCH} * *$} & \multirow[b]{2}{*}{$\triangle T C H$} \\
\hline \multicolumn{3}{|c|}{ Tratamentos } & & & & & $N$ & $P$ & $k$ & & \\
\hline NO & PO & KO & 40 & 2,01 & 0,18 & $1,0.4$ & 3 & 17 & -17 & 50 & +10 \\
\hline NO & PO & $K I$ & 50 & 2,06 & 0,19 & 1,24 & -6 & 6 & 6 & 51 & +1 \\
\hline NO & PO & $k 2$ & 61 & 2,10 & 0,20 & 1,05 & 3 & 29 & -29 & 54 & -7 \\
\hline NO & $P I$ & KO & 41 & 2,04 & 0,19 & 1,07 & -3 & 17 & -17 & 59 & +18 \\
\hline NO & $P I$ & $\mathrm{KI}$ & 43 & 2,04 & 0,19 & 1,24 & -9 & 9 & 9 & 46 & +3 \\
\hline NO & $P 1$ & $k 2$ & 52 & 2,50 & 0,19 & 1,29 & 37 & -37 & -3 & 63 & +11 \\
\hline$N I$ & PO & $\mathrm{KO}$ & 44 & 2,11 & 0,19 & 1,03 & 15 & 15 & -15 & 51 & +7 \\
\hline NI & PO & $\mathrm{KI}$ & 51 & 2,05 & 0,18 & 1,15 & 0 & 4 & -4 & 54 & +3 \\
\hline NI & $\mathrm{PO}$ & $k 2$ & 54 & 2,15 & 0,19 & 1,32 & -7 & -3 & 7 & 64 & +10 \\
\hline NI & $P I$ & $\mathrm{KO}$ & 59 & 2,18 & 0,20 & 1.17 & 0 & 12 & -12 & 46 & -13 \\
\hline NI & PI & $K I$ & 46 & 2,13 & 0,19 & 1,12 & 9 & 9 & -9 & 53 & +17 \\
\hline$N I$ & $P 1$ & $\mathrm{~K} 2$ & 63 & 2,13 & 0,20 & 1,36 & -14 & 6 & 14 & 68 & +5 \\
\hline N2 & PO & KO & 49 & 2,13 & 0,19 & 1,12 & 0 & 14 & -14 & 44 & -5 \\
\hline N2 & $P O$ & $K I$ & 44 & 2,14 & 0,19 & 1,30 & -9 & 0 & 3 & 55 & +11 \\
\hline N2 & PO & $k .2$ & 64 & 2,18 & 0,20 & 1,39 & -13 & -3 & 13 & 62 & -2 \\
\hline N2 & PI & KO & 53 & $2,1.1$ & 0,20 & ].,08 & -6 & 24 & -24 & 65 & +12 \\
\hline N2 & PI & $K I$ & 65 & 2,15 & 0,18 & 1,07 & 18 & 0 & -18 & 68 & +3 \\
\hline N2 & $P 1$ & $\mathrm{~K} 2$ & 68 & 2,15 & 0,20 & 1,30 & -9 & 9 & 9 & 72 & +4 \\
\hline N3 & PO & KO & 54 & 2,15 & 0, IS & 1,04 & 15 & 22 & -22 & 55 & +1 \\
\hline N3 & PO & $K I$ & 55 & 2,20 & 0,18 & 1,23 & 14 & -14 & 0 & 56 & +11 \\
\hline N3 & PO & $\mathrm{K} 2$ & 62 & 2,23 & 0,19 & 1,36 & 0 & -12 & 12 & 72 & +10 \\
\hline N3 & $P 1$ & $\mathrm{KO}$ & 42 & 2,23 & 0,20 & 1,08 & 9 & 25 & -25 & 86 & +24 \\
\hline N3 & $P I$ & $K I$ & 66 & 2,18 & 0,19 & 1,30 & -9 & -9 & 9 & 72 & +6 \\
\hline N3 & PI & $\mathrm{k} 2$ & 72 & 2,26 & 0,20 & 1,16 & $\overline{0}$ & 18 & -16 & - & - \\
\hline & & & & & & & & & & $\Sigma$ & +140 \\
\hline
\end{tabular}

Produção (t cana/ha! outida no einseía fatorial.

** Produção (t canarta) que se obteria, caso fosse corrigido o elemeri to mais deficiente (aträvés dos inndices trensformados) com a dose imediatamente superion. 
TABELA 30 - Tratamentos (fatorial $N \times P \times K-4 \times 2 \times 3$ ) aplicados ao solo LVa, percentagens de $N$, $P$ e $K$ na folha +3 coletada cos 5 meses de idade, indices transformados do DRIS a a diferença entre as produções $(\triangle T C H)$, chtidas e esperadas através das corre ções pelo DRIS.

\begin{tabular}{|c|c|c|c|c|c|c|c|c|c|c|c|}
\hline & & & & & & & Ind & - tran & $f$ & & \\
\hline Tra & tame & ntos & TCH* & $\% N$ & $\% P$ & $\% K$ & $N$ & $P$ & $K$ & TCH** & $\triangle T C H$ \\
\hline NO & $\mathrm{PO}$ & KO & 40 & 1,95 & 0,18 & 1,21 & 0 & 26 & -26 & 50 & +10 \\
\hline NO & PO & $K I$ & 50 & 1,98 & 0,17 & 1,44 & -9 & -23 & 23 & 43 & -7 \\
\hline NO & PO & $K 2$ & 61 & 2,05 & 0,18 & 1,47 & -10 & 0 & 16 & 54 & -7 \\
\hline NO & $P I$ & KO & 41 & 2,02 & 0,18 & 1,36 & -11 & 11 & -3 & 59 & +18 \\
\hline NO & $\mathrm{PI}$ & $K I$ & 43 & 2,04 & 0,18 & 1,38 & -3 & 0 & 3 & 46 & +3 \\
\hline NO & $\mathrm{PI}$ & $\mathrm{K} 2$ & 52 & 2,07 & 0,18 & 1,26 & 15 & 23 & -23 & 63 & +11 \\
\hline$N I$ & PO & KO & 44 & 1,96 & 0,28 & 1,24 & -12 & 28 & -28 & 51 & +7 \\
\hline $\mathrm{NI}$ & PO & $\mathrm{KI}$ & 51 & 2,03 & 0,18 & 1,29 & -3 & 19 & -19 & 54 & +3 \\
\hline NI & PO & $k 2$ & 54 & 2,03 & 0,18 & 1.41 & -9 & -3 & 9 & 64 & +10 \\
\hline $\mathrm{NI}$ & $\mathrm{Pl}$ & KO & 59 & $2,1.5$ & 0,18 & 1,26 & 31 & 15 & -31 & 46 & -13 \\
\hline $\mathrm{NI}$ & $\mathrm{Pl}$ & $K I$ & 46 & 2,10 & 0,18 & 1,38 & 3 & 5 & -5 & 63 & +17 \\
\hline NI & $\mathrm{PI}$ & $\mathrm{K} 2$ & 63 & 2,032 & 0,18 & 1.44 & -15 & 9 & 15 & 63 & +5 \\
\hline N2 & PO & $\mathrm{kO}$ & 49 & 2,02 & 0,17 & 1,36 & 3 & -7 & 7 & 53 & +4 \\
\hline N2 & PO & $K I$ & 44 & 2,07 & 0,17 & 1.44 & -3 & -11 & 11 & 35 & +21 \\
\hline N2 & PD & $\mathrm{k} 2$ & 64 & 2,09 & 0,18 & 1.45 & 0 & -12 & 12 & 68 & +4 \\
\hline N2 & $P I$ & KO & 53 & 2,06 & 0,18 & 1,20 & 29 & 27 & -29 & 65 & +12 \\
\hline $\mathrm{N} 2$ & $\mathrm{Pl}$ & $\mathrm{KI}$ & 65 & 2,07 & 0,18 & 1,35 & 0 & 8 & -8 & 68 & +3 \\
\hline N2 & PI & $k 2$ & 68 & 2,10 & 0,28 & 1,50 & -6 & -20 & 20 & 72 & +4 \\
\hline N3 & PO & KO & 54 & 2,02 & 0,18 & 1,15 & 24 & 44 & -44 & 55 & +1 \\
\hline N3 & PO & $K . I$ & 55 & 2,08 & 0,18 & 1,30 & 14 & 6 & -14 & 82 & +7 \\
\hline N3 & PO & $\mathrm{K} 2$ & 62 & 2,01 & 0,17 & 1,44 & -9 & -17 & 27 & 72 & +10 \\
\hline N3 & $P 1$ & KO & 42 & 2,00 & 0,19 & 1,21 & 15 & 39 & -39 & 66 & +24 \\
\hline N3 & $\mathrm{PI}$ & $k I$ & 58 & 2,04 & 0,18 & 1,44 & -11 & -9 & $1 i$ & 72 & +6 \\
\hline N3 & $\mathrm{PI}$ & $k 2$ & 72 & 2,05 & 0,19 & 1,33 & -12 & 18 & -18 & - & - \\
\hline & & & & & & & & & & $\Sigma$ & +153 \\
\hline
\end{tabular}

* Produção (t cana/ha) obtida no ensajo fatorial

* Produção (t cana/ha) que se obtería, caso fosse corrigido o ejemen to mais deficionte ítreves dos índices transformados oom a dose imediatamente superior. 
TABELA 31 - Tratamentos (fatorial $N \times P \times K-4 \times 2 \times 3$ ) aplicados ao solo LVa, percentagens de $N, P$ e $K$ na folha +3 coletada aos 6 meses de idade, índices transformados do DRIS e a diferença entre as produções $(\triangle T C H)$, obtidas e esperadas através das corre ções pelo DRIS.

\begin{tabular}{|c|c|c|c|c|c|c|c|c|c|c|c|}
\hline \multirow{2}{*}{\multicolumn{3}{|c|}{ Tratamentos }} & \multirow{3}{*}{$\frac{\mathrm{TCH}^{*}}{40}$} & \multirow{3}{*}{$\frac{\% N}{1.91}$} & \multirow{3}{*}{$\frac{\% P}{0,17}$} & \multirow{3}{*}{$\frac{3 \mathrm{~K}}{1.38}$} & \multicolumn{3}{|c|}{ Ind.transf. } & \multirow[b]{2}{*}{ TCHit* } & \multirow[b]{2}{*}{$\triangle T C H$} \\
\hline & & & & & & & \multirow{2}{*}{$\frac{N}{10}$} & \multirow{2}{*}{$\frac{P}{6}$} & \multirow{2}{*}{$\frac{k}{-10}$} & & \\
\hline NO & $\mathrm{PO}$ & KO & & & & & & & & 50 & +10 \\
\hline nO & PO & $K I$ & 50 & 2,00 & 0,18 & 1,54 & 6 & -10 & 10 & 43 & -7 \\
\hline NO & $\mathrm{PO}$ & $k 2$ & 61 & 2,01 & 0,17 & 1,42 & 29 & -29 & -3 & 52 & -9 \\
\hline NO & PI & KO & 41 & 1,92 & 0,18 & 1,42 & 0 & 10 & -10 & 43 & +2 \\
\hline NO & PI & $\mathrm{KI}$ & 43 & 1,90 & 0,18 & 1,51 & -17 & 17 & 9 & 46 & +3 \\
\hline NO & $P I$ & $\mathrm{~K} 2$ & 52 & 1,72 & 0,19 & $I, 39$ & -4.5 & 45 & -9 & 63 & +11 \\
\hline NI & PO & KO & 44 & 2,02 & 0,18 & \pm .27 & 42 & 42 & -42 & 51 & +7 \\
\hline NI & PO & $K I$ & 51 & 1,91 & $0, I B$ & 1,39 & 0 & 14 & -14 & 54 & +3 \\
\hline$N I$ & PO & $k 2$ & 54 & 2,00 & 0,28 & 1,51 & 7 & -7 & 3 & 68 & +14 \\
\hline $\mathrm{NI}$ & PI & KO & 59 & 2,03 & 0,18 & 1,32 & 38 & 30 & --38 & 46 & -13 \\
\hline$N I$ & PI & $K I$ & 46 & 1,95 & 0,17 & 1,50 & 6 & -10 & 10 & 65 & +19 \\
\hline$N I$ & $P I$ & $k 2$ & 63 & 1,95 & 0,18 & 1,56 & -12 & 3 & 12 & 58 & +5 \\
\hline N2 & PO & KO & 49 & 1,99 & 0,17 & 1,38 & 20 & -6 & -20 & 44 & -5 \\
\hline $\mathrm{N} 2$ & PO & $K I$ & 44 & 1,93 & 0,18 & 1,59 & -18 & -12 & 18 & 55 & +11 \\
\hline N2 & $\mathrm{PO}$ & $\mathrm{K} 2$ & 64 & 1,96 & 0,18 & 1,63 & -18 & -22 & 22 & 58 & +4 \\
\hline $\mathrm{N2}$ & PI & KO & 53 & $1,9.9$ & 0,18 & 1,38 & 18 & 23 & -23 & 65 & +12 \\
\hline N2 & $P I$ & $\mathrm{KI}$ & 65 & 1,97 & 0,18 & 1,45 & -6 & 8 & -8 & 68 & +3 \\
\hline N2 & PI & $k 2$ & 68 & 2,03 & 0,18 & 1,56 & 9 & -13 & 13 & 72 & +4 \\
\hline N3 & PO & KO & 54 & 1,92 & 0.19 & 1,47 & -20 & 20 & -.12 & 55 & +1 \\
\hline N3 & $P O$ & $K I$ & 55 & 2,00 & 0,18 & 1,51 & 7 & -7 & 3 & 56 & +11 \\
\hline N3 & PO & $k 2$ & 82 & 2,02 & 0,18 & 1,47 & 8 & 6 & -8 & 72 & +10 \\
\hline N3 & PI & $\mathrm{KO}$ & 42 & 2,01 & 0,18 & 1,39 & 21 & 21 & -21 & 66 & $\div 24$ \\
\hline N3 & $P I$ & $K I$ & 86 & 2,03 & 0,17 & 1,39 & 24 & -15 & -24 & 72 & +6 \\
\hline N3 & PI & $k 2$ & 72 & 2,00 & 0,18 & 1,63 & -15 & -15 & 15 & - & - \\
\hline & & & & & & & & & & $\Sigma$ & +125 \\
\hline
\end{tabular}

* Produção (t cana/ha) obtida no ensaio fatorial

** Produção (t cana/ha) que se obteria, caso fosse corrigido o elemento mais deficiente (através dos índices transformados com a dose imediatamente superior. 


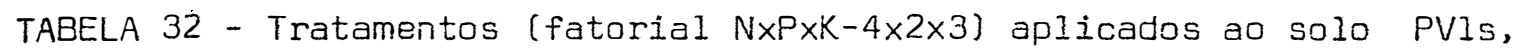
percentagens de $N, P$ e $K$ na folha +3 coletada aos 3 meses de idade, índices transformados do DRIS e a diferença entre as produções $(\triangle T C H)$, obtidas e esperadas através das corre ções pelo DRIS.

\begin{tabular}{|c|c|c|c|c|c|c|c|c|c|c|c|}
\hline & & & & & & & ind & .tran & sf. & & \\
\hline Tra & tame & ntos & TCH* & $\because N$ & $\% P$ & $\% K$ & $N$ & $P$ & $k$ & TCH** & $\triangle T C H$ \\
\hline NO & $\mathrm{PO}$ & KO & 49 & 2,25 & 0,24 & 1,95 & 13 & -13 & 1 & 66 & +17 \\
\hline NO & PO & $K I$ & 60 & 2,21 & 0,26 & 2,18 & -31 & -3 & 31 & 64 & +4 \\
\hline NO & PO & $k 2$ & 64 & 2,10 & 0,27 & 2,24 & -51. & 27 & 51 & 70 & +6 \\
\hline NO & $P 1$ & KO & 55 & 2,12 & 0,28 & 2,09 & -43 & 43 & 12 & 66 & +11 \\
\hline NO & $P I$ & $K I$ & 62 & 2,30 & 0,27 & 2,03 & -15 & 15 & -12 & 66 & +4 \\
\hline NO & PI & $k 2$ & 60 & 2,26 & 0,26 & 2,15 & -22 & -6 & 22 & 67 & +7 \\
\hline $\mathrm{NI}$ & PO & KO & 63 & 2,24 & 0,25 & 1,91 & 11 & -3 & -11 & 64 & +1 \\
\hline NI & $\mathrm{PO}$ & $\mathrm{KI}$ & 64 & 2,35 & 0,27 & 2,04 & 3 & 8 & -8 & 70 & +6 \\
\hline$N I$ & PO & $k 2$ & 70 & 2,26 & 0,27 & 2,12 & -19 & 19 & 15 & 68 & -2 \\
\hline NI & $P I$ & KO & 66 & 2,16 & 0,26 & 1,89 & -18 & 26 & -26 & 66 & 0 \\
\hline$N I$ & PI & $K I$ & 66 & 2,28 & 0,25 & 2,21 & -15 & -33 & 33 & 54 & -12 \\
\hline NI & $P I$ & $\times 2$ & 67 & 2,14 & 0,25 & 2,10 & -27 & -9 & 27 & 32 & +15 \\
\hline N2 & PO & KO & 56 & 2,19 & 0,26 & 1,97 & -17 & 17 & -12 & 54 & -2 \\
\hline N2 & PO & $\mathrm{KI}$ & 64 & 2,29 & 0,26 & 2,12 & -9 & -15 & 15 & 54 & -10 \\
\hline N2 & PO & $\mathrm{K} 2$ & 68 & 2,12 & 0,24 & 2,06 & -27 & -24 & 27 & 73 & +5 \\
\hline N2 & $P I$ & $\mathrm{KO}$ & 74 & 2,27 & 0,25 & 1,89 & 17 & 9 & -17 & 54 & -20 \\
\hline $\mathrm{N} 2$ & PI & $K I$ & 54 & 2,32 & 0,27 & 2,21 & -20 & 0 & 20 & 79 & +25 \\
\hline N2 & $P I$ & $k 2$ & 82 & 2,32 & 0,26 & 1,98 & 8 & 3 & -8 & 75 & -7 \\
\hline N3 & PO & KO & 54 & 2,39 & 0,26 & 2,00 & -3 & 13 & -13 & 63 & +9 \\
\hline N3 & $P O$ & $K I$ & 63 & 2,20 & 0.25 & 1,99 & -7 & 3 & 7 & 79 & +16 \\
\hline N3 & PO & $\mathrm{K} 2$ & 73 & 2,29 & 0,24 & 2,10 & 21 & -39 & 39 & 75 & +2 \\
\hline N3 & $P I$ & $\mathrm{KO}$ & 6 & 2,26 & 0,25 & 2,07 & -6 & -14 & 14 & 79 & +19 \\
\hline N3 & $\mathrm{Pl}$ & $x I$ & 79 & 2,25 & 0,25 & 2,00 & 5 & -10 & 10 & 75 & -7 \\
\hline N3 & $P I$ & $\mathrm{~K} 2$ & 75 & 2,33 & 0,27 & 2,30 & -30 & -24 & 30 & - & - \\
\hline & & & & & & & & & & $\Sigma$ & +30 \\
\hline
\end{tabular}

* Produçä́o (t cana/ha) obtida no ensaic fatorial.

** Produça (t cana/ha) que se obterie, caso fosse corrigido o elemen to mais deficiente (através dos índices transformados) com a dose imediatamente superior. 


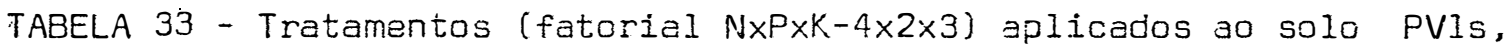
percentagens de $N, P$ e $K$ na folha +3 coletada aos 4 meses de idade, indices transformados do DRIS e a diferença entre as produções $(\triangle T C H)$, obtidas e esperadas através das corre ções pelo DRIS.

\begin{tabular}{|c|c|c|c|c|c|c|c|c|c|c|c|}
\hline & & & & & & & Ind & - trar & sf. & & \\
\hline Tra & tame & ntos & $\mathrm{TCH}^{*}$ & $\% N$ & $\% F$ & $\% K$ & $N$ & $P$ & $k$ & TCH** & $\triangle T C H$ \\
\hline NO & PO & KO & 49 & 2,01 & 0,18 & 1,32 & -3 & -5 & 3 & 55 & +6 \\
\hline NO & PO & $\mathrm{KI}$ & 60 & 2,05 & 0,19 & 1,51 & -22 & -6 & 20 & 64 & +4 \\
\hline NO & PO & $k 2$ & 64 & 2,21 & 0,20 & 1,45 & -6 & 0 & 6 & 70 & +5 \\
\hline NO & $P 1$ & $\mathrm{KO}$ & 55 & 2,16 & 0,20 & 1,39 & -7 & 7 & 3 & 66 & +11 \\
\hline NO & PI & $K I$ & 62 & 2,10 & 0,20 & 1,39 & -8 & 8 & 6 & 66 & +4 \\
\hline NO & $P I$ & $K 2$ & 60 & 2,01 & 0,18 & 1,51 & -23 & -21 & 23 & 67 & +7 \\
\hline N1 & PO & KO & 63 & 2,01 & 0,17 & 1,17 & 18 & -13 & -12 & 64 & +1 \\
\hline $\mathrm{NI}$ & PO & $K I$ & 54 & 2,26 & 0,19 & 1,39 & 11 & -.11 & 3 & 56 & +2 \\
\hline NI & PO & $k 2$ & 70 & 2,20 & 0,19 & 1,39 & 8 & -8 & 6 & 57 & -3 \\
\hline$N I$ & PI & $\mathrm{KO}$ & $6 E$ & 2,24 & 0,22 & 1,47 & -17 & 17 & 3 & 74 & +8 \\
\hline $\mathrm{NI}$ & PI & $K I$ & 66 & 2,37 & 0,21 & 1,25 & 25 & 9 & -25 & 67 & $+I$ \\
\hline NI & PI & $k 2$ & 67 & 2,00 & 0,20 & 1,48 & -24 & 12 & 24 & 82 & +15 \\
\hline N2 & PO & $K O$ & 56 & 2,27 & 0,20 & 1,30 & 12 & 5 & -12 & 64 & +8 \\
\hline N2 & PO & $K I$ & 64 & 2,16 & 0,19 & 1,50 & 3 & -19 & 19 & 54 & -10 \\
\hline N2 & PO & $k 2$ & 68 & 2,25 & 0,18 & 1,53 & 27 & -33 & 33 & 82 & +14 \\
\hline N2 & $P I$ & KO & 74 & 2,24 & 0,21 & 1,45 & -10 & 10 & 0 & 80 & -14 \\
\hline $\mathrm{N} 2$ & $P I$ & $K I$ & 54 & 2,14 & 0,21 & 1,38 & -13 & 13 & -3 & 79 & +25 \\
\hline N2 & $\mathrm{Pl}$ & $\times 2$ & 82 & 2,18 & 0,21 & 1,33 & -3 & 13 & -13 & 75 & -7 \\
\hline N3 & PO & KO & 54 & 2,22 & 0,19 & $i, 24$ & 18 & -6 & -18 & 63 & +9 \\
\hline N3 & PO & $K I$ & 63 & 2,21 & 0,19 & $I, 47$ & 9 & -17 & 17 & 79 & +16 \\
\hline N3 & PO & $k 2$ & 73 & 2,16 & 0,17 & 1,30 & 25 & -25 & 3 & 75 & +2 \\
\hline N3 & $P 1$ & KO & 60 & 2,23 & 0,21 & 1,33 & -8 & 14 & -14 & 79 & +19 \\
\hline N3 & PI & $K I$ & 79 & 2,42 & 0,20 & 1,54 & 17 & -17 & 9 & 75 & -4 \\
\hline N3 & $P I$ & $k 2$ & 75 & 2,37 & 0,22 & 1,50 & -8 & 8 & 0 & - & - \\
\hline
\end{tabular}

$\Sigma=+120$

* Produção (t cana/ha) obtida no ensaio fatoridal.

** Produção ( $t$ cana/ha) que se obtoria, caso fosse corrisido o elemen to mais deficiente (através dos índices transformicidos? com a dose imediatamente superior. 
TABELA 34 - Tratamentos (fatorial $N \times P \times K-4 \times 2 \times 3$ ) aplicados ao solo PVIs, percentagens de $N$, P e K na folta +3 coletada aos 5 meses de idade, indices transformados do DRIS e a diferença entre as produções $(\triangle T C H)$, obtidas e esperadas através das correções pelo DRIS.

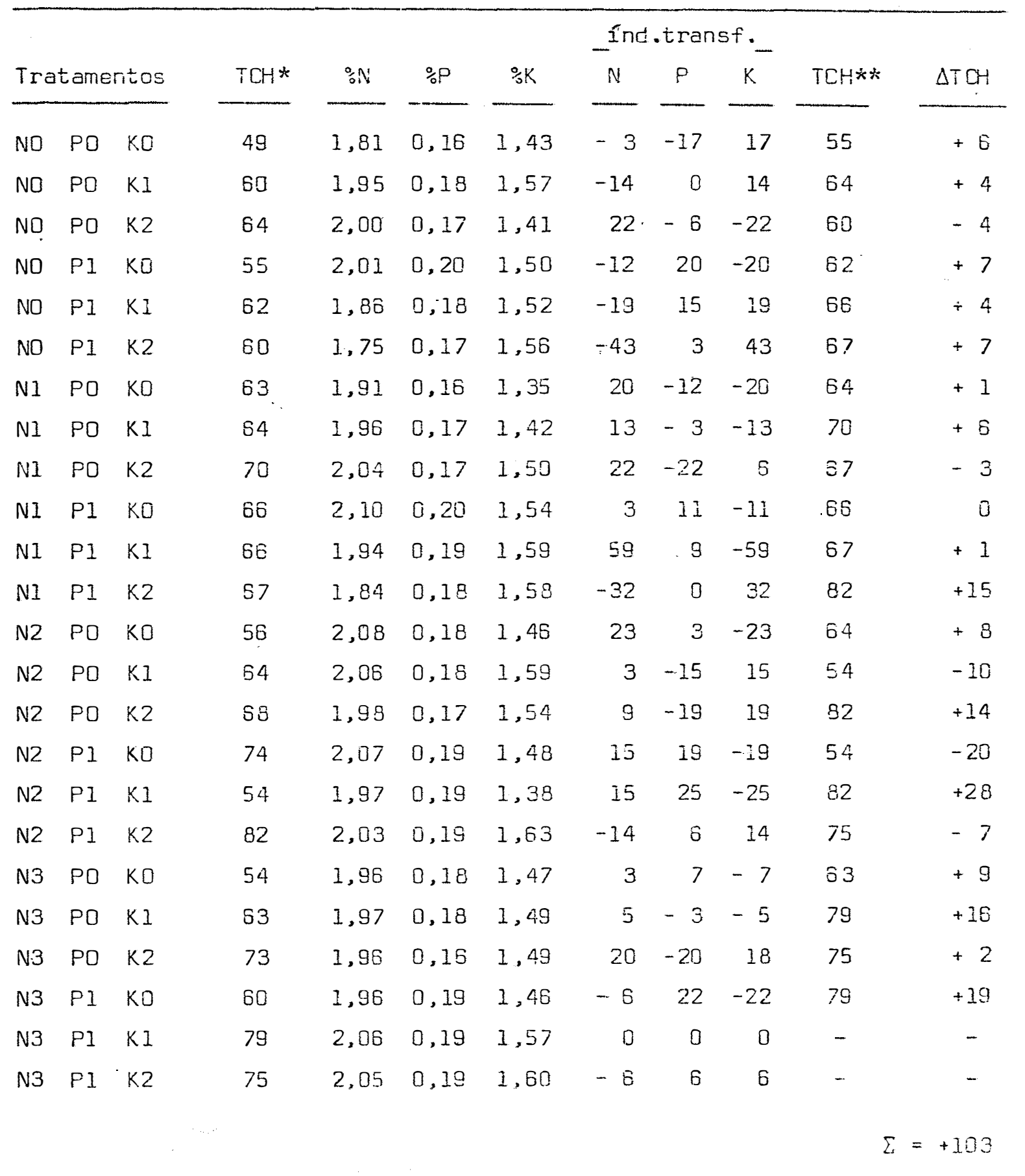

\footnotetext{
* Produção (t cana/hal ootida no ensaio fatorial

** Produção (t cana/ha) que se ubteria, caso fosse corrigido o elemen to mais deficiente (através jos índices transformados? com a jose imediatamente superior.
} 


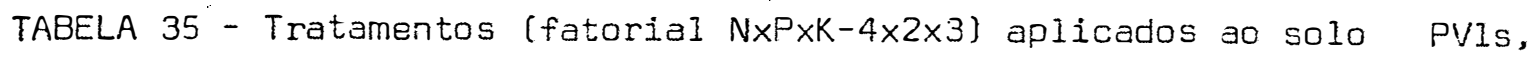
percentagens de $N$, $P$ e $K$ na folha +3 coletada aos $a$ meses de idade, índices transformados do DRIS e a diferença entre as produções $(\triangle T C H)$, obtidas $\varepsilon$ esperades através das correçẽes pelo BRIS.

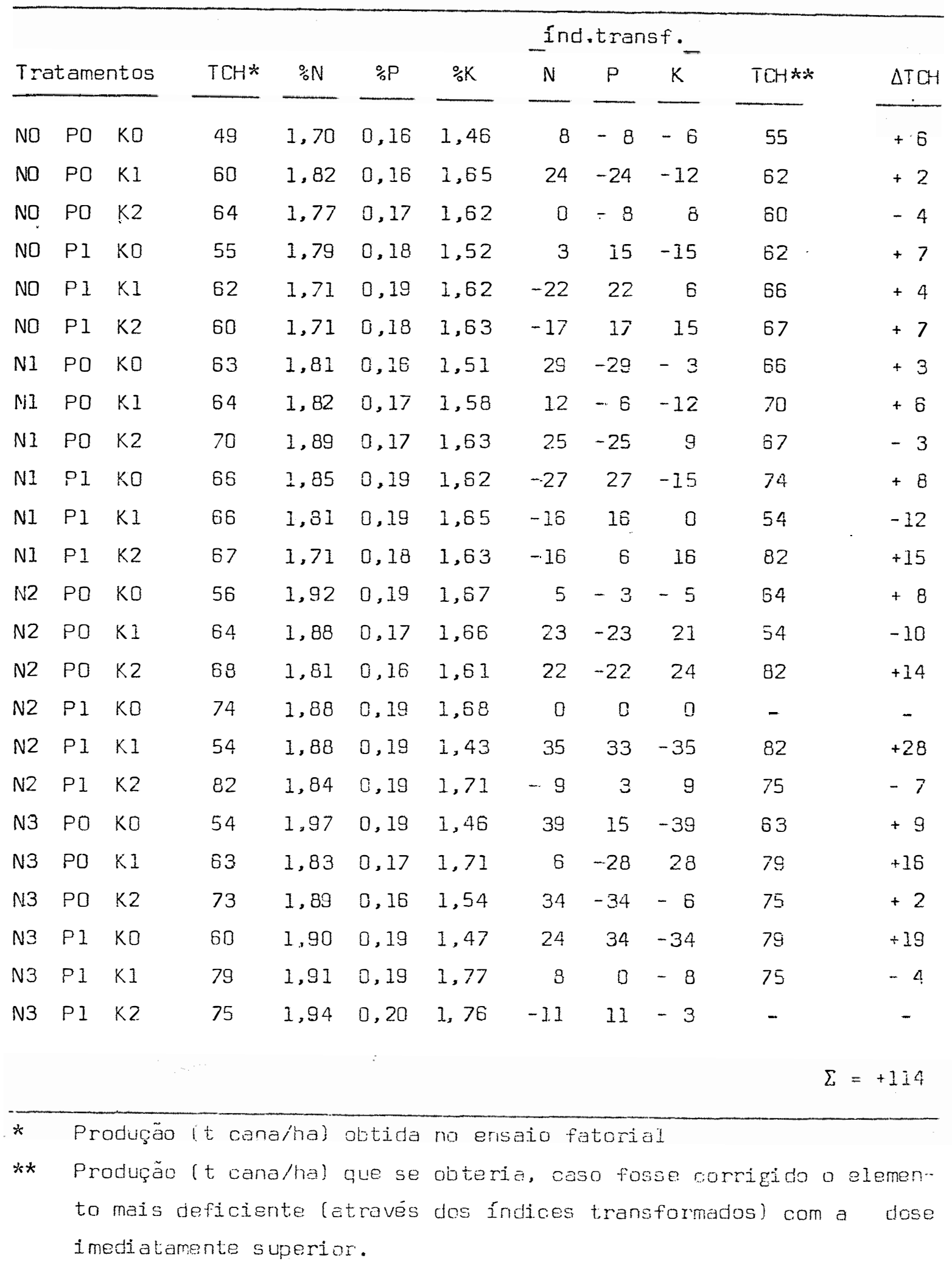


TABELA 36 - Tratamentos (fatorial $N \times P \times K-4 \times 2 \times 3$ ) aplicados ao solo LR, per centagens de $N$, $P$ e $K$ na foiha + 3 coletada aos 3 meses de idade, indices transformados do DRIS e a diferença entre as produções $(\triangle T C H)$, obtidas e esperadas atravēs das correçōes pelo DRIS.

\begin{tabular}{|c|c|c|c|c|c|c|c|c|c|c|c|}
\hline & & & & & & & Ind & tran & $5 \div$ & & \\
\hline Tra & tame & ntos & TCH* & $\% N$ & $\because P$ & $\% k$ & $N$ & $P$ & $K$ & TCHA* & $\triangle T C H$ \\
\hline NO & PO & $\mathrm{KO}$ & 54 & 1,98 & 0,19 & 1,23 & -19 & 19 & -9 & 62 & $+\overline{8}$ \\
\hline NO & PO & $K I$ & 57 & 1,78 & 0,18 & 1,48 & -29 & 15 & 29 & 48 & -3 \\
\hline NO & PO & $\mathrm{K} 2$ & 48 & 2,07 & 0,19 & 1,36 & -13 & 13 & 12 & 52 & +14 \\
\hline no & PI & KO & 65 & 1,87 & 0,19 & 1,23 & -29 & 29 & -3 & 72 & +6 \\
\hline NO & PI & $K I$ & 62 & 2,11 & 0,18 & 1,39 & -10 & 0 & 10 & 66 & +4 \\
\hline NO & $\mathrm{Pl}$ & $\mathrm{K} 2$ & 54 & 1,36 & 0,19 & 1,43 & -26 & 18 & 26 & 70 & +16 \\
\hline NI & PO & $\mathrm{KO}$ & 52 & 2,22 & 0,18 & 1,28 & 4 & -6 & -4 & 72 & +10 \\
\hline NI & PO & $K I$ & 48 & 2,23 & 0,18 & 1,07 & 26 & 12 & -28 & 62 & +14 \\
\hline N1 & PO & $K 2$ & 62 & 2,21 & 0,17 & $I, 29$ & 13 & -13 & -9 & 70 & +8 \\
\hline$N I$ & $\mathrm{PI}$ & KO & 72 & 2,24 & 0,18 & 1,20 & 12 & 6 & -12 & SG & -6 \\
\hline $\mathrm{NI}$ & $P I$ & $K I$ & 66 & 2,34 & 0,10 & 1,39 & 5 & -5 & 3 & 70 & +4 \\
\hline $\mathrm{NI}$ & PI & $k 2$ & io & 2,21 & 0,18 & 1,13 & 12 & 12 & -12 & 83 & +13 \\
\hline N2 & PD & KO & 63 & 2,28 & 0,18 & 0,96 & 43 & 36 & -43 & 62 & -1 \\
\hline N2 & PO & $K I$ & 62 & 2,25 & 0,18 & 1,14 & 20 & 15 & -20 & 64 & +2 \\
\hline N2 & $\mathrm{PO}$ & $k 2$ & 64 & 2,27 & 0,18 & 1,25 & 9 & -9 & -9 & 83 & +19 \\
\hline $\mathrm{N} 2$ & $P I$ & KO & 74 & 2,28 & 0,19 & 1,21 & 13 & 9 & -13 & 65 & -8 \\
\hline N2 & $P I$ & $k 1$ & 65 & 2,31 & 0,17 & 1,14 & 29 & -6 & -29 & 83 & +18 \\
\hline N2 & $P I$ & $k 2$ & 83 & 2,31 & 0,18 & 1,46 & 3 & -13 & 13 & 80 & -3 \\
\hline N3 & PO & Ko & 69 & 2,37 & 0,19 & 1,32 & 6 & 0 & -6 & 57 & -12 \\
\hline N3 & PO & $K I$ & 57 & 2,26 & 0,17 & 1,16 & 19 & -9 & -19 & 68 & +11 \\
\hline N3 & PO & $k 2$ & 68 & 2,37 & 0,19 & I. 23 & 17 & 3 & -17 & 80 & +12 \\
\hline N3 & PI. & $K O$ & 62 & 2,34 & 0,19 & 1,23 & 14 & 8 & -14 & 69 & +7 \\
\hline N3 & PI & $K I$ & 69 & 2,28 & 0,18 & 1,14 & 23 & 9 & -23 & 80 & +11 \\
\hline N3 & $P I$ & $k 2$ & 80 & 2,32 & 0,18 & 1,34 & 9 & -9 & -3 & - & - \\
\hline & & & & & & & & & & & +137 \\
\hline
\end{tabular}

* Produção (t canaiha) obtida no enseio fatorial.

** Produção (t cana/ha) que se obteria, caso fosse corrigido o alemento mais deficiente (através dos índices transformados) com a dose imediatamente superior. 


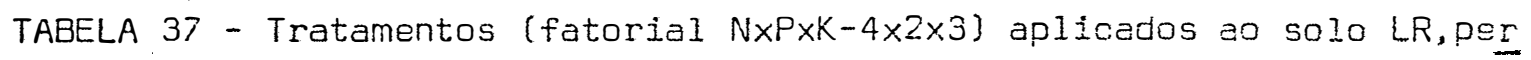
centagens de $\mathrm{N}, \mathrm{P}$ e $\mathrm{K}$ na folha +3 coletada aos 4 meses de idade, indices transformados do DRIS e a diferença entre as produções $(\triangle T C H)$, obtidas e esperadas através das correções peIo DRIS.

\begin{tabular}{|c|c|c|c|c|c|c|c|c|c|c|c|}
\hline \multirow{2}{*}{\multicolumn{3}{|c|}{ Tratamentos }} & \multirow{3}{*}{$\frac{\mathrm{TCH}^{*}}{54}$} & \multirow{3}{*}{$\frac{\% N}{1,35}$} & \multirow{3}{*}{$\frac{\% P}{0,17}$} & \multirow{3}{*}{$\frac{\% K}{1,30}$} & \multicolumn{3}{|c|}{ Ind.transf. } & \multirow{3}{*}{$\frac{T C H * *}{62}$} & \multirow{3}{*}{$\begin{array}{r}\triangle T C H \\
+8\end{array}$} \\
\hline & & & & & & & \multirow{2}{*}{$\frac{N}{-57}$} & \multirow{2}{*}{$\frac{P}{57}$} & \multirow{2}{*}{$\frac{k}{-15}$} & & \\
\hline NO & PO & $\mathrm{KO}$ & & & & & & & & & \\
\hline NO & PO & $K I$ & 57 & 1,55 & 0,19 & 1,30 & -42 & 58 & -58 & 48 & -3 \\
\hline NO & PO & $k 2$ & 48 & 1,48 & 0,18 & 1,41 & -39 & 39 & -3 & 62 & +14 \\
\hline NO & PI & KO & 66 & 1,47 & 0,18 & 1,32 & -42 & 42 & -30 & 72 & +8 \\
\hline NO & $P I$ & $k 1$ & 62 & 1,52 & 0,17 & 1,40 & 0 & 18 & -18 & 54 & -8 \\
\hline NO & $P I$ & $\mathrm{~K} 2$ & 54 & 1,49 & 0.19 & 1,41 & -47 & 47 & -12 & 70 & +16 \\
\hline NI & $\mathrm{PO}$ & $\mathrm{KC}$ & 62 & 1,74 & 0,18 & 1,30 & 24 & -32 & 32 & 72 & +10 \\
\hline NI &.$P O$ & $\mathrm{KI}$ & 48 & 1,76 & 0,19 & 1,13 & 39 & 85 & -85 & 62 & +14 \\
\hline NI & PO & $k 2$ & 62 & 1,71 & 0,19 & 1,43 & -12 & 28 & -28 & 64 & +2 \\
\hline$N I$ & $P 1$ & $\mathrm{KO}$ & 72 & 1,76 & 0,18 & 1,50 & 6 & 0 & -6 & 66 & -6 \\
\hline NI & PI & $K I$ & 66 & 1,81 & 0,18 & 1,40 & 23 & 14 & -23 & 70 & +4 \\
\hline $\mathrm{NI}$ & $P I$ & $k 2$ & 70 & 1,76 & 0,18 & 1,35 & 24 & 26 & -26 & 83 & +13 \\
\hline N2 & PO & KO & 53 & 1,72 & 0,17 & 1,23 & 37 & 18 & -37 & 62 & -1 \\
\hline N2 & PO & $K I$ & 62 & 1,95 & 0,19 & 1,35 & 44 & 42 & -.44 & 64 & +2 \\
\hline N2 & $P O$ & $k 2$ & 64 & $1,92$. & 0,17 & 1,46 & 29 & -29 & -27 & 83 & +13 \\
\hline N2 & $P I$ & KO & 74 & 1,95 & 0,19 & 1,47 & 26 & $\hat{o}$ & -20 & 65 & -9 \\
\hline N2 & $P 1$ & $K I$ & 65 & 1,86 & 0,18 & 1,27 & 48 & 24 & -48 & 83 & +18 \\
\hline N2 & $P I$ & $k 2$ & 83 & 1,85 & 0,19 & 1,54 & 3 & 15 & -15 & 80 & -3 \\
\hline N3 & PO & KO & 69 & 2,12 & 0,18 & 1,40 & 60 & -18 & -60 & 57 & -12 \\
\hline N3 & PO & $K I$ & 57 & 1,85 & 0,17 & 1.51 & 56. & 18 & -56 & 68 & +11 \\
\hline N3 & PO & $k 2$ & 68 & 1,84 & 0,19 & 1,57 & 3 & 5 & -5 & 80 & +12 \\
\hline N3 & $P I$ & KO & 62 & 1,95 & 0,19 & 1,25 & 60 & 62 & -62 & 69 & +7 \\
\hline N3 & $P I$ & $K I$ & 69 & 2,35 & 0,19 & 1,32 & 34 & $-1 \overline{8}$ & -94 & 80 & +11 \\
\hline N3 & $P 1$ & $k 2$ & 80 & 1,83 & 0,20 & 1,88 & 0 & 2 & -2 & - & $+1 \overline{19}$ \\
\hline
\end{tabular}

* Produção (t cana/ha) obtida no ensaio fatorial

*x Produção (t canciha) que se obteria, caso fosee corrigido o elemento mais deficiente (através dos f́ndices transformadosi con a dose imediatamente superior. 


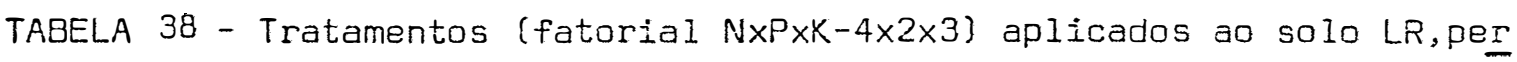
centagens de $N$, P \& $K$ na folha +3 coletada aos 5 meses de idade, indices transformados do DRIS e a diferença entre as produções $(\triangle T C H)$, obtidas e esperadas através das correções pelo DRIS.

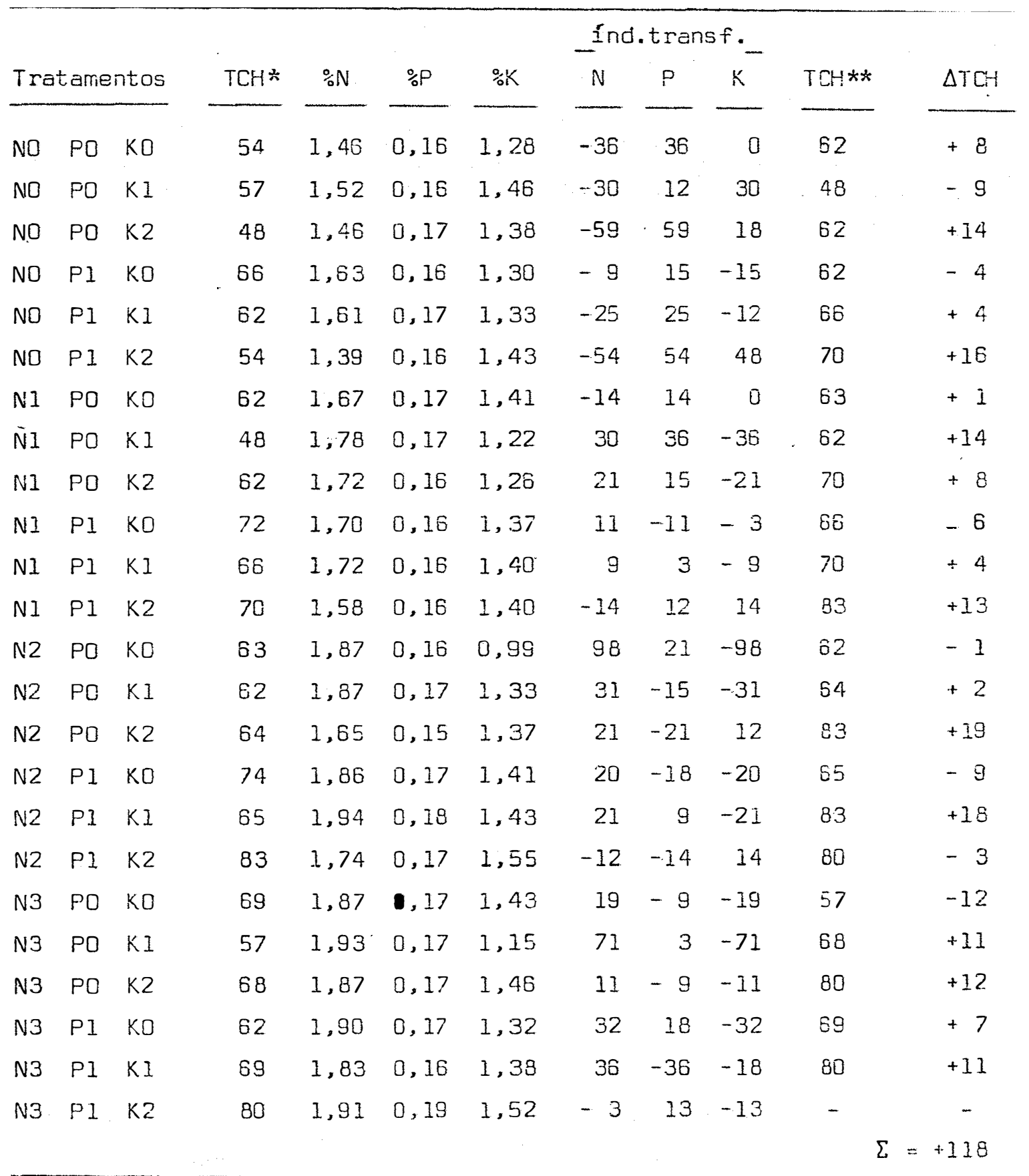

* Produção (t cana/ha) obtida no ensaio fatorial

* Pruduçón (t cana/ha) que se obteria, caso fosse corrigido o elemen to mais deficiente (através dos índices transformados) com a cose imediatamente superior. 
TABELA 39 - Tratamentos (fatorial $N \times P \times K-4 \times 2 \times 3$ ) aplicados ao solo LR,per centagens de $N$, P e K na folha +3 coletada aos 6 meses de idade, indices transformados do DRIS e a diferença entre as produções $(\triangle T C H)$, óttidas e esperadas através das correções pelo DRIS.

\begin{tabular}{|c|c|c|c|c|c|c|c|c|c|c|c|}
\hline \multirow{2}{*}{\multicolumn{3}{|c|}{ Tratamentos }} & \multirow{3}{*}{$\frac{\mathrm{TCH}^{*}}{54}$} & \multirow{3}{*}{$\frac{\% N}{1,38}$} & \multirow{3}{*}{$\frac{\% P}{0,16}$} & \multirow{3}{*}{$\frac{\% k}{1.63}$} & \multicolumn{3}{|c|}{ Ind.transf._. } & \multirow{3}{*}{$\frac{T C H * *}{62}$} & \multirow{3}{*}{$\begin{array}{r}\triangle T C H \\
+8\end{array}$} \\
\hline & & & & & & & \multirow{2}{*}{$\frac{N}{-S}$} & \multirow{2}{*}{$\frac{P}{9}$} & \multirow{2}{*}{$\frac{k}{9}$} & & \\
\hline NO & PO & KO & & & & & & & & & \\
\hline NO & PO & $K I$ & 57 & 1,41 & 0,15 & 1,59 & 8 & -8 & 6 & 62 & +5 \\
\hline ND & PO & $k 2$ & 48 & 1,35 & 0, is & 1,65 & -14 & 12 & 14 & 52 & $\div 14$ \\
\hline NO & $\mathrm{PI}$ & KO & 66 & 1,30 & 0,14 & 1,45 & -3 & 3 & 3 & 72 & +6 \\
\hline No & $P I$ & KI & 62 & 1,37 & 0,15 & 1,52 & -5 & 5 & -3 & 66 & +4 \\
\hline NO & P1 & $\mathrm{k} 2$ & 54 & 1,28 & 0,15 & 1,49 & -11 & 11 & 6 & 70 & +16 \\
\hline$N I$ & PO & KO & 62 & 1,44 & 0,16 & 1.57 & 3 & 3 & -3 & 48 & -14 \\
\hline NI & PO & $K 1$ & 48 & 1,37 & 0,16 & 1.45 & -5 & 14 & -14 & 82 & +14 \\
\hline NI & $P O$ & $k 2$ & 62 & 1,49 & 0,10 & 1,35 & 5 & -5 & 3 & 70 & +8 \\
\hline NI & PI & KO & 72 & 1,54 & 0,17 & 1,65 & 3 & 5 & -5 & $6 \varepsilon$ & $-\varepsilon$ \\
\hline NI & $P I$ & $K I$ & 66 & 1,40 & 0, In & 1,57 & -12 & 12 & -6 & 65 & -1 \\
\hline NI & PI & $\mathrm{k} 2$ & 70 & 1,43 & 0,16 & 1,55 & -6 & 10 & -10 & 83 & +13 \\
\hline N2 & PO & KO & 63 & 1,56 & 0,15 & 1,48 & 24 & 3 & -24 & 62 & -1 \\
\hline N2 & $P O$ & $K I$ & 82 & 1,40 & 0,16 & 1,52 & 0 & 10 & -10 & 64 & +2 \\
\hline N2 & $\mathrm{PO}$ & $k 2$ & 64 & 1,44 & 0,16 & 1.54 & 0 & 10 & -10 & 88 & +4 \\
\hline N2 & $P I$ & KO & 74 & 1,58 & 0,17 & 1,57 & 16 & 12 & -13 & $E 5$ & -9 \\
\hline N2 & $\mathrm{Pl}$ & $K I$ & 65 & 1,29 & 0,16 & 1,51 & -20 & 20 & 0 & 89 & +4 \\
\hline N2 & $P I$ & $k 2$ & 83 & 1,47 & 0,15 & 1,78 & -3 & -19 & 19 & 80 & -3 \\
\hline N3 & PO & KO & 69 & 1,41 & 0,17 & 1,52 & -18 & 18 & -18 & 57 & -12 \\
\hline N3 & PO & $K I$ & 57 & 1,49 & 0,17 & 1,49 & 9 & 19 & -19 & 68 & +11 \\
\hline N3 & PO & $\mathrm{K} 2$ & 68 & 1,48 & 0,16 & 1,72 & 0 & -8 & 8 & 80 & +12 \\
\hline N3 & $P 1$ & KO & 62 & 1,48 & 0,17 & 1,57 & -9 & 17 & -17 & 59 & +7 \\
\hline N3 & PI & $K I$ & 69 & 1,53 & 0,17 & 1,44 & 18 & 26 & -26 & 80 & $+I I$ \\
\hline N3 & $P I$ & $\times 2$ & 80 & 1,43 & 0,16 & 1,57 & 0 & 4 & -4 & - & - \\
\hline & & & & & & & & & & & +93 \\
\hline
\end{tabular}

* Produção (t caneína) obtidè no ensajo fatorial

** Produção (t eana/ha) que se obteria, caso fosse corrigide o ejemen to mais reficiente (através dos findices transformados) com a dose imediatamente superior. 
TABELA 43 - Efeito das épocas de amostragens sobre o balanço NPK, em or dem decrescente de necessidade, para o solo Latossol Verme tho Escuro-orto irrigado.

\begin{tabular}{|c|c|c|c|c|c|c|}
\hline \multicolumn{3}{|c|}{ Tratamentos } & \multirow{2}{*}{$\frac{3^{\circ} \text { mês }}{N>K>P}$} & \multirow{2}{*}{$\frac{4^{\circ} \text { més }}{K>N>P}$} & \multirow{2}{*}{$\frac{58 \text { més }}{\text { B } N>P}$} & \multirow{2}{*}{$\frac{6^{\circ} \text { mess }}{B>P>N}$} \\
\hline NO & PO & KO & & & & \\
\hline NO & PO & $K I$ & (k) $>P>N$ & (B) $>N>P$ & $N>K>P$ & (1) $>N>P$. \\
\hline NO & PO & $\mathrm{K} 2$ & (N) $P=K$ & (N) $P>K$ & (N) $>P>K$ & $P>N>K$ \\
\hline NO & PI & KO & $(x)>N>P$ & (R) $>P>N$ & (K) $>N>P$ & $N>K>P$ \\
\hline NO & $\mathrm{Pl}$ & $K I$ & (R) $N=P$ & (K) $N>P$ & $N>P>K$ & $K=N>P$ \\
\hline NO & $\mathrm{Pl}$ & $\mathrm{k} 2$ & (N) $P>K$ & (N) $P>K$ & (N) $P>K$ & $P>K>N$ \\
\hline $\mathrm{NI}$ & PO & KO & (N) $>K>P$ & $(K>P>N$ & N $>P>K$ & (R) $>N>P$ \\
\hline $\mathrm{NI}$ & PO & $K I$ & $P>N>K$ & (N) $>P>K$ & (N) $P>K$ & $K>P>N$ \\
\hline $\mathrm{NI}$ & PO & $\mathrm{K} 2$ & (N) $>P>P$ & (N) $>K>P$ & (N) $P>K$ & $K>N>P$ \\
\hline NI & Pl & KO & (1) $>N>P$ & (Q) $>P>N$ & (1) $>N>P$ & K $>N>P$ \\
\hline $\mathrm{NI}$ & $P I$ & $K I$ & (N) $K>P$ & (N) $>K>P$ & (N) $P>K$ & $P>K>N$ \\
\hline$N I$ & $P I$ & $\times 2$ & (N) $P>k$ & (P) $>N>K$. & (D) $>N>K$ & ND $>K>P$ \\
\hline N2 & PO & KO & (K) $>P>N$ & (R) $>P>N$ & $(R>>N>P$ & ( $)>N>P$ \\
\hline N2 & $\mathrm{PO}$ & $K I$ & (R) $>P>N$ & (R) $>N>P$ & (K) $>N>P$ & (R) $>N=P$ \\
\hline N2 & PO & $\mathrm{k} 2$ & $K>P>N$ & $P>N>K$ & $\therefore$ (N) $>P>K$ & (N) $>P>K$ \\
\hline N2 & $P I$ & KO & (K) $>N>P$ & (R) $>P>N$ & $N>K>P$ & $(B>N>P$ \\
\hline N2 & $P I$ & $K .1$ & (N) $>P>K$ & (N) $>K>P$ & (A1) $>P>K$ & $K>P>N$ \\
\hline N2 & $\mathrm{Pl}$ & $k 2$ & (P) $>N>K$ & (P) $>N>K$ & (N) $>P>K$ & (N) $>P>K$ \\
\hline N3 & PO & KO & $P>N>K$ & (B) $>N>P$ & (R) $>N>P$ & (K) $>P>N$ \\
\hline N3 & PO & $k 1$ & (P) $>N>K$ & (P) $>K>N$ & $N>P>K$ & P $=N>K$ \\
\hline N3 & PO & $\mathrm{k} 2$ & (P) $>N>K$ & (P) $>N>K$ & $K>P>N$ & (P) $>N>K$ \\
\hline N3 & $P I$ & KO & $(R)>P>N$ & (1) $N>P$ & (1) $>N>P$ & (1) $>N>P$ \\
\hline N3 & PI & $K I$ & $(R)>P>N$ & (1) $>P>N$ & $P>K>N$ & $N>K>P$ \\
\hline N3 & $P I$ & $K 2$ & $N>P>K$ & (P) $>N>K$ & (P) $>N>K$ & $P>N>K$ \\
\hline
\end{tabular}

ou $\bigcirc=$ indicam diagnósticos semelhantes pelo QRIS num mesmo tratamento. 
TABELA 44 - Efeito das épocas de amostragens sobre o balanço NPK, ern or dem decrescente de necessidade, para o solo Latossol Verme Iho Escuro-orto.

\begin{tabular}{|c|c|c|c|c|c|c|}
\hline \multicolumn{3}{|c|}{ Tratamentos } & \multirow{2}{*}{$\frac{3^{8} \text { mês }}{R>N>P}$} & \multirow{2}{*}{48 més } & \multirow{2}{*}{$\frac{58 \text { més }}{K>N \geq P}$} & \multirow{2}{*}{$\frac{S^{\circ} \text { miês }}{K>N>P}$} \\
\hline NO & $\mathrm{PO}$ & KO & & & & \\
\hline NO & PO & $K I$ & (N) $>P>K$ & $K>N>P$ & $N=k>P$ & (N) $>k>P$ \\
\hline NO & PO & $\mathrm{k} 2$ & $P>N>K$ & (N) $P>K$ & (N) $>k>P$ & (N) $>P>k$ \\
\hline NO & $P I$ & KO & (R) $>N>P$ & (B) $>N>P$ & (K) $>N>P$ & $N>k>p$ \\
\hline NO & $P I$ & $\mathrm{KI}$ & $\widehat{K}>N>P$ & $\widehat{K}>N>P$ & (N) $>K>P$ & (N) $>K>P$ \\
\hline NO & PI & $\mathrm{k} 2$ & (N) $>P>K$ & (N) $P>K$ & (iN) $>K>P$ & (ii) $>P>K$ \\
\hline$N I$ & PO & KO & (R) $>P>N$ & (R) $>N>P$ & (k) $>N>P$ & (K) $>N>P$ \\
\hline$N I$ & PO & $K I$ & (P) $>N>K$ & (P) $>K>N$ & $N>K>P$ & $(P)=K>N$ \\
\hline $\mathrm{NI}$ & PO & $\mathrm{k} 2$ & (P) $>N>K$ & (P) $>k>N$ & {$[\widehat{N}]>K>P$} & NN $>P>K$ \\
\hline $\mathrm{NI}$ & PI & $\mathrm{KO}$ & $(\mathbb{K})>N>P$ & $(B>P>N$ & $Q>N>P$ & (K) $>N>P$ \\
\hline $\mathrm{NI}$ & $P I$ & $K I$ & (B) $>P>N$ & $(\mathbb{B}=N>P$ & $(B)=N>P$ & $N>K>P$ \\
\hline $\mathrm{NI}$ & Pl & $k 2$ & $K>N>P$ & N $>k>P$ & (N) $>P>K$ & N $>k>P$ \\
\hline N2 & PO & $K O$ & $(R)>P>N$ & $(B)>N=P$ & (B) $>N>P$ & (N) $>F>N$ \\
\hline $\mathrm{N} 2$ & PO & $K I$ & (P) $>N>K$ & $K>F>N$ & $N>K>P$ & (D) $=N>K$ \\
\hline N2 & PO & $k 2$ & (N) $>P>K$ & (i) $>P>K$ & $P>N>K$ & (PI) $>P>K$ \\
\hline N2 & $\mathrm{Pl}$ & $k 0$ & $(R)>N>P$ & (R) $>N>P$ & $B>N>P$ & $B>N>P$ \\
\hline $\mathrm{N} 2$ & $\mathrm{Pl}$ & $K I$ & $P>N>K$ & (1) $>P>N$ & (R) $>N>P$ & (B) $>P>N$ \\
\hline N2 & $P_{1}$ & $k 2$ & (P) $>N>K$ & (P) $>K>N$ & (P) $>N>K$ & $N>P=K$ \\
\hline N3 & $\mathrm{PO}$ & KO & $(K)>P>N$ & $K>N>P$ & (B) $>N>P$ & (B) $>N=P$ \\
\hline N3 & PO & $\mathrm{Kl}$ & $P>K>N$ & (1) $>N>P$ & (i) $>N>P$ & $N>P>K$ \\
\hline N3 & PO & $k 2$ & (P) $>N>K$ & (P) $>N>K$ & (P) $>K>N$ & (P) $>N>K$ \\
\hline N3 & $\mathrm{Pl}$ & KO & (K) $>N>P$ & (1) $>N>P$ & $(B)>N>P$. & $B>N>P$ \\
\hline N3 & $P I$ & $K I$ & $B>N>P$ & $N>K>P$ & $A>P>N$ & (k) $>N>P$ \\
\hline N3 & $P I$ & $\mathrm{k} 2$ & (P) $>N>K$ & (P) $>K>N$ & $K>N>P$ & P) $>K>N$ \\
\hline
\end{tabular}

Oou $\bigcirc$ = indicam diagnósticos semelnantes pelo DRIS num mesmo tratamento. 
TABELA 45 - Efeito das épocas de amostragens sobre o balanço NPK, em or dem decrescente de necessidade, para o solo Latossol Verme Iho Amarelo - fase arenose.

\begin{tabular}{|c|c|c|c|c|c|c|}
\hline \multicolumn{3}{|c|}{ Tratamentos } & \multirow{2}{*}{38 mês } & \multirow{2}{*}{$\frac{4^{8} \text { mês }}{(K) N>P}$} & \multirow{2}{*}{ (R) $>N>P$} & \multirow{2}{*}{$\frac{6^{\circ} \text { més }}{K>P>N}$} \\
\hline NO & $P O$ & KO & & & & \\
\hline NO & PO & $K I$ & (N) $>P>K$ & (N) $P=K$ & (P) $>N>K$ & P) $N>K$ \\
\hline NO & PO & $k 2$ & (N) $>P>K$ & $K>N>P$ & (N)> $P>K$ & $P>K>N$ \\
\hline NO & PI & $K O$ & (N) $K>P$ & (X) $>N>P$ & (N) $>K>P$ & $\widehat{B}>N>P$ \\
\hline NO & $P I$ & $K I$ & (iv) $P>k$ & (N) $>P=K$ & (N) $>P>K$ & (i) $x>P$ \\
\hline NO & $\mathrm{PI}$ & $\mathrm{k} 2$ & (P) $>N>K$ & (P) $>K>N$ & $K>N>P$ & $N>K>P$ \\
\hline$N I$ & $\mathrm{PO}$ & KO & (K) $>N>P$ & (R) $>N=P$ & $R>N>P$ & (K) $>N=P$ \\
\hline $\mathrm{NI}$ & PO & $K I$ & $N>P>K$ & (R) $>N>P$ & (1) $>N>P$ & (K) $>N>P$ \\
\hline $\mathrm{NI}$ & PO & $k 2$ & (N) $>K>P$ & (N) $>P>K$ & (A) $>P>K$ & $P>K>N$ \\
\hline $\mathrm{NI}$ & $\mathrm{Pl}$ & Ko & $(B)>P>N$ & (R) $>N>P$ & (R) $>P>N$ & (K) $>P>N$ \\
\hline $\mathrm{NI}$ & $\mathrm{Pl}$ & $K I$ & $N>P>K$ & (K) $>N=P$ & (R) $>N>P$ & $P>N>K$ \\
\hline$N I$ & $\mathrm{PI}$ & $K 2$ & (N) $>K>P$ & (1) $>P>K$ & (N) $>P>K$ & (N) $>P>K$ \\
\hline $\mathrm{N} 2$ & PO & KO & (R) $>N>P$ & (K) $>N>P$ & $P>N>K$ & (K) $>P>N$ \\
\hline N2 & PO & $K I$ & (P) $>N>K$ & (N) $>P>K$ & (P) $>N>K$ & (N) $>P>K$ \\
\hline N2 & PO & $k 2$ & (N) $>P>K$ & [N]> $P>K$ & (P) $>N>K$ & P $>N>K$ \\
\hline N2 & PI & KO & (K) $>N>P$ & (1) $>N>P$ & (R) $>P>N$ & (R) $>N>P$ \\
\hline N2 & $P I$ & $K I$ & $N>P>K$ & (1) $>P>N$ & (1) $>N>P$ & (K) $>N>P$ \\
\hline N2 & $P I$ & $K 2$ & (N) $>P=K$ & (N) $>P=K$ & (P) $>N>K$ & (P) $>N>K$ \\
\hline N3 & PO & KO & $P>K>N$ & (B) $>N>P$ & $(B>N>P$ & $N>K>P$ \\
\hline N3 & PO & $K I$ & P $>K>N$ & (P) $>k>N$ & $K>P>N$ & (P) $>K>N$ \\
\hline N3 & PO & $k 2$ & (P) $>N>K$ & (P) $>N>K$ & (P) $>N>K$ & $K>P>N$ \\
\hline N3 & $P I$ & KO & $\ll>N>P$ & $\mathbb{R}>N>P$ & $(R>N>P$ & (K) $>N=P$ \\
\hline N3 & $P I$ & $K I$ & (P) $>N>K$ & $P=N>K$. & $N>P>K$ & $K>P>N$ \\
\hline N3 & $P I$ & $k 2$ & (P) $>N>K$ & (人) $>N>P$ & $(x>N>P$ & $P=N>k$ \\
\hline
\end{tabular}

ou $\bigcirc=$ indicom diagnósticos semelhantes pelo aRIS num mesmo tratamento. 
TABELA 46 - Efeito das épocas de amostragens sobre o balanço NPK, em or dem decrescente de necessidade, para o solo Podzólico Verme Iho Amarelo - variação Laras.

\begin{tabular}{|c|c|c|c|c|c|c|}
\hline \multicolumn{3}{|c|}{ Tratamentos } & \multirow{2}{*}{$\frac{3^{8} \text { més }}{P>K>N}$} & \multirow{2}{*}{$\frac{4^{\circ} \text { mês }}{\text { (P) }>N>K}$} & \multirow{2}{*}{$\frac{5^{2} \mathrm{mês}}{(\mathrm{P})>N>K}$} & \multirow{2}{*}{$\frac{\theta^{\circ} \text { més }}{\text { (P) }>K>N}$} \\
\hline NO & PO & KO & & & & \\
\hline NO & $\mathrm{PO}$ & $K I$ & (N) $P>K$ & (N) $>P>K$ & (N) $>P>K$ & $P>K>N$ \\
\hline NO & PO & $k 2$ & NDP $P>K$ & (N) $>P>K$ & $K>P>N$ & $P>N>K$ \\
\hline NO & $\mathrm{Pl}$ & KO & (N) $>K>P$ & (N) $>K>P$ & $\widehat{B}>N>P$ & $\otimes>N>P$ \\
\hline NO & $\mathrm{Pl}$ & $\mathrm{KI}$ & (Ni) $>K>P$ & (D) $>K>P$ & (N) $>P>K$ & (N) $>k>P$ \\
\hline NO & PI & $\mathrm{k} 2$ & (N) $P>K$ & (N) $>P>K$ & (Ni) $>P>K$ & (N) $>K>P$ \\
\hline$N I$ & PO & KO & (K) $>P>N$ & (P) $>K>N$ & (R) $>P>N$ & $>K>N$ \\
\hline $\mathrm{NI}$ & PO & $\mathrm{KI}$ & (K) $>N>P$ & $P>K>N$ & (R) $>P>N$ & (D) $>P>N$ \\
\hline NI & PO & $k 2$ & $N>K>P$ & (P) $>K>N$ & (F) $>K>N$ & (P) $>K>N$ \\
\hline$N I$ & $P 1$ & KO & (R) $>N>P$ & (N) $>K>P$ & $(k>N>P$ & $\mathbb{N}>K>P$ \\
\hline $\mathrm{NI}$ & $P I$ & $K I$ & $P>N>K$ & (R) $>P>N$ & (B) $>P>N$ & $N>K>P$ \\
\hline NI & $P I$ & $\mathrm{~K} 2$ & (iv) $P>K$ & (N) $>P>K$ & (N) $>P>K$ & (N)> $P>k$ \\
\hline N2 & PO & $\mathrm{KO}$ & $N>K>P$ & (B) $>P>N$ & $(8)>P>N$ & $B>P>N$ \\
\hline N2 & PO & $K I$ & (P) $>N>K$ & (P) $>N>K$ & P $>N>K$ & (F) $>k>N$ \\
\hline N2 & PO & $k 2$ & $N>P>K$ & (P) $>N>K$ & (P) $N>K$ & (P) $>n>k$ \\
\hline N2 & P1 & KO & $(R)>P>N$ & $N>P>K$ & (i) $>N>P$ & $\underline{R}=P=N$ \\
\hline N2 & PI & $K I$ & (N) $>P>K$ & [N] $>K>P$ & K) $>N>P$ & (R) $>P>N$ \\
\hline$N 2$ & $\mathrm{PI}$ & $k 2$ & $\widehat{k}>P>N$ & K) $>N>P$ & (N) $>P>k$ & (i) $>P>K$. \\
\hline N3 & $\mathrm{PO}$ & $\mathrm{KO}$ & $(\mathbb{N}>N>P$ & (R) $>P>N$ & (R) $>N>P$ & (K) $>P>N$ \\
\hline N3 & PO & $K I$ & $N>P>K$ & (P) $>N>K$ & $K>P>N$ & (P) $>N>K$ \\
\hline N3 & PO & $k 2$ & (P) $>N>K$ & (P) $>K>N$ & (P) $>K>N$ & (P) $>K>N$ \\
\hline N3 & $P I$ & KO & $P>N>K$ & (R) $>N>P$ & (K) $>N>P$ & (K) $>N>P$ \\
\hline N3 & Pl & $K I$ & (P) $>N>K$ & (P) $>K>N$ & $(P)=N=K$ & $K>P>N$ \\
\hline N3 & $P 1$ & $k 2$ & (N) $>P>K$ & (N) $>K>P$ & (i) $>P=K$ & (N) $>K>P$ \\
\hline
\end{tabular}

$\bigcirc$ ou $\bigcirc=$ indican diagnósticos semelhantes pelo DRIS num mesmo tra.tamento. 
TABELA 47 - Efeito das épocas de amostragens sobre o balanço NPK, em or dem decrescente de necessidade, para o solo Latossol Roxo.

\begin{tabular}{|c|c|c|c|c|c|c|}
\hline \multicolumn{3}{|c|}{ Tratamentos } & \multirow{2}{*}{$\frac{3^{8} \text { mês }}{(N)>K>P}$} & \multirow{2}{*}{$\frac{4^{\circ} \text { mês }}{\text { (A) }>K>P}$} & \multirow{2}{*}{$\begin{array}{l}5{ }^{\circ} \mathrm{mes} \\
\text { (A) }>K>P\end{array}$} & \multirow{2}{*}{$\frac{6^{8} \mathrm{més}}{(\mathbb{N}>K=P}$} \\
\hline NO & PO & KO & & & & \\
\hline NO & PO & $K I$ & (N) $>P>K$ & $K>N>P$ & (N) $>P>K$ & $P>K>N$ \\
\hline NO & PO & $\mathrm{K} 2$ & (N) $>K>P$ & (N) $>K>P$ & (N) $>K>P$ & (N) $>P>\dot{K}$ \\
\hline NO & PI & KO & (N) $>K>P$ & (N) $>K>P$ & $K>N>P$ & (N) $>P=K$ \\
\hline NO & $\mathrm{Pl}$ & $\mathrm{KI}$ & (N) $>P>K$ & $K>N>P$ & ND $>K>P$ & (N) $>K>P$ \\
\hline NO & $P I$ & $\mathrm{k} 2$ & (N) $>P>K$ & (ii) $>K>P$ & (N) $>K>P$ & (N) $>K>P$ \\
\hline NI & PO & KO & (P) $>K>N$ & (P) $>N>K$ & $N>K>P$ & $K>N=P$ \\
\hline NI & PO & $K I$ & $(8)>P>N$ & (1) $>N>P$ & (K) $>N>P$ & (R) $>N>P$ \\
\hline$N I$ & PO & $k 2$ & (P) $>K>N$ & (B) $>N>P$ & 《) $>P>N$ & (P) $>K>N$ \\
\hline $\mathrm{NI}$ & $P I$ & KO & (K) $>P>N$ & (K) $>P>N$ & $P>K>N$ & (K) $>N>P$ \\
\hline $\mathrm{NI}$ & PI & $\mathrm{Kl}$ & $P>K>N$ & $(B)>P>N$ & (B) $>P>N$ & $N>K>P$ \\
\hline $\mathrm{NI}$ & $P I$ & $k 2$ & (B) $>P=N$ & (i) $>N>P$ & $N>P>K$ & (R) $>N>$ ? \\
\hline N2 & PO & K.O & (K) $>P>N$ & (B) $>P>N$ & (R) $>P>N$ & $B>P>N$ \\
\hline $\mathrm{N} 2$ & PO & $K I$ & (K) $>P>N$ & (R) $>P>N$ & (R) $>P>N$ & (B) $>N>P$ \\
\hline $\mathrm{N} 2$ & PO & $k 2$ & $P=K>N$ & (P) $>K>N$ & (D) $>K>N$ & $K>N>P$ \\
\hline N2 & $\mathrm{Pl}$ & $\mathrm{KO}$ & (R) $>P>N$ & (1) $>P>N$ & (R) $>P>N$ & (R) $>P>N$ \\
\hline N2 & $\mathrm{Pl}$ & $\mathrm{KI}$ & (B) $>P>N$ & (1) $>P>N$ & (R) $>P>N$ & $N>K>P$ \\
\hline N2 & $P I$ & $k 2$ & P $>N>K$ & $K>N>P$ & (P) $>N>K$ & (P) $>N>K$ \\
\hline N3 & PO & KO & (K) $>P>N$ & (1) $>P>N$ & (K) $>P>N$ & $K=N>P$ \\
\hline N3 & PO & $\mathrm{KI}$ & (B) $>P>N$ & (R) $>P>N$ & $(R>P>N$ & (R) $>N>P$ \\
\hline N3 & PO & $\mathrm{K} 2$ & (R) $>P>N$ & (B) $>N>P$ & (R) $>P>N$ & $P>N>K$ \\
\hline N3 & $P I$ & KO & (K) $>P>N$ & (1) $>N>P$ & $(K)>P>N$ & (R) $>N>P$ \\
\hline N3 & $\mathrm{Pl}$ & $k I$ & (R) $>P>N$ & (1) $>P>N$ & $P>K>N$ & (K) $>N>F$ \\
\hline N3 & $\mathrm{Pl}$ & $k 2$ & $P>K>N$ & (K) $>N>P$. & (1) $>N>P$ & (R) $>N>P$ \\
\hline
\end{tabular}

O ou $\bigcirc=$ indicam diagnósticos semelhantes pelo oRIS num mesmo trata mento. 
9. LITERATURA EITADA

BASSINELLO,A.I., 1976. Característica agroindustriais de algumas variedades comerciais. 2. Brasil Açucareiro. Rio de Janeiro, 87 (4) : 8-10.

BEAUFILS, E.R., 1956. Recherche d'une exploratation ratio nelle de l'Hevea basée sur l'analyse minérale de diversas parties de la plante. In: VII Congr. Soil Sci., paris, p. $360-374$.

BEAUFILS, E.R., 1971. Physiological diagnosis; a guide for improving maize production based on principies developed for rubber trees. Fertilizer Soc. South Afr. J.., (I): $1-30$.

×BEAUFILS,E.R., 1973. Diagnosis and recommendations integra ted system (DRIS); a general scheme for experimentation - and calibratjon besed or prinoiples developed from re search in olant nutrition. Soil Sci. Bull., (1):l-132p. 
BEAUFILS, E.R. e M.E. SUMNER, 1976. Application of the DRIS approach for calibrating soil, plant yield and plant quality factors on sugarcane. Proc. South Afr. Sugar Tech. Assoc., jun., p. 1-7.

BEAUFILS, E.R. e M.E. SUMNER, 1977. Effect of time of sam pling on the diagnosis of the $N, P, K, C a$ and $M g$ require ments of sugarcane by the DRIS approach. Proc. South Afr. Sugar Tech. Ass., jun., p. 1-6.

BITTENCOURT, V.C.; J. ORLANDO F:; E. ZAMBELLO JR., 1378 . Determination of the available soil phosphorus for sugar cane in troplicalsoils extracted with $\mathrm{H}_{2} \mathrm{SO}_{4} 0,5 \mathrm{~N}$. In: XVI Congress of the International Society of Sugar Cane Technologists, São Paulo, p. 1175-1186.

BRASIL. Ministério da Agricultura. Comissão de Solos, 1960. Levantamento de reconhecimento dos solos do Esta. do de São Paulo; contribuição à carta de Solos do Brasil. Rio de Janeiro, $634 \mathrm{p}$. (Boletim Técnico, 12).

BRASIL. Ministério da Agricultura. Divisão de Pesquisa Pedológica, 1971. Levantamento de reconhecimento dos So los do Nordeste do Estado do Paraná; informe preliminar. Curitiba, $144 \mathrm{p}$. (Boletim Técnico, 16 ).

BUCCHANAN, E.J., 1966. Direct sampling and analysis of in dividual consignements. South Afr. Sugar J.. 50 (11): $1049-1059$.

CATANI, R.A. e 0. JACINTHO, 1974. Análise química para ava liar a fertilidade do solo. Piracicaba, ESALQ/USP. 57 P. (Bol. Científico, 37).

CONOVER, W.J., 1971. Practical nonparametric statistics. New York, John Wiley. $462 \mathrm{p}$. 
nas, Coordenadoria de Assistêncía Técnica Integral. 34p. (Boletim Técnico, I18).

EVANS, H., 1959. Elements other nitrogen, potassium and phosphorus in mineral nutrition of sugarcane. In: $X$ Con gress of the International Society of Suger Cane Techno logists, Hawaii, p. 473-506.

FARQUHAR, R.H., 1965. The interpretation and use of tissue analysis within a fertilizer advisory service for sugar cane in North Queensland. In: XII Congress of the Inter national Society of Sugarcane Technologists, Puerto Rico, p. $227-236$.

FRANÇA, F.V. e O. FREIRE, 1975. Estudo agrotécnico das ter ras da Usina São José; levantamento semi-detalhado dos so los da Usina são José. Piracicaba, ESALQ/USP. $275 \mathrm{p}$.

GALLO, J.R.; R. HIROCE e R. AlVAREZ, ig62. Amostragem de ca na-de-açúcar para fins de análise foliar. Bragantia.Carn pinas, 21 (54): 899-92I.

GALLO, J.R.; R. HIROCE e R. ALVAREZ, 1968. Levantamento do estado nutricional de canaviais do Estado de São Paulo. Bragantia. Campinas, 27 (30):365-382.

GEUS, J.G. de, 1967. Fertilizer guide for tropical and sub tropical farming. Zurich, Center d'Etude de I'Azote. $277 \mathrm{p}$.

GOMEZ-ALVAREZ, F... 1971. Effect of time of sampling in su garcane on foliar analysis in Venezuela. In : XIV Congress of the International Society of Sugar cane Technologists, Louisiana, p. 702-70?.

GOMEZ-ALVAREZ, F., 1974. Correlacion entre algunos niveles de nutrients er la hoja de í caña de azucar. Rev. Fao. Agron. Maracay, 7 (4): 5-12. 
GOSNELL, J.M. e A.C. LONG, 1971. Some factors affecting foliar analysis in sugarcane. Proc. South Afr. Sugar Tech. Ass., Natal, (45): 217-222.

HUMBERT, R.P., 1974. El cultivo de la caña de azucar: Mé xico, Continental, $719 \mathrm{p}$.

JACOB, A. e H. von UEXKÜLL, 196I. Fertilización; nutricion y abonado de los cultivos tropicales y sub-tropicales. Amsterdam, IHM, $626 \mathrm{p}$.

MALAVOLTA, E. e H.P. HAAG, 1964. Nutrição e adubação. In: Instituto Brasileiro de Potassa. Cultura e adubação da cona-de-açúcar. São Paulo, cap. 9, p. 237-278.

Malavolta, E.; F. PIMENTEl gomes; t. CCURY; C.P. ARREU; 0. VALSECHI, H.P. HAAG; M.O.C. BRASIL SOBRINHO; F.A.F.MELLO; J.D.P. ARZOLLA; S. ARZOLLA; G. RANZANI; E.J. KIEHL; O.J. CROCOMO; L.M. MENARD; R.F. NOVAES; O. FREIRE E E.R.OLIVEI RA, 1963. A diagnose foliar na cana-de-acúcar. 4. ResuI tados de 40 ensaios fatoriais NPK $3 \times 3 \times 3$, primeiro corte no. Estado de São Paulo. Piracicaba, ESALQ/USF. $47 \mathrm{p}$.

MCLEAN, F.C., 1973. A method of assorting foliar data to determine optimal levels of $N$, $P$ and $K$ for differente va rieties of sugarcane. (Presented to the Meeting $W$. In dian Sugar Tech.). $9 \mathrm{p}$.

MEYER, J.H., 1975. Advances in the interpretation of foliar analyses of sugarcane in the South African Sugar Industry, South Afr. Sugar J., 59 (11): $569-585$.

MILLER, G.G., 1962. Diagnostic foliar de nitrogênio em ca ña de azucar. Acta Agron. Palmira, 12 : 141-170.

MOHAN RAO, N.V.; G. RAMA RAO E E. JAGANNADHA RAO, 1956.. STL dies on sugarcane ratoons. In: IX Congress International Society of Sugar Cane Technologists, New Delhi. p.233254. 
ORLANDO F, J., 1975. Cana-de-açúcar; recomendação de adu bação mineral para o Estado de São Paulo. Brasil Açucareiro. Rio de Janeiro, 86 (6) : $9-12$.

ORLANDO F⿱. J., 1978. Absorção dos macronutrientes pela ca na-de-açúcar (Saccharum spp) variedade CB4l-76 em 3 Gran des Grupos de Solos no Estado de São Paulo. Piracicaba, ESALQ/USP, $154 \mathrm{p}$. (Tese de Doutoramento).

ORLANDO F:, J. e. E. ZAMBELLO JR., 1977. Influência varietal na adubação nitrogenada em soqueiras de cena-de-açúcar. In: XVI Congresso Brasileiro de Ciência do Solo, São Luiz. (no prelo).

ORLANDO F\%, J.; E. ZAMBELLO JR. e T. COLLETTI, 1977. LOCZIização do fertilizante em soqueira de cana-de-açücar; es tudo preiminar. In: XVI Congresso Brasileiro de Cién cia do Solo, São Luiz. (no prelo).

ORLANDO F⿱, J.; E. ZAMBELLO JR. e H.P. HAAG, 1978. Influen ce of varieties and soil types on nutritional status of leaves of sugar cane ratoons. In: XVI Congress of the International Society of Sugar Cane Technologists, São Paulo, P. 1165-1174.

PIMENTEL GOMES, F., 1976. Curso de estatistica experimental. 6a. ed. São Paulo, Nobel. 430 p.

PINAZZA, A.H.; D.O.S. BACCHI e H. de CAMPOS, 1979. Sistemas de produção de cana-de-açúcar em uso pelas usirias do Esta do de São Paulo. In: $1^{8}$ Congresso Nacional da Sociedade dos Técnicos Açucareiros do Brasil, Maceió. (no preío).

PLANALSUCAR, 1975. Relatório Anual, Estações Experimentais. Piracicaba. $80 \mathrm{p}$.

POIgevin, N. LE, l964. Métodos de diagnose foliar utilizados nas plantaçãos jo Grupo Booker na Guiana Inglesa. 
2. pte. Interpretação de resultados. Fertilité, 21 :1217 .

\SAMUELS, G., 1969. Foliar diagnosis for sugarcane. Chica go, Adams Press. 362 P.

SAMUELS, S. e P. LANDRAU JR., 1952. The response of sugarcane to fertilizers. 1. The arecibo cycle, 1944-1950. J. Agr. Univ. P. Rico. Rio Piedras, 36 (3): 203-229.

SAMUELS, G. e P. LANDRAU JR., 1954. The influence of potas - sium on the yield and sucrose content of sugarcane. 3 . Agr. Univ. P. Rico. Rio Piedras, 38 (4) : 170-178.

SAMUELS, G.;B.G. CAPO E I.S. BANGDIWALA, 1953. The nitrogen content of sugarcane as influenced by moisture and age. In: VIII Congress International Society of Sugarcane Tech nologists, Jamaica, P. 16-24.

SAMUELS, G.; B.G. CAPO; P. LANDRAU JR., S. ALERS-ALERS e A. RIERA, i955. The method of foliar diagnosis as appiied to sugarcane. Bull. Agr. Exp. Sta., (123): 1-47.

SARRUGE, J.R. e H.P. HAAG, 1974. Análise química em plantas. Piracicaba, ESALQ/USP. $56 \mathrm{P}$.

SEITEC- Projetos e Desenvolvimento, 1973. Ante projeto da Estação Central-Sul. São Paulo. Cap. 1 e 2, 42 P.

SLATYER, R.0., 1967. Methodology of a wather balance study conducted on a desert woodland (Acacia anema F., Moell) community in Central Australia. UNESCO Arid Zone Res. $16: 15-26$.

SOUSA, J.A.G.C., 1976. Recomendeções para a cultura da ca na-de-açücar no Estajo de São Paulo. Araras, IAA/PLANAL SUCAR. $24 \mathrm{p}$. (Boletim Técnico, 1 ). 
SUMNER, M.E., 1977a. Application of Beaufils'Diagnostic in dices to maize data published in the literature irrespec tive of age and conditions. Plant and Soil, (46) : $359-$ 369.

SUMNER, M.E., 1977b. Preliminary NPK foliar diagnostic norms for wheat. Communications in Soil Science and Plant Analysis, 8. (2): $149-167$.

SUMNER, M.E., 1978. Normas preliminares para el diagnostico foliar de N, P e K en la soja. Revista de la fotassa, (1) : $1-9$.

SUMNER, M.E. e E.R. BEAUFILS, 1975. Oiagnosis of the NPK requirements of sugarcane irrespective of plant age and season using Beaufils'system (ORIS); preliminary observations. Proc. South Afr. Sug., Jun./jul. P. I-5.

VITLOS, A.J. e I.D. LAWRIE, 1963. Foliar diagnosis as a guide to the mineral nutrition of sugarcane in Trinidad. Trop. Agric., 40: 173-183.

WOOD, G.H. e R.A. WDOD, 1967. The estimation of cane root development and distribution using radiophosphorus. Proc. South Afr. Sugar Tech. Ass., apr.p. 1-8.

ZAMBELLO JR., E. e J. ORLANDO F\%, 1977. Diagnose foliar em soqueiras de 2 variedades de cana-de-açúcar cultivadas em Terra-Roxa Estruturada. In: XVI Congresso Brasizeira de Ciência do Solo, São Luiz. (no prelo).

ZAMBELLO JR., E. e J. ORLANDO F⿻, 1978. Aplicação do siste ma integrado de diagnose e recomendação (DRIS) em soqueiras de 3 variedades de cana-de-açúcar. In: XII Reunião Brasileira de Fertilidade do Soio, Goiánia. (no prelo).

ZAMBELlO JR., E. e J. ORLANDO F?, 1979a. Sistema Integrado de diagnose e recomendação (DRIS) aplicado a cana-pianta- 
com e sem irrigação. In: I Congresso Nacional dos Técnicos Açucareiros do Brasil, Maceió. (no prelo).

ZAMBELLO JR., E. e J. ORLANDO F8, 1979b. Diagnosis and re commendations integrated system (DRIS) applied to various sugarcane tissues. In: XVII Congress of the International Society of Sugarcane Technologists., Manila. (no preio).

ZAMBELLO JR., E.; J. ORLANDO F8; J.T. COLLETTI e A.J. ROSSETTO, 1977. Adubação de soqueiras de 3 variedades de ca na-de-açúcar (Saccharum spp) cultivadas em Tarra-Roxa Es truturada no Estado de São Paulo. Brasil Açucareiro. Rio de Janeiro, 89 (3): $11-17$. 